US Army Corps

of Engineers ${ }_{\circledast}$

Engineer Research and

Development Center

Integrated Climate Assessment for Army Enterprise Planning

\title{
Range Days Lost to Heat Risk Model User's Guide
}

Byron M. Garton

July 2019

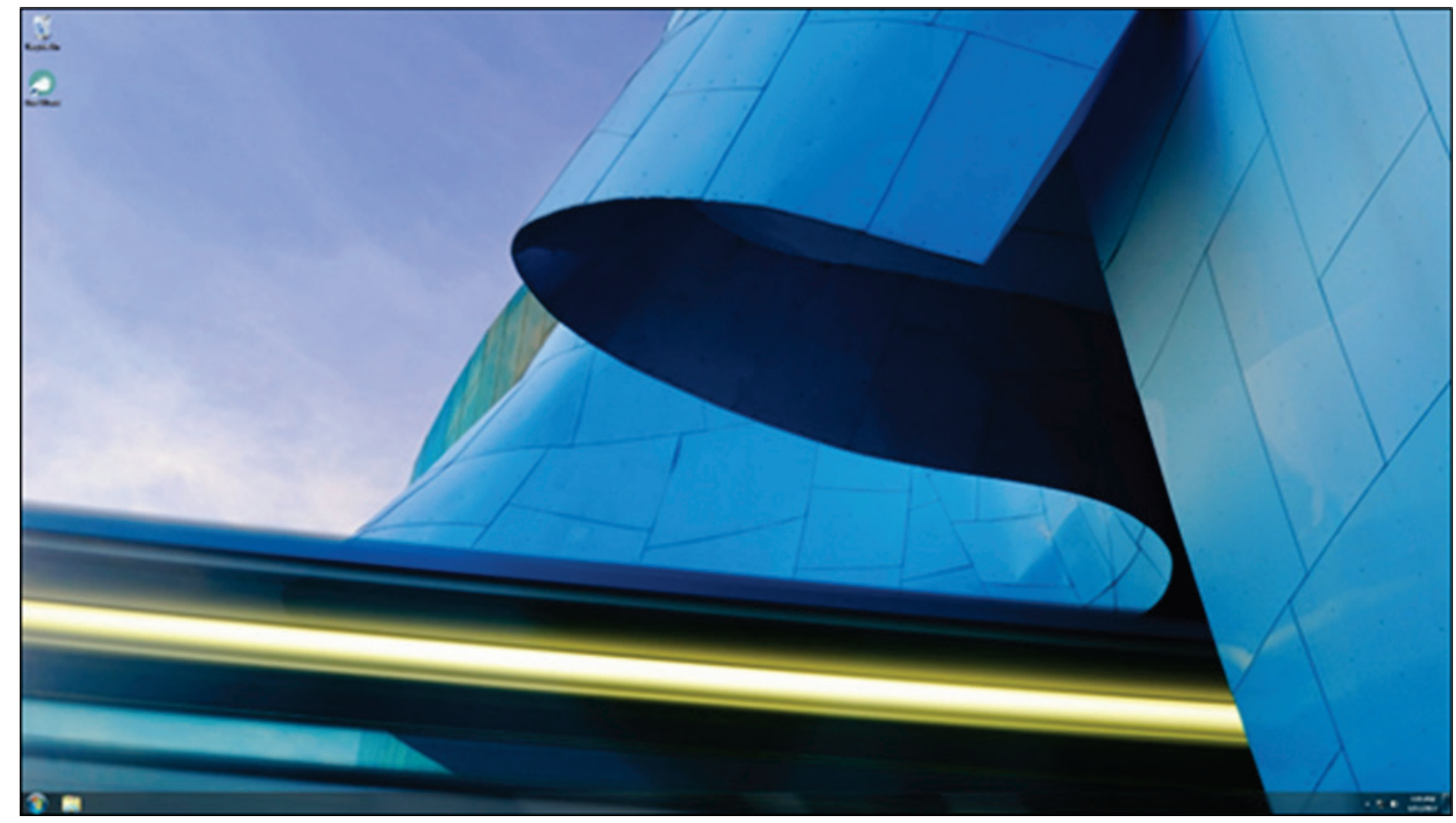


The U.S. Army Engineer Research and Development Center (ERDC) solves the nation's toughest engineering and environmental challenges. ERDC develops innovative solutions in civil and military engineering, geospatial sciences, water resources, and environmental sciences for the Army, the Department of Defense, civilian agencies, and our nation's public good. Find out more at www.erdc.usace.army.mil.

To search for other technical reports published by ERDC, visit the ERDC online library at http://acwc.sdp.sirsi.net/client/default. 


\title{
Range Days Lost to Heat Risk Model User's Guide
}

\author{
Byron M. Garton \\ Information Technology Laboratory \\ U.S. Army Engineer Research and Development Center \\ 3909 Halls Ferry Road \\ Vicksburg, MS 39180-6199
}

Final report

Approved for public release; distribution is unlimited.

\author{
Prepared for U.S. Army Corps of Engineers \\ Washington, DC 20314-1000 \\ Under Project 402188 Integrated Climate Assessment for Army Enterprise Planning
}




\section{Abstract}

Maintaining and increasing the capacity to perform training exercises on Department of Defense (DoD) lands is essential to future force readiness and effectiveness. The risk of heat related illness on ranges as a potential result of climate change is one factor affecting the availability of training areas. Assessing the impact of future climate change is an essential part of ensuring future availability of live fire ranges.

This document describes the process of executing the Range Days Lost to Heat Risk Model, as it exists at the time of this writing, within the common computational environment established under the software integration effort of the Integrated Climate Assessment for Army Enterprise Planning work package.

DISCLAIMER: The contents of this report are not to be used for advertising, publication, or promotional purposes. Citation of trade names does not constitute an official endorsement or approval of the use of such commercial products. All product names and trademarks cited are the property of their respective owners. The findings of this report are not to be construed as an official Department of the Army position unless so designated by other authorized documents. 


\section{Contents}

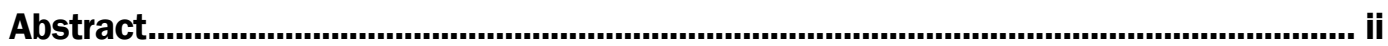

Figures and Tables.....................................................................................................................

Preface

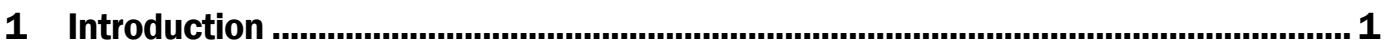

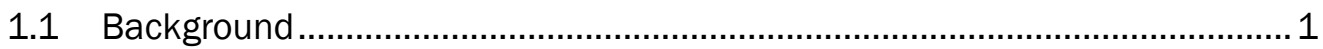

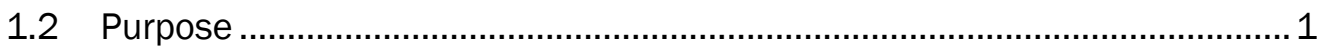

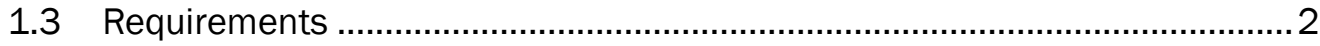

2 Viewing Computed Data.......................................................................................... 3

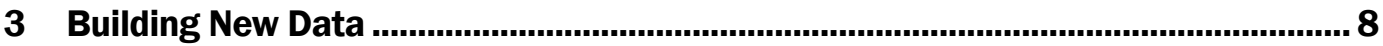

$4 \quad$ Known Issues and Limitations …......................................................................11

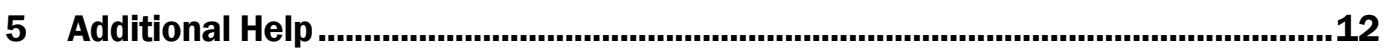

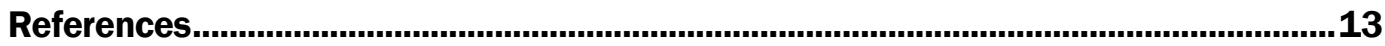

Appendix A: Acronyms and Abbreviations .............................................................14

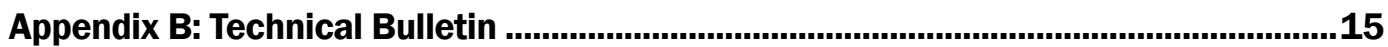

Report Documentation Page 


\section{Figures and Tables}

\section{Figures}

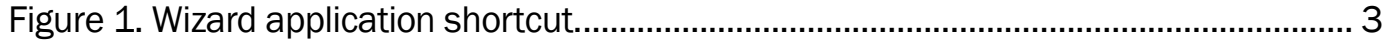

Figure 2. Range Days Lost to Heat Risk Model icon......................................................... 4

Figure 3. Range Days Lost to Heat Risk Model first screen............................................... 4

Figure 4. Range Days Lost to Heat Risk Model second screen.......................................... 5

Figure 5. Results in the chart viewer window. ................................................................ 6

Figure 6. Launch Python IDLE from the third model screen within the Wizard.................... 8

Figure 7. Python IDLE development environment. ................................................................ 9

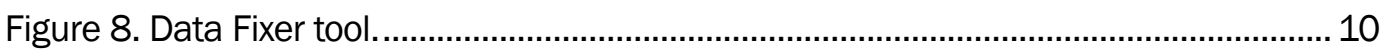

\section{Tables}

Table 1. Doctrinal heat risk categories and guidelines contained in TB MED 507 (2003)..... 


\section{Preface}

This research was conducted for the U.S. Engineer Research and Development Center-Construction Engineering Research Laboratory (ERDC-CERL) under Project 402188, Integrated Climate Assessment for Army Enterprise Planning. The Technical Monitor was Dr. James D. Westervelt of ERDC-CERL.

The work was performed by the Information Technology Laboratory (ITL), Scientific Software Branch (SSB), of the Computational Science and Engineering Division (CSED). At the time of publication, Mr. Timothy W. Dunaway was Chief of the SSB, Dr. Jerrell R. Ballard was Chief of the CSED, and Dr. Robert M. Wallace was the Technical Director. The Deputy Director of ERDC-ITL was Ms. Patti S. Duett, and the Director was Dr. David A. Horner.

COL Ivan P. Beckman was the Commander of ERDC, and Dr. David W. Pittman was the Director. 


\section{Introduction}

\subsection{Background}

The Range Days Lost to Heat Risk Model attempts to predict the number of days that fall within five heat risk categories as described in Army publication TB MED 507 (2013) that will occur in the future based on future climate projections for various Department of Defense (DoD) installations (TB MED 507 (2003) is provided in Appendix B).

The risk of heat related illness on ranges is one factor affecting the availability of training areas which is an essential part of future force readiness and effectiveness. Wet Bulb Globe Temperature (WBGT) is used to calculate potential heat risk to personnel during training. Assessing the impact of future climate change on WGBT plays a vital role in maintaining and increasing the capacity to perform training exercises on DoD lands and ensures the future availability of live fire ranges. The predicted effect of climate change on range heat risk to personnel is intended to be utilized in other force stationing analysis applications as a Military Value Analysis (MVA) attribute.

\subsection{Purpose}

This model makes use of a common computational environment and a user assistance application that were implemented as part of the Software Integration effort within the Integrated Climate Assessment for Army Enterprise Planning work package. The virtual environment will be referred to throughout this document as the Virtual Machine or VM, and the user assistance application will be referred to as the Wizard. For more information about the Software Integration effort, the virtual environment, and the user assistance application, refer to the Analytical Model Integration Methods Technical Report listed in the references section of this document.

Executing the model is a two-step process that requires using Python IDLE development environment, MS Excel ${ }^{\circledR}$, and a basic text editor such as MS Notepad ${ }^{\circledR}$. Each step for viewing and building data sets is thoroughly documented in the following sections to limit user confusion and ensure accurate results. 


\subsection{Requirements}

Software requirements for the Growing Degree Days Model include the Python IDLE development environment, a basic text editor such as MS Notepad ${ }^{\circledR}$, and MS Excel ${ }^{\circledR}$ version 2013 or higher.

A working knowledge of Microsoft Office products is recommended as well as a basic understanding of editing file paths in a text file and executing Python code within the IDLE environment. 


\section{Viewing Computed Data}

Pre-built dataset viewing is available to end users by accessing the model from within the Wizard application. The Wizard is accessible from the Integrated Climate Assessment for Army Enterprise Planning VM by clicking the shortcut located on the desktop (Figures 1-3).

Figure 1. Wizard application shortcut.

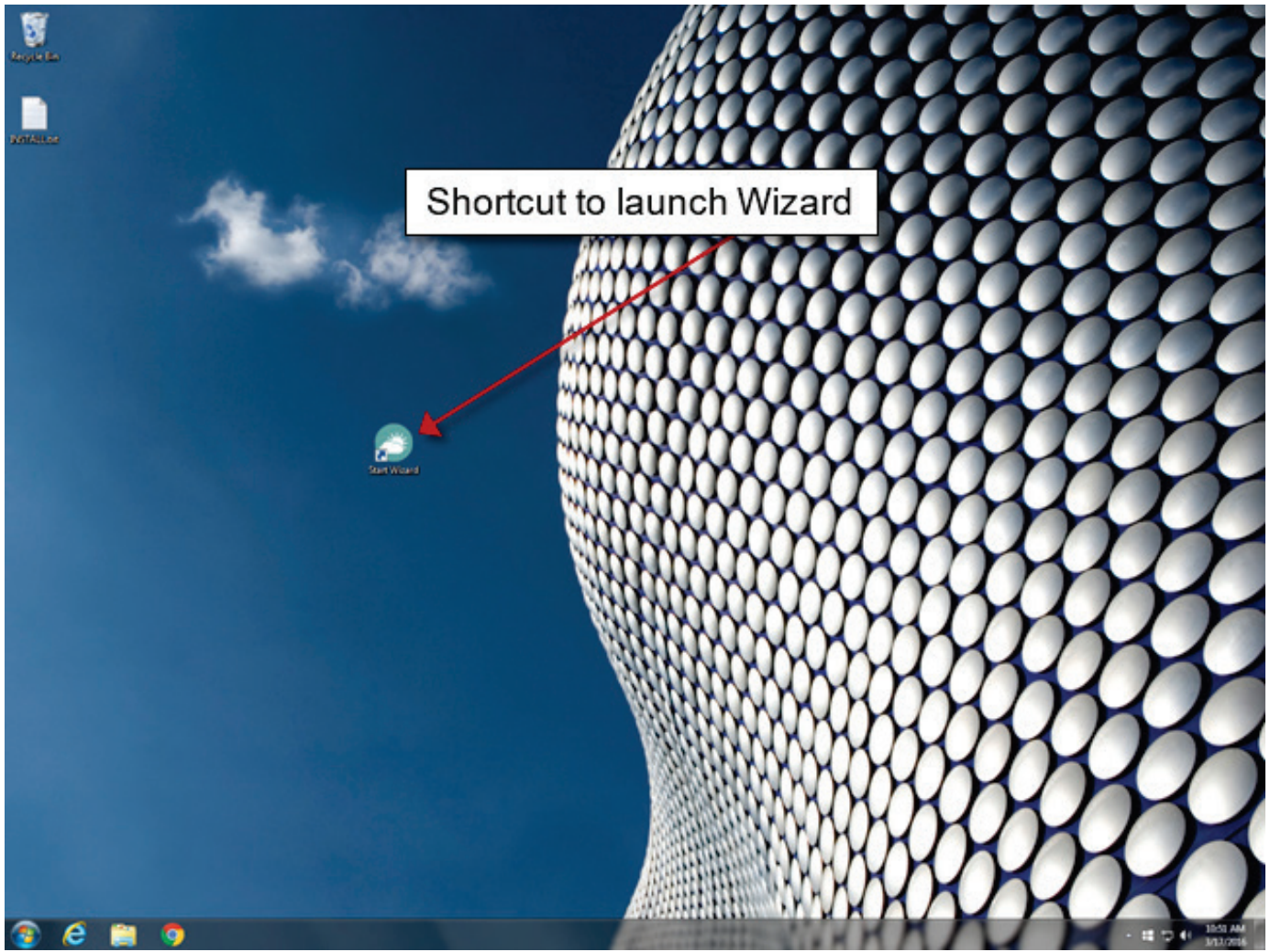


Figure 2. Range Days Lost to Heat Risk Model icon.

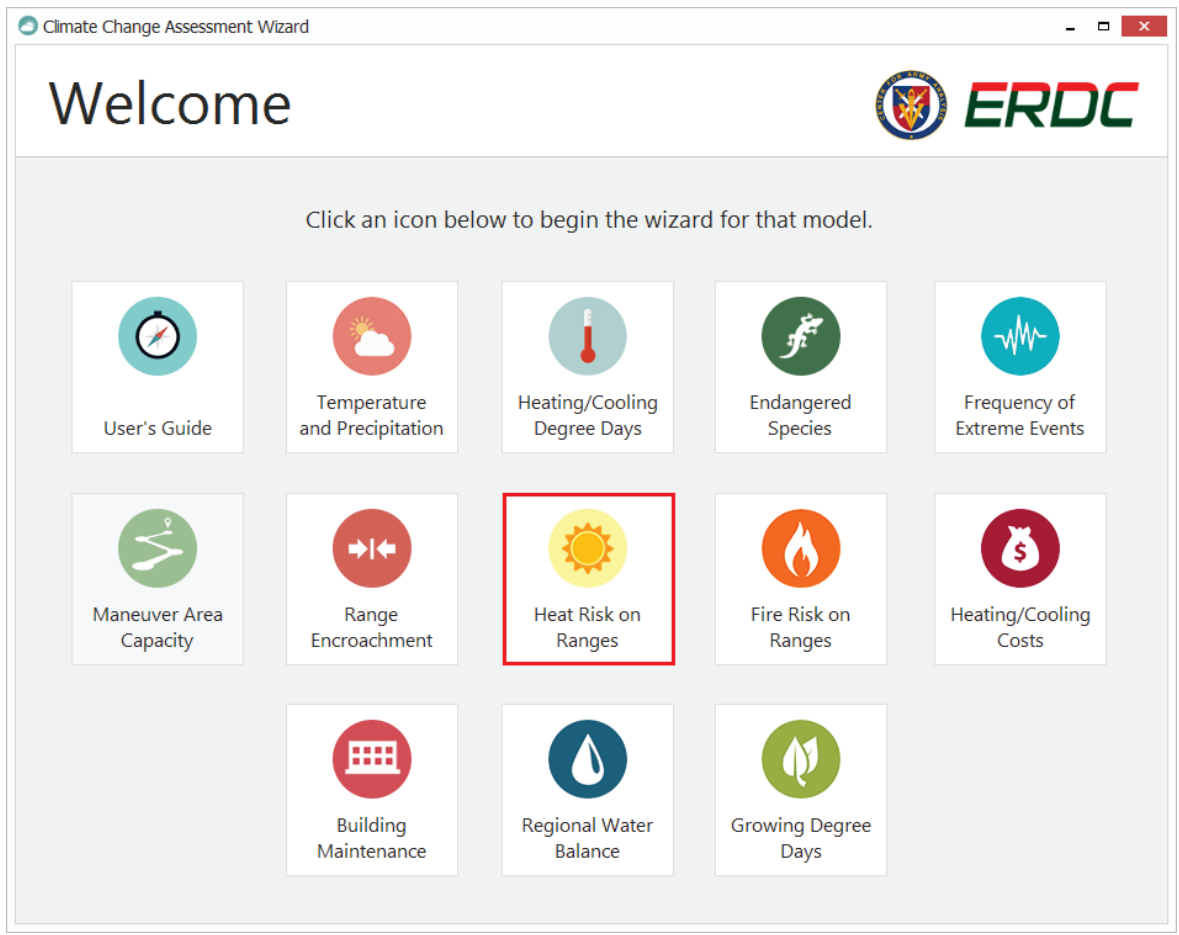

Figure 3. Range Days Lost to Heat Risk Model first screen.

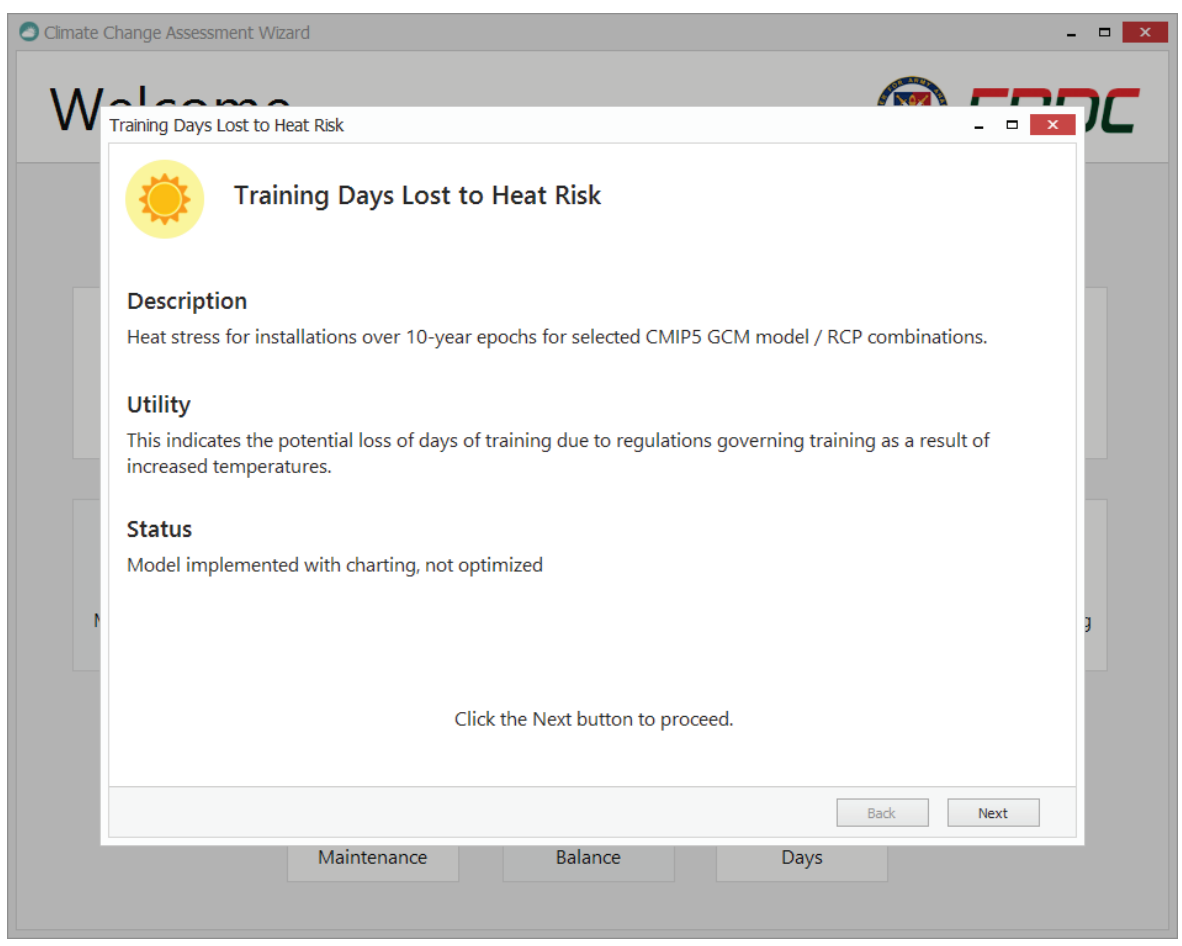

The second screen within the model (Figure 4) allows the end user to view the datasets in graphical or tabular mode. Users can choose the desired view type from the View drop down combo box. Options within this box 
are Graphs and Tabular. Graphs displays the data as standard line graphs while Tabular displays the data in a table layout within an Excel spreadsheet.

Figure 4. Range Days Lost to Heat Risk Model second screen.

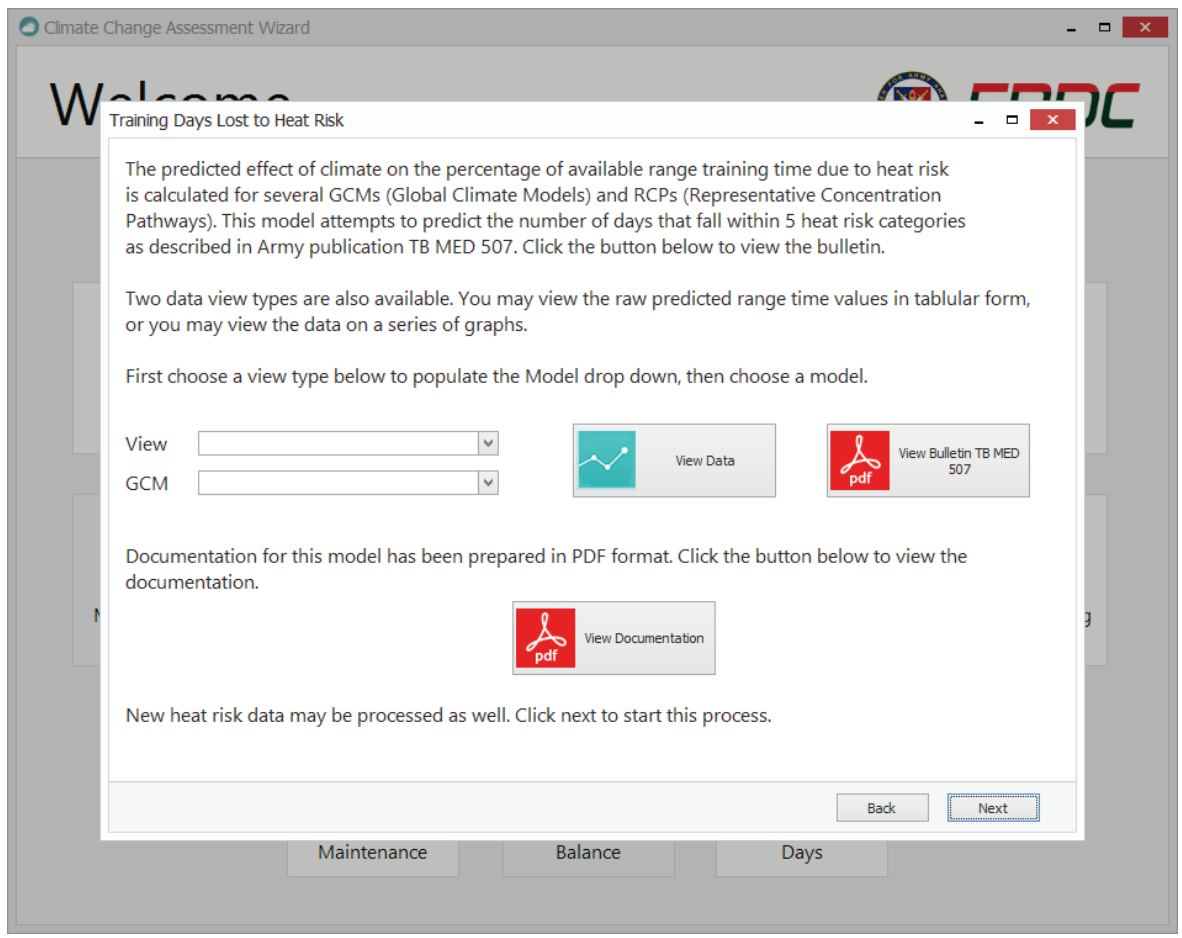

Next, choose a General Circulation Model (GCM) and Representative Concentration Pathway (RCP) type from the drop down combo box to filter only data related to that GCM/RCP. At the time of publication, there are ten GCMs within the dataset for this model. RCP 2.6, 4.5, and 8.5 were chosen to represent lower bound, middle, and upper bounds for each GCM. Each GCM contains these RCPs, with the exception of CNRM-CM- 5 and GFDL-CM3.

Once both of the choices are made, click the View Data button to launch the chart viewer window (Figure 5). 
Figure 5. Results in the chart viewer window.

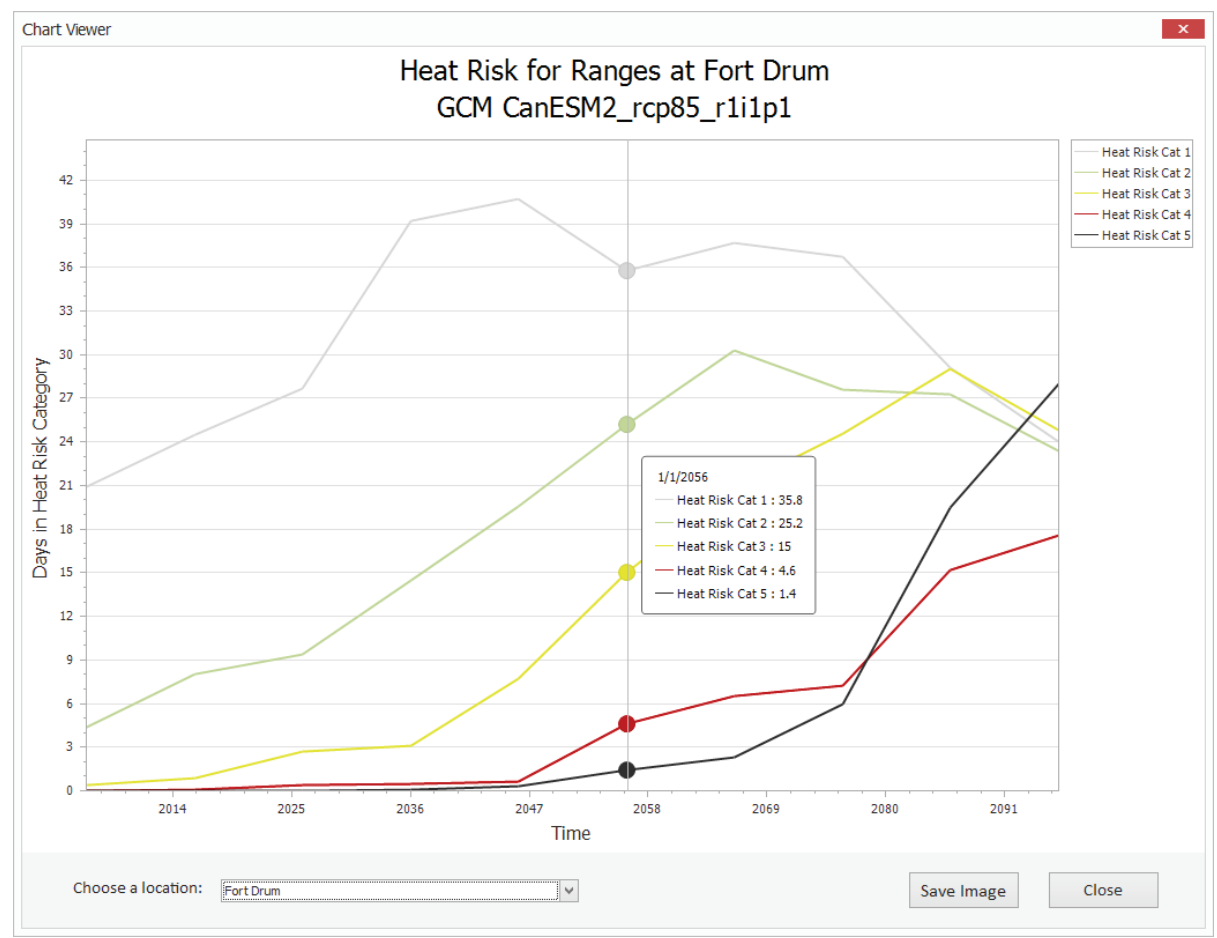

The average number of days in five different heat risk categories are plotted as line graphs with the number of days charted on the $\mathrm{Y}$-axis, and 10-year epochs are charted on the $\mathrm{X}$-axis. The user can change the charted values by choosing a different geographical location from the drop down combo box near the bottom left of the window (Figure 5). Upon selecting a location, the data will automatically filter to include only those values found within the chosen area. Table 1 lists and describes each of the five heat risk categories as defined by TB MED 507 (2003). 
Table 1. Doctrinal heat risk categories and guidelines contained in TB MED 507 (2003).

\begin{tabular}{|c|c|c|c|c|c|c|c|c|c|}
\hline \multicolumn{3}{|c|}{ Easy Work } & \multicolumn{3}{|c|}{ Moderate Work } & \multicolumn{3}{|c|}{ Hard Work } & - The work/rest times and fluid \\
\hline \multicolumn{3}{|c|}{$\begin{array}{l}\text { - Weapon Maintenance } \\
\text { - Walking Hard Surface at } 2.5 \mathrm{mph} \text {, } \\
<30 \mathrm{lb} \text { Load } \\
\text { - Marksmanship Training } \\
\text { - Drill and Ceremony } \\
\text { - Manual of Arms }\end{array}$} & \multicolumn{3}{|c|}{$\begin{array}{l}\text { - Walking Loose Sand at } 2.5 \mathrm{mph} \text {, } \\
\text { No Load } \\
\text { - Walking Hard Surface at } 3.5 \mathrm{mph} \text {, } \\
<40 \mathrm{lb} \text { Load } \\
\text { - Calisthenics } \\
\text { - Patrolling } \\
\text { - Individual Movement Techniques, } \\
\text { i.e., Low Crawi or High Crawl } \\
\text { - Defensive Position Construction }\end{array}$} & \multicolumn{3}{|c|}{$\begin{array}{l}\text { - Walking Hard Surface at } 3.5 \mathrm{mph} \text {, } \\
\geq 40 \mathrm{lb} \text { Load } \\
\text { - Walking Loose Sand at } 2.5 \mathrm{mph} \\
\text { with Load } \\
\text { - Field Assaults }\end{array}$} & $\begin{array}{l}\text { performance and hydration for } \\
\text { at least } 4 \mathrm{hrs} \text { of work in the } \\
\text { specified heat category. Fluid } \\
\text { needs can vary based on } \\
\text { individual differences ( } \pm 1 / 4 \mathrm{qt} / \mathrm{hr} \text { ) } \\
\text { and exposure to full sun or full } \\
\text { shade ( } \pm 1 / 4 \mathrm{qt} / \mathrm{hr}) \\
\text { - } \mathrm{NL}=\mathrm{no} \text { limit to work time per hr. } \\
\text { - Rest = minimal physical activity }\end{array}$ \\
\hline \multirow[b]{2}{*}{$\begin{array}{c}\text { Heat } \\
\text { Category }\end{array}$} & \multirow[b]{2}{*}{$\begin{array}{l}\text { WBGT } \\
\text { Index, F⿳亠丷厂 }\end{array}$} & \multicolumn{3}{|c|}{ Easy Work } & \multicolumn{2}{|c|}{ Moderate Work } & \multicolumn{2}{|c|}{ Hard Work } & \multirow{7}{*}{$\begin{array}{l}\text { in shade if possible. } \\
\text { - CAUTION: Hourly fluid intake } \\
\text { should not exceed } 11^{2} \text { qts. } \\
\text { Daily fluid intake should not } \\
\text { exceed } 12 \text { qts. } \\
\text { - If wearing body armor, add } 5^{\circ} \mathrm{F} \text { to } \\
\text { WBGT index in humid climates. } \\
\text { - If doing Easy Work and wearing } \\
\text { NBC (MOPP 4) clothing, add } \\
10^{\circ} \mathrm{F} \text { to WBGT index. } \\
\text { - If doing Moderate or Hard Work } \\
\text { and wearing NBC (MOPP 4) } \\
\text { clothing, add } 20^{\circ} \mathrm{F} \text { to WBGT } \\
\text { index. }\end{array}$} \\
\hline & & \multicolumn{2}{|c|}{$\begin{array}{c}\text { Work/Rest } \\
(\min )\end{array}$} & $\begin{array}{l}\text { Water } \\
\text { Intake } \\
\text { (qt/hr) }\end{array}$ & $\begin{array}{c}\text { Work/Rest } \\
(\min )\end{array}$ & $\begin{array}{l}\text { Water } \\
\text { Intake } \\
\text { (qt/hr) }\end{array}$ & $\begin{array}{c}\text { Work/Rest } \\
(\text { min) }\end{array}$ & $\begin{array}{l}\text { Water } \\
\text { Intake } \\
\text { (qt/hr) }\end{array}$ & \\
\hline 1 & $78^{\circ}-81.9^{\circ}$ & \multicolumn{2}{|l|}{ NL } & $1 / 2$ & NL & $3 / 4$ & $40 / 20 \mathrm{~min}$ & $2 / 4$ & \\
\hline$\stackrel{2}{2}$ & $82^{\circ}-84.9^{\circ}$ & \multicolumn{2}{|l|}{ NL } & $1 / 2$ & $50 / 10 \mathrm{~min}$ & $3 / 4$ & $30 / 30 \mathrm{~min}$ & 1 & \\
\hline $\begin{array}{c}3 \\
\text { (reLLOW) }\end{array}$ & $85^{\circ}-87.9^{\circ}$ & \multicolumn{2}{|l|}{ NL } & $3 / 4$ & $40 / 20 \mathrm{~min}$ & $3 / 4$ & $30 / 30 \mathrm{~min}$ & 1 & \\
\hline $\begin{array}{c}4 \\
\text { (REO) }\end{array}$ & $88^{\circ}-89.9^{\circ}$ & \multicolumn{2}{|c|}{ NL } & $3 / 4$ & $30 / 30 \mathrm{~min}$ & $3 / 4$ & $20 / 40 \mathrm{~min}$ & 1 & \\
\hline $\begin{array}{c}5 \\
\text { (BLACK) }\end{array}$ & $>90^{\circ}$ & \multicolumn{2}{|c|}{$50 / 10 \mathrm{~min}$} & 1 & $20 / 40 \mathrm{~min}$ & 1 & $10 / 50 \mathrm{~min}$ & 1 & \\
\hline \multicolumn{10}{|c|}{ 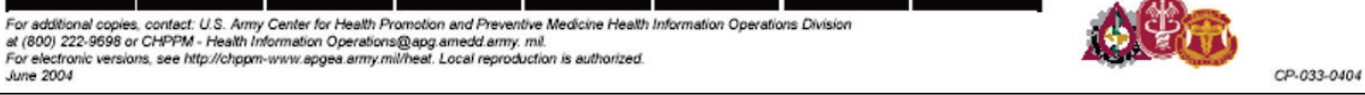 } \\
\hline
\end{tabular}

Charts can be saved to the user's computer by clicking the Save Image button near the bottom right of the window (Figure 5). The resulting file is saved to a location of the user's choosing in the universal Joint Photographic Experts Group (JPEG) image file format. 


\section{Building New Data}

Building new datasets is not possible within the Wizard interface but can be accomplished within the VM by running a Python Script from the Python IDLE development environment. The following instructions should be followed carefully to produce new data from this model.

The Python IDLE development environment is pre-installed inside the VM, and may be launched automatically from the Wizard application or accessed from the Windows Start menu (Figure 6 and Figure 7).

Figure 6. Launch Python IDLE from the third model screen within the Wizard.

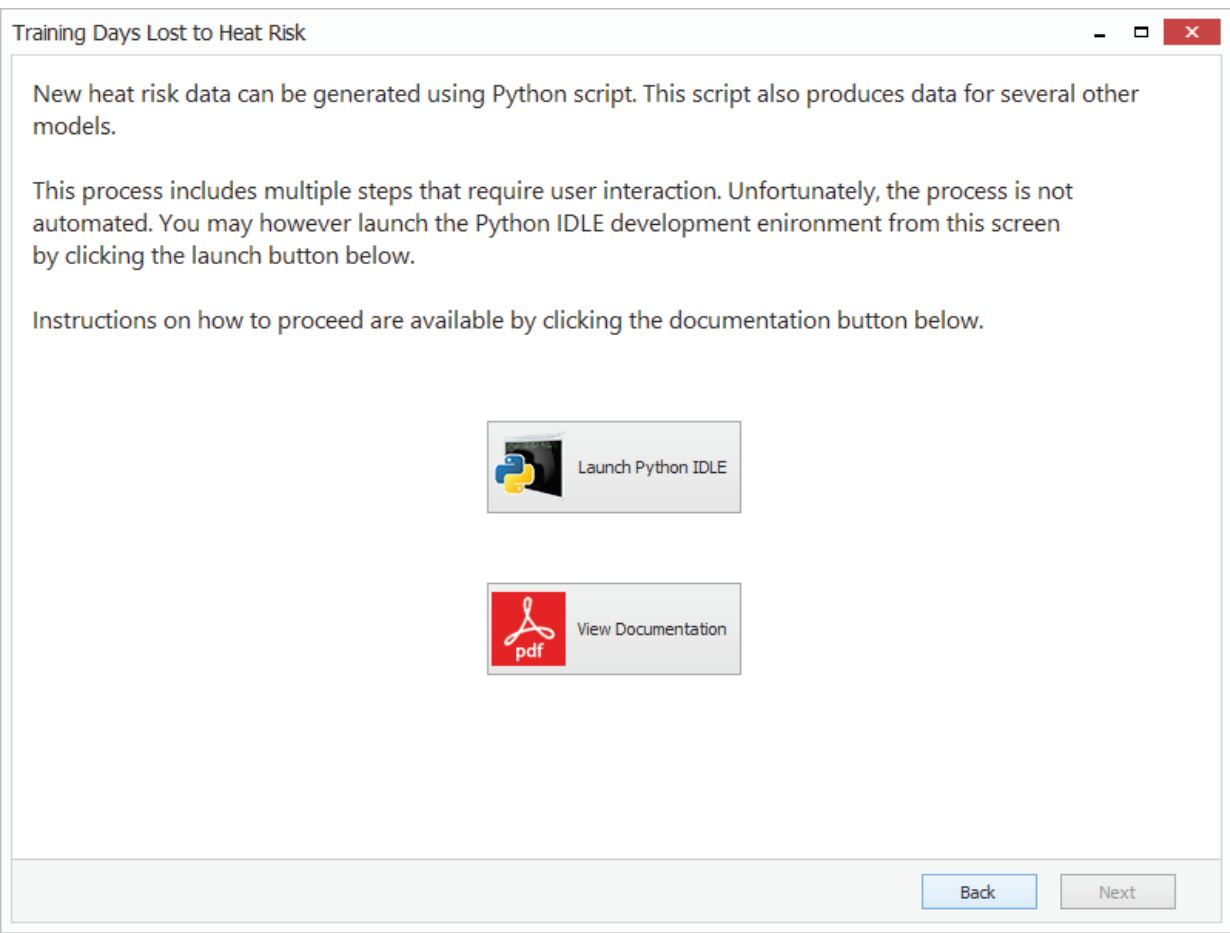


Figure 7. Python IDLE development environment.

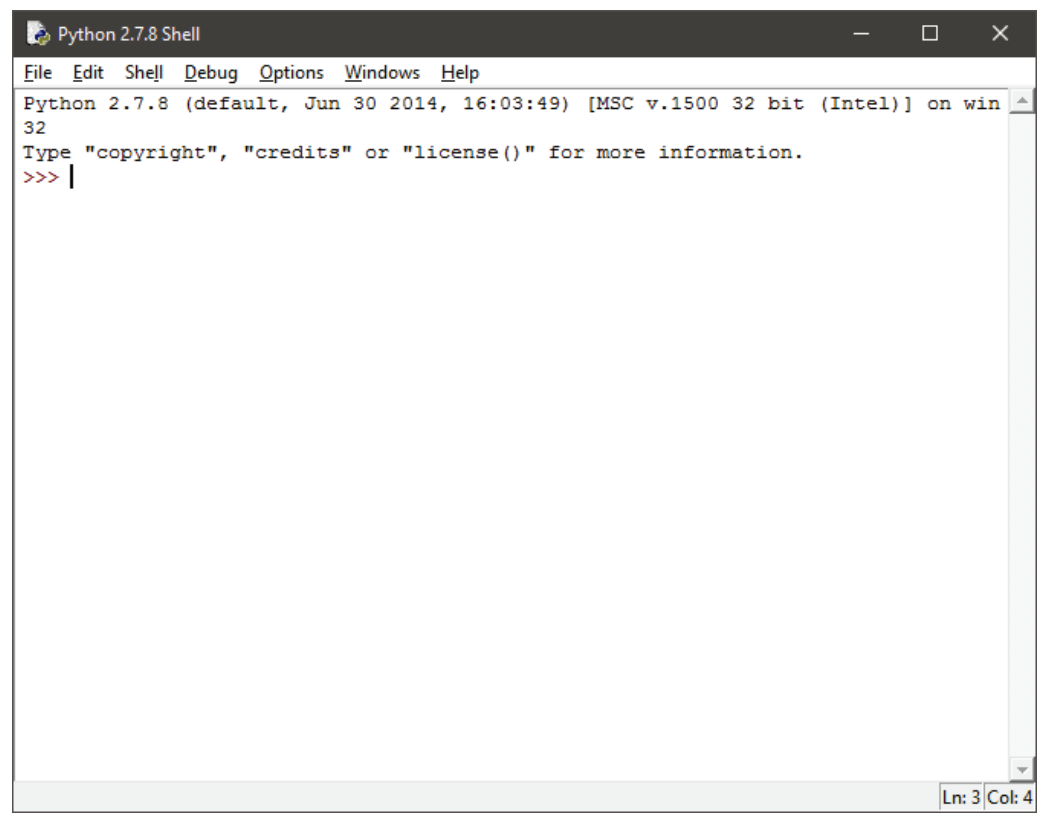

After opening IDLE, open the Python script by selecting File->open and browse to the file C: \Models $\backslash$ SharedData \Model \heat-fire risk days climate projections.py. Once the file is loaded, ensure line 19 points to a text file that contains a list of GCMs to process. This file has been pre-made, so no adjustments to it should be necessary, unless new GCM's are to be processed. The file location is $C: \backslash$ Model $\backslash$ Data-2 $\backslash G C M$ Model Runs.txt. Use a text editor such as MS Notepad ${ }^{\circledR}$ to make modifications to this file. Also note that daily climate data from the Temperature and Precipitation Model must be processed prior to running this Heat Risk on Ranges Model. Refer to lines 16-18 for the file paths. If new climate data is to be processed, the files that are output from the Temperature and Precipitation Model must be located in the same prior directory, or lines 16-18 must be modified to match the location of the output files. Refer to the user's guide for that model for more information about its output files.

Output from this model is in the form of CSV files, one for each GCM/RCP combination. Note that this process can be rather lengthy, depending on the number of GCMs that are being processed. It is not unusual for the script to run for several hours.

After running the Python script, another post processing script must be run. Locate the EXE file in the model folder within VM. (c: $\backslash$ Models $\backslash$ Shared-Data \DataFixer.exe). Set the input and 
output paths by clicking the Change buttons. Ensure that the output folder that's entered exists before starting the process. Finally, click Fix It to process the data (Figure 8).

Figure 8. Data Fixer tool.

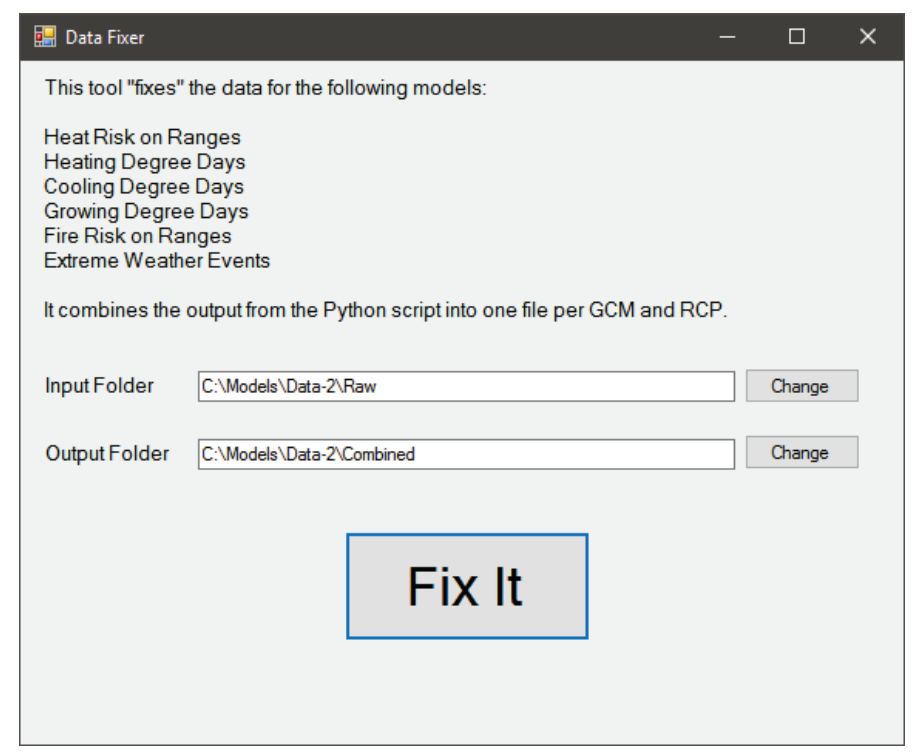

Post processing the data is fairly quick. It should not take more than a couple of minutes to complete. After this step, the data is ready to be viewed within the Wizard application. The post processing app source code is located at $\mathrm{C}: \backslash$ Models $\backslash \mathrm{VS}$ Projects $\backslash$ DataFixerHeatFire. 


\section{Known Issues and Limitations}

Building new data with this model can be a very lengthy process.

Depending on the number of GCMs being processed, it is not unusual for the Python script to take several hours complete, even on very powerful, modern computers. 


\section{Additional Help}

Additional questions or concerns should be directed to the Program Manager of the Integrated Climate Assessment for Army Enterprise Planning program.

Paul M. Loechl

ERDC-CERL

Paul.M.Loech|@usace.army.mil

217-373-5892

Marty Garton

ERDC-ITL

Byron.m.garton@usace.army.mil

601-634-2888 


\section{References}

Garton, B. M. 2019. Analytical Model Software Integration Methods. ERDC/ITL SR-194. Vicksburg, MS: Information Technology Laboratory (ITL) - U.S. Engineer Research and Development Center.

Headquarters, Department of the Army and Air Force (HQDA and HQAF). 2003. Heat Stress Control and Heat Casualty Management. Technical Bulleting Medical 507/Air Force Pamphlet 48-152 (I) (TB MED 507/AFPAM 48-152 [I]). Washington, DC: Headquarters, Department of the Army and Air Force, https://www.dir.ca.gov/oshsb/documents/Heat_illness_prevention_tbmed507.pdf 


\section{Appendix A: Acronyms and Abbreviations}

Term

CSV

DoD

ERDC

ERDC-CERL

ERDC-ITL

GCM

GDD

MVA

PM

$\mathrm{RCP}$

\section{Definition}

Comma Separated Values

Department of Defense

Engineer Research and Development Center

Engineer Research and Development Center-

Construction Engineering Research Laboratory

Engineer Research and Development Center-

Information Technology Laboratory

Global Circulation Model

Growing Degree Days

Military Value Analysis

Program Manager

Representative Concentration Pathway 


\section{Appendix B: Technical Bulletin}




\section{TECHNICAL BULLETIN}

\section{HEAT STRESS CONTROL AND HEAT CASUALTY MANAGEMENT}

APPROVED FOR PUBLIC RELEASE; DISTRIBUTION IS UNLIMITED. 
TB MED 507/AFPAM 48-152 (I)*

TECHNICAL BULLETIN

HEADQUARTERS

MEDICAL 507

AIR FORCE PAMPHLET 48-152 (I)

\author{
DEPARTMENT OF THE ARMY \\ AND AIR FORCE \\ Washington, DC, 7 March 2003
}

\title{
HEAT STRESS CONTROL AND HEAT CASUALTY MANAGEMENT
}

You can help to improve this bulletin. If you find any mistakes or have a recommendation to improve procedures, please let us know. Mail a memorandum or DA Form 2028 (Recommended Changes to Publications and Blank Forms) directly to Office of The Surgeon General, ATTN: DASG-PPM-NC, 5111 Leesburg Pike, Falls Church, VA 22041-3258.

Paragraph Page

Chapter 1 INTRODUCTION

Purpose

References

Explanation of abbreviations and terms

Roles

$1-1$

$1-2$

$1-3$

$1-4$

(n)

Chapter 2 PHYSIOLOGIC RESPONSES AND ADAPTATIONS TO HEAT

Heat stress in military operations

2-1 5

Heat exchange and environmental heat stress

Physiologic relationships

Mental performance
Adaptations to heat stress

Chapter 3 HEAT STRESS MANAGEMENT

General

Fluid replacement

19

Electrolyte (salt) replacement

22

Special military situations

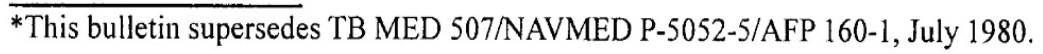


TB MED 507/AFPAM 48-152 (I)

Paragraph Page

Chapter 4 HEAT ILLNESS AND INJURY

$\begin{array}{lll}\text { Injury spectrum } & 4-1 & 27\end{array}$

Risk factors $\quad 4-2 \quad 27$

Minor heat illnesses and heat-related $\quad 4-3 \quad 30$ conditions

Heat exhaustion

Exertional heat injury and exertional rhabdomyolysis

Heat stroke

Fluid and electrolyte imbalances

$4-4 \quad 31$

$4-5 \quad 33$

$4-6 \quad 34$

$4-7 \quad 38$

Chapter 5 MANAGEMENT OF HEAT CASUALTIES

Clinical management $\quad 5-1 \quad 39$

Body cooling

Rehydration

Adjunctive therapy

Surveillance

$5-2 \quad 39$

$5-3 \quad 43$

$5-4 \quad 44$

$5-5 \quad 44$

Appendix A REFERENCES

Appendix B WET BULB GLOBE TEMPERATURE INDEX 51

Appendix C HOT WEATHER DEPLOYMENT TIPS

Appendix D COMMANDER'S, SENIOR NCO'S AND INSTRUCTOR'S $\quad 59$

GUIDE TO RISK MANAGEMENT OF HEAT CASUALTIES

Appendix E PREPARATION OF 0.1 PERCENT SALT WATER DRINKING 61 SOLUTION
47

30
31
33
34
38

39
39
43
44
44

1

62 
List of Tables

\begin{tabular}{|c|c|}
\hline Number & Title \\
\hline $2-1$ & Actions of heat acclimatization \\
\hline $3-1$ & $\begin{array}{l}\text { Fluid replacement and work/rest guidelines for warm weather } \\
\text { training conditions (Applies to average size and heat-acclimatized } \\
\text { soldier wearing battle dress uniform (BDU), hot weather.) }\end{array}$ \\
\hline $3-2$ & Heat acclimatization strategies \\
\hline $3-3$ & $\begin{array}{l}\text { Recommendations for continuous work duration and fluid } \\
\text { replacement during warm weather training conditions (Applies to } \\
\text { average size and heat acclimated soldier wearing BDU, hot weather.) }\end{array}$ \\
\hline $3-4$ & $\begin{array}{l}\text { Daily energy expenditures (measured by double-labeled water) of } \\
\text { military activities }\end{array}$ \\
\hline $3-5$ & $\begin{array}{l}\text { Distances that soldiers can march in the desert (at night) with } \\
\text { different amounts of water before being limited by dehydration } \\
\text { exhaustion }\end{array}$ \\
\hline $3-6$ & FITS reference values \\
\hline $4-1$ & Drugs implicated in intolerance to heat stress \\
\hline $4-2$ & Questions for assessment of mental status \\
\hline $4-3$ & Comparison of classical and exertional heat stroke \\
\hline
\end{tabular}

List of Figures

Page

2-1 Energy (heat) transfer of a soldier performing physical work in 6

2-2 Effects of climatic heat (comparable to heat category 3 or greater $\quad 8$

3-1 Heat strain decision process

3-2 Illustration of core temperature (steady-state) responses during

physical work (four metabolic rates) during compensated (CHS) and uncompensated (UCHS) heat stress

3-3 Relationship between core temperature and incidence of exhaustion $\quad 14$

from heat strain during physical work in UCHS and CHS

3-4 Influence of time-weighted metabolic rate (W) on work-time when 18 wearing NBC protective clothing (closed) in hot weather in soldiers with UCHS

3-5 Daily water requirements during various daily climatic (day time average $\quad 20$ WBGT) and metabolic ( $\mathrm{kcal} / \mathrm{d})$ conditions

3-6 Daily sodium requirements during various daily climatic (WBGT) and 23 metabolic $(\mathrm{kcal} / \mathrm{d})$ conditions

4-1 Spectrum of heat casualties, encompassing the continuum of mild 27 (heat exhaustion) to severe (heat stroke) with associated categories of physiologic dysfunction

4-2 Army hospitalizations for heat illnesses and hyposmolality/hyponatremia 28 from 1990 through 2002 
TB MED 507/AFPAM 48-152 (I)

List of Figures Continued

$\begin{array}{clc}\text { Number } & \text { Title } & \text { Page } \\ & & \\ 4-3 & \text { Schematic for Treatment of Acute Exertional Rhabdomyolosis } & 35 \\ 5-1 & \text { Warning signs and symptoms of heat illness and injury } & 40 \\ 5-2 & \text { Schematic for field treatment of heat casualties by 91 W medics } & 41 \\ \text { 5-3 } & \text { Schematic for MTF treatment of heat casualties } & 42 \\ \text { B-1 } & \text { Dry and wet bulb thermometers } & 52\end{array}$


TB MED 507/AFPAM 48-152 (I)

\section{CHAPTER 1}

\section{INTRODUCTION}

\section{1-1. Purpose}

This bulletin provides guidance to military and civilian health care providers and allied medical personnel to-

a. Develop an evidence-based preventive program to protect military personnel from heat stress and associated adverse health effects.

b. Understand the diagnosis and treatment of heat casualties, exertional heat injury (EHI), and exertional heat stroke (see glossary).

c. Understand the physiologic responses and adaptations to heat (chapter 2).

d. Implement procedures on managing heat stress (chapter 3).

e. Understand the risk factors for heat casualties (chapter 4).

f. Implement treatments for heat casualties (chapter 5).

g. Understand the effect of fluid and electrolyte imbalances (para 4-7).

h. Understand the methodology, needed equipment, use of, and correction procedures for the wet bulb globe temperature (WBGT) index (appendix B).

i. Prevent heat casualties during deployment (appendix $\mathrm{C}$ ).

j. Implement the procedures needed to prepare a 0.1 percent salt water drinking solution (appendix E).

k. Provide background information for reporting and data collection of epidemiological information to note trends and to identify individual, work, and environmental factors that are not adequately controlled by preventive measures and policies.

\section{1-2. References}

Required and related publications are listed in appendix A.

\section{1-3. Explanation of abbreviations and terms}

The glossary contains a list of abbreviations and terms used in this publication.

\section{1-4. Roles}

a. Unit commanders, medical officers, medics and combat lifesavers should coordinate to implement educational and training programs at all levels in the command based on the principles of this document. They should review all training and operations to make sure adequate planning is made for emergency medical support and heat injury assessment and management where tactically feasible.

b. Unit commanders will-

(1) Integrate the medical officer into all unit staff functions.

(2) Assess training/mission hazards from heat stress.

(3) Develop and implement controls for heat stress exposure.

(4) Ensure soldiers are heat acclimatized.

(5) Ensure soldiers are provided adequate clothing, shade, and sunscreens to prevent sunburn.

(6) Enforce appropriate fluid replacement discipline and work-rest cycles.

(7) Ensure that training and operational plans incorporate the degrading effect of heat on their schedules by adding rest (in shade) and hydration stops.

(8) Ensure planning for all aspects of fluid and food availability.

(9) Provide safe alternative training for individuals or units identified at particular risk of being heat casualties. 


\section{TB MED 507/AFPAM 48-152 (I)}

(10) Ensure the study of mean and extreme climatic conditions at the deployment site in the advance planning stages, to include the 24-hour pattern of temperature and humidity for the deployment site, as well as the times of sunrise and sunset. The 24-hour weather information is available at http:// www.weather.com.

(11) Ensure that communication links are established to obtain regular real-time weather data and predictions to decrease the risk of heat casualties or to provide windows of opportunity for critical military operations.

c. Unit medical officers will-

(1) Understand the commander's intent and mission goals and advise the commander on the potential adverse effects of heat and propose practical options for control of heat stress under difficult circumstances.

(2) Assess each component of heat stress (condition of the soldier, environmental heat stress, and mission requirements) to plan for the primary prevention of heat casualties.

(3) Assess the workload of the proposed training or operation by answering the following questions:

(a) What work rate and duration is planned?

(b) What uniform/equipment will be worn?

(c) Will the soldier be protected from solar heat load?

(d) Will the soldier be exposed to other sources of radiant heat (such as radiators, boilers, or hot metal objects)?

(4) Calculate on-site heat stress indices using the WBGT index and provide guidance for regulating physical training and fluid replacement according to the WBGT value.

(5) Assist the logistician in estimating potable water requirements (drinking and hygiene uses), establishing an adequate water logistic system, and educating soldiers on their water requirements.

(6) Provide direct medical oversight during the initial heat acclimatization period.

(7) Monitor soldier hydration status through urine (frequency, volume, color), body weight change (if possible), and orthostatic problems.

(8) Educate the soldiers on the steps needed to minimize the risk of heat casualties, to include hydration, nutrition, skin hygiene, rest and avoidance of risk factors (including alcohol, drugs and substance abuse).

(9) Educate soldiers in recognizing the signs of impending heat casualties and the basics of buddy aid.

(10) Establish a field expedient surveillance procedure to detect heat strain before significant casualties occur.

(11) Estimate the rate of heat casualties and arrange required medical support associated with each course of action.

(12) Integrate the estimates of casualty rates, mission compatible preventive measures and medical support requirements with the alternatives developed by the command staff.

(13) Become aware of what types of illnesses are being seen at sick call and what medications are being used.

(14) Develop a casualty evacuation plan to include a means of cooling and monitoring patients.

(15) Interview soldiers diagnosed as having signs and symptoms of being heat casualties to describe predisposing conditions and the circumstances surrounding the development.

(16) Report heat casualties to the Preventive Medicine Office for reporting to the U.S. Army Safety Center per AR 385-40.

(17) Communicate to field activities immediately upon recognition of heat casualty sentinel events and clusters.

d. Medics and combat lifesavers will recognize and treat heat casualties and implement measures to reduce the risk of additional casualties.

e. Soldiers will- 
TB MED 507/AFPAM 48-152 (I)

(1) Become familiar with recognizing the early signs and symptoms of becoming a heat casualty, and report as soon as possible to the unit medic/medical officer if they or their buddy develop symptoms.

(2) Drink enough fluid to stay adequately hydrated.

(3) Ensure their deployment kits contain an initial supply of stock hats, sunglasses, sunscreen, lip balm, and skin-care items.

(4) Attend lectures and receive appropriate written materials well in advance of deployment.

(5) Practice the buddy system to monitor performance and health.

f. Local medical commands will track heat illnesses. 
TB MED 507/AFPAM 48-152 (I)

\section{CHAPTER 2}

\section{PHYSIOLOGIC RESPONSES AND ADAPTATIONS TO HEAT}

\section{2-1. Heat stress in military operations}

a. Troops participating in military deployments often will encounter heat stress that requires management for successful mission accomplishment. Excessive heat stress will degrade mental and physical performance capabilities and eventually cause heat casualties.

b. U.S. military operations were successfully conducted in extreme hot weather climates (for example, World War II Pacific and North African campaigns, Vietnam, and Operation Desert Storm in Southwest Asia) that required troops to perform strenuous exercise for long hours and push their physiologic limits. Humans (if heat acclimated, given adequate shade and water, and able to limit physical activity) can tolerate extended exposure to any naturally occurring climatic heat stress. However, military situations, such as working in engine or boiler rooms, operating certain combat vehicles, firefighting and wearing protective clothing in hot environments, can involve heat stress conditions so severe they cannot be tolerated for extended periods. In addition, mission requirements that demand intense physical activity can lead to dehydration and make successful heat stress management very difficult.

c. Military training exercises, whether initial entry training, special badge qualification training, or military operations training, often occur during hot weather seasons and can present significant heat stress. Individuals in these situations often are not fully heat acclimatized requiring unit commanders and trainers to actively plan for heat injury prevention. These training environments provide an opportunity to train personnel in using appropriate work-rest cycles and fluid replacement guidelines.

d. Leadership is key for training in hot weather environments and for successful hot weather military operations. Soldiers should have confidence that they can master the environment through the use of preventive measures. Lessons learned from previous hot weather deployments must be emphasized. Leaders must learn their unit's capabilities and manage heat exposure relative to the provided guidance. Guidance is based on the "average" soldier, and there is significant individual variability. Supporting medical officers must ensure that the principles of this document are incorporated into the commander's plans and play an active role in all phases of training and operations: pre, during, and post. The best way to ensure this is to take an active role in the planning process for all operations or training.

\section{2-2. Heat exchange and environmental heat stress}

a. Heat stress refers to environmental and host conditions that tend to increase body temperature. Heat strain refers to physiological and or psychological consequences of heat stress.

b. Body heat exchange occurs by convection, radiation, conduction, and evaporation. Figure 2-1 schematically shows energy (heat) transfer of a soldier performing physical work in hot weather. Metabolic heat ( 70 percent of energy expended) is released from active skeletal muscles and transferred from the body core to skin. Heat exchange from skin to the environment is influenced by air temperature; air humidity; wind speed; solar, sky, and ground radiation; and clothing.

(1) Convection is heat transfer by moving a gas or liquid over the body, whether induced by thermal currents, body motion or natural movement of air (wind) or water. Heat loss by convection to air occurs when air temperature, in contact with skin, is below body temperature; conversely, heat gain by convection from air occurs when air temperature approaches or exceeds that of the body.

(2) Heat loss by radiation occurs when surrounding objects have lower surface temperatures than the body, and heat gain by radiation (solar, sky, large objects and ground) occurs when surrounding objects have higher surface temperatures than body surface temperature. Accordingly, temperature combinations of the sky, ground and surrounding objects may exist which result in body heat gain due to radiation, even 
TB MED 507/AFPAM 48-152 (1)

though the air temperature is below that of the body. Radiative heat exchange is independent of air motion.

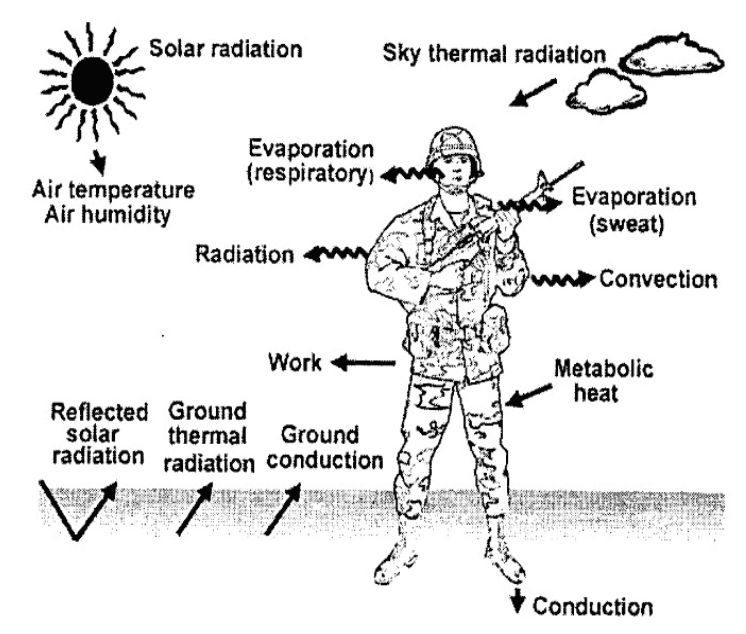

Figure 2-1. Energy (heat) transfer of a soldier performing physical work in hot weather

(3) Conduction of heat to or from solid objects is usually minimal, since little contact surface is involved. Contact with hot liquids or surfaces above $114^{\circ}$ Fahrenheit $(F)\left(46^{\circ}\right.$ centigrade $\left.(C)\right)$ can produce pain, and slightly higher temperatures can produce burns.

(4) Evaporative heat loss accounts for all body cooling when ambient temperatures are equal or above skin temperatures. Eccrine sweat glands secrete fluid onto the skin surface permitting evaporative cooling when liquid is converted to water vapor. When more body heat must be dissipated, these fluid losses increase due to heavier sweating, which may for short periods of time exceed 2 liters per hour. The rate of sweat evaporation depends upon air movement and the water vapor pressure gradient between the skin and the environment, so in still or moist air the sweat tends to collect on the skin. If sweat is not evaporated, the skin surface becomes soaked which suppresses sweat secretion. For this reason, it is important to allow air circulation to the skin, especially torso areas, to maximize evaporative cooling. Sweat that drips off the body or clothing provides no cooling benefit.

c. High air temperature, high humidity, thermal radiation, and low air movement are causes of environmental heat stress. Air temperature is measured from a shaded dry bulb thermometer. The contribution of humidity is determined from a wet bulb temperature, which is measured by covering a thermometer bulb with a wet wick. Aspirated wet bulb temperature is obtained when an air current is blown over the wick. Natural (unventilated) wet bulb temperature is obtained when natural airflow around the bulb is not augmented or restricted. Natural wet bulb temperature is higher than aspirated wet bulb temperature, particularly in still air; convergence begins at low air movements, with the two becoming nearly the same at an air velocity of approximately 7 miles per hour (mph) ( 3.1 meters per second). Radiant heat (solar load) is assessed by a "black globe" thermometer consisting of a 6-inch hollow copper sphere, painted matte (flat) black on the outside, and containing a thermometer at the center of the sphere. Air movement is measured from an anemometer.

d. The U.S. Army employs the WBGT index to mark levels of environmental heat stress. Appendix B provides equipment and instructions to measure WBGT as well as commercial sources for automated systems. The WBGT is an empirical index used to roughly demonstrate environmental heat stress for determining various physical activity levels and fluid replacement strategies to maximize performance and 
TB MED 507/AFPAM 48-152 (I)

minimize heat casualty risk during training. The Environmental Heat Stress Monitor from Southwest Research Institute (Appendix B) has heat stress guidance software embedded with the sensor measurement system.

e. The WBGT can vary greatly over short durations and distances in unpredictable ways. For example, on a sunny calm day an open field may have a higher WBGT than an adjacent forest, but on a windy cloudy day the forest may have a higher WBGT. Therefore, the WBGT value measured at one location on a post or region should serve only as general guides. When training or operations require moderate or hard intensity physical demands as defined in paragraph 3-2b, the WBGT should be measured at the site of training or location of operations if the mission permits. The WBGT must be taken and recorded by trained personnel and be made available to unit commanders and to supporting medical personnel who are involved in the evaluation and management of any potential heat casualty.

\section{2-3. Physiologic relationships}

a. Body temperature is normally regulated within a narrow range through two parallel processes: behavioral temperature regulation and physiological temperature regulation. Behavioral thermoregulation includes seeking shade, slowing down or discontinuing exercise or work, or removing clothing/equipment. In military situations, behavioral thermoregulatory drives are often overridden by motivation to successfully complete the mission. Physiological temperature regulation operates through heat loss responses (sweating and increased skin blood flow), which are proportional to the elevated core temperature and modified by skin temperature (warm skin enhances heat loss responses). Body heat loss by conduction, convection and radiation is mediated by altering skin blood flow. Body heat loss by evaporation is primarily by secreting sweat.

b. If the body stores heat, skin and or core temperature will increase. In response, the body initiates heat loss responses (sweating and increased skin blood flow). Unless the heat stress exceeds the thermoregulatory system's capacity to dissipate heat, the heat loss responses will increase until they restore heat balance, so core temperature stops increasing. If climate or clothing limits heat loss below the rate of heat production, then increases in sweating and skin blood flow will not restore heat balance but will only increase physiological strain.

c. Heat stress increases skin blood flow that elevates skin temperature. Skin temperature generally increases with ambient temperature but remains below core temperature. When sweating does not occur, increasing skin blood flow will elevate skin temperature, and decreasing skin blood flow will lower skin temperature nearer to ambient temperature. Thus, heat loss by conduction, convection and radiation is controlled by varying skin blood flow, and thereby skin temperature. When sweating occurs, the tendency of skin blood flow to warm the skin is approximately balanced by the tendency of sweating to cool the skin. Therefore after sweating has begun, a high skin blood flow primarily acts to deliver heat to the skin where it is dissipated by sweat evaporation.

d. Skin temperature is higher in warmer environments, while core temperature is relatively unaffected over a wide range of ambient temperatures. Thus at hotter ambient temperatures, the core-to-skin thermal gradient becomes narrower, and skin blood flow increases to achieve heat transfer sufficient for thermal balance. If evaporative cooling is not present, the core temperature will increase and widen the core-to-skin temperature gradient to help achieve sufficient heat transfer. Likewise, if increased evaporative cooling lowers skin temperature, the core-to-skin thermal gradient becomes wider, and skin blood flow requirements are proportionately less to achieve the same heat transfer.

e. Maintaining a high skin blood flow strains the cardiovascular system during physical work in the heat. High skin blood flow is associated with pooling of blood in compliant skin and subcutaneous vascular beds. This pooling reduces cardiac filling and stroke volume, thus requiring a higher heart rate to maintain cardiac output. For these conditions, the primary cardiovascular challenge is to have sufficient cardiac output to simultaneously support high skin blood flow for heat dissipation and high muscle blood flow for metabolism. To help compensate for reduced cardiac filling, sympathetic activity is increased to elevate 
TB MED 507/AFPAM 48-152 (I)

myocardial contractility and to divert blood flow from the viscera to skin and muscle. The reduction in visceral blood flow, if excessive, can contribute to the development of heat injury.

f. Since hot weather elicits high sweating rates, soldiers will dehydrate if they do not replace their water losses. Dehydration reduces evaporative and convective heat loss, increases body temperature $\left(\sim 0.36^{\circ} \mathrm{F}\right.$ or $0.2^{\circ} \mathrm{C}$ per percent of body weight loss), increases cardiovascular strain (heart rate $\sim 5$ beats per minute per percent of body weight loss), may reduce the core temperature that can be tolerated, and increases the risk of heat casualties. Dehydration reduces physical work capabilities in the heat. Over consumption of water (hyperhydration) provides no physiologic advantage (compared to normal hydration) and acts to increase urine water loss. If soldiers substantially over-consume fluids over an extended (typically $>4$ hours) period while not replacing their salt losses, they can develop hyponatremia (low blood sodium).

g. Figure 2-2 describes the effects of climatic heat and dehydration on physical work (aerobic exercise) capabilities based on a literature compilation. This analysis is based on highly motivated and heat acclimated soldiers in temperate and very hot climates. Note that dehydration reduces physical work capabilities in temperate (dashed line) and hot (dotted line) climates. The combination of heat stress and moderate (4 percent of body weight loss (BWL)) dehydration can reduce physical work capabilities by $\sim 50$ percent of what is expected for fully hydrated soldiers in temperate conditions. How the dehydration is achieved, the specific exercise task and individual tolerance to dehydration and heat stress can modify the relationships described below.

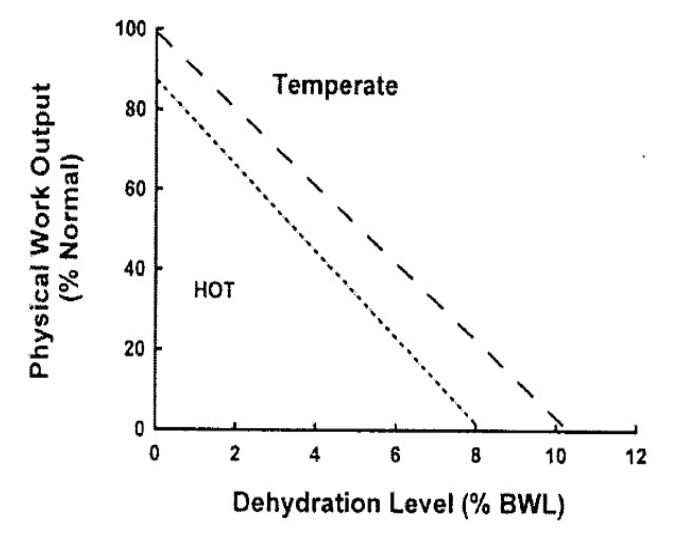

Figure 2-2. Effects of climatic heat (comparable to heat category 3 or greater (see Table 3-3)) and dehydration on reducing physical work output.

\section{2-4. Mental performance}

a. Heat stress can reduce mental performance, which is probably mediated by thermal discomfort (from high skin temperature, high skin wettedness, and cardiovascular strain). However, a very incomplete database exists relating mental performance degradation relative to graded levels of heat stress and strain. Mental performance degrades the most in boring, monotonous and repetitive tasks. In addition, tasks that require attention to detail, concentration, and short-term memory and are not self-paced may degrade from heat stress. Heat stress slows reaction time and decision times. Routine tasks are done more slowly. Errors of omission are more common. Vigilant task performance will degrade slightly after 30 minutes and markedly after 2 to 3 hours. 
b. Dehydration ( $>2$ percent BWL) adversely affects mental function (for example, serial addition, response time and word recognition) during heat exposure. These performance decrements probably increase with the level of dehydration.

\section{2-5. Adaptations to heat stress}

a. Biological adaptations to repeated heat stress include heat acclimatization (see glossary) and acquired thermal tolerance (see glossary). The magnitude of both adaptations depends on the intensity, duration, frequency, and number of heat exposures. These adaptations are complementary as heat acclimatization reduces physiologic strain, and acquired thermal tolerance improves tissue resistance injury for a given heat strain.

b. Heat acclimatization is induced when repeated heat exposures are sufficiently stressful to elevate core and skin temperatures and provoke perfuse sweating. During initial heat exposure, physiologic strain will be highest, as manifested by elevated core temperature and heart rate. The magnitude of physiologic strain will decrease each subsequent day of heat acclimatization. For example, an acclimatized soldier might have core temperature and heart rate reductions of $\sim 2^{\circ} \mathrm{F}\left(\sim 1.1^{\circ} \mathrm{C}\right)$ and 40 beats per minute, respectively (compared to the first day for unacclimatized soldiers) when performing physical work in desert heat.

c. Heat acclimatization dramatically improves comfort and physical work capabilities. Troops more easily complete military tasks in the heat that earlier were difficult and can complete some tasks that were impossible. For example, in severe desert conditions, it is unlikely that unacclimatized soldiers attempting a 100 -minute march will be able to complete the walk on day 1 . However, with repeated days of exerciseheat exposure, $\sim 40$ percent will be successful by day $3, \sim 80$ percent will be successful by day 5 and all soldiers will be successful by the eighth acclimatization day. In addition, the signs of discomfort and distress will decrease each day. It might be expected that for soldiers performing heavy work (forced march) in severe desert heat, $\sim 45$ percent will experience fainting on day 1, 20 percent on day 2 , $\sim 10$ percent on day 3 , and none by the fifth acclimatization day.

d. The effects of heat acclimatization on mental performance have not been determined. Since heat acclimatization improves thermal comfort and reduces cardiovascular strain, it should translate into better sustainment of mental performance.

e. Heat acclimatization is specific to the climate and activity level. Optimal acclimatization requires living and working in the specific climate in which soldiers will be deployed. However, acclimatization to hot, dry (for example, desert) or moist (for example, jungle) climates markedly improves the soldier's ability to work in the other climate. Soldiers who only perform light or brief physical work will achieve the level of acclimatization needed to perform that task. If they attempt more strenuous or prolonged work, they will need to gain additional acclimatization and possibly improved physical fitness to perform that task in the heat.

f. Table 2-1 provides the physiologic adaptations mediated by heat acclimatization. These adaptations include improved sweating, better fluid balance, improved cardiovascular stability, and lowered metabolic rate. Improved sweating is probably the most important physiologic adaptation, because it increases heat loss and reduces cardiovascular strain (by decreasing skin temperature and thereby skin blood flow requirements). Improved sweating responses include earlier onset, higher sweating rates, and sweat glands becoming resistant to hidromeiosis (wet skin suppressing sweating by causing swelling of stratum corneum and partly occluding the sweat-gland ducts), so high sweat rates can be sustained.

g. Acquired thermal tolerance refers to cellular adaptations induced by heat exposure that protect tissue/organs from heat injury. This allows the soldier to become more resistant to heat injury with subsequently more severe heat exposures. Acquired thermal tolerance can be induced by heat exposure or physical exercise and if both are employed together the benefits will be maximized.

h. Acquired thermal tolerance is associated with heat shock proteins (HSPs), which provide protection and accelerate repair of cells from heat exposure and other stressors. After the initial heat exposure, HSP 
TB MED 507/AFPAM 48-152(I)

Table 2-1. Actions of heat acclimatization

\begin{tabular}{ll}
\hline Thermal Comfort - Improved & Exercise Performance - Improved \\
\hline Core Temperature - Reduced & Cardiovascular Stability - Improved \\
Sweating - Improved & Heart Rate - Lowered \\
Earlier Onset & Stroke Volume - Increased \\
Higher Rate & Blood Pressure - Better Defended \\
Redistribution (Jungle) & Myocardial Compliance - Improved \\
Hidromeiosis Resistance & \\
(Jungle) & Fluid Balance - Improved \\
& Thirst - Improved \\
Skin Blood Flow - Improved & Electrolyte Loss (sweat and urine) - \\
Earlier Onset & Reduced \\
Higher Rate (Jungle) & Total Body Water - Increased \\
& Plasma (Blood) Volume - Increased and \\
Metabolic Rate - Lowered & Better Defended \\
\hline
\end{tabular}

messenger ribonucleic acid levels peak (within hours) and subsequent HSP synthesis depends on the severity and cumulative heat stress imposed. The time course for induction and decay of HSP responses are believed to be somewhat similar to those for heat acclimatization. The HSPs are grouped into families, based upon their molecular mass. Each family has different locations and functions within a cell. The HSP responses vary between specific tissues, as brain and liver demonstrate greater responses than skeletal muscle tissue. Generally, the tissues more susceptible to heat injury have greater HSP responses. In addition, other cellular systems (for example, stress kinase pathways or antioxidant enzymes) probably contribute to improved acquired thermal tolerance. Recently, many genes have been identified that are either up-regulated or down-regulated via heat stress; however, their possible contributions to improved acquired thermal tolerance have not been determined. 
TB MED 507/AFPAM 48-152 (I)

\section{CHAPTER 3}

\section{HEAT STRESS MANAGEMENT}

\section{3-1. General}

a. Heat stress is imposed by the combination of mission and individual and environmental risk factors. Environmental risk factors include temperature, humidity, wind, and solar load. Mission risk factors include the work intensity (metabolic rate), duration of heat exposure, and clothing/equipment worn. Wearing special clothing, such as body armor or nuclear, biological and chemical (NBC) protective clothing, can impede heat dissipation (see glossary) and increase heat strain. Individual risk factors include the soldiers' physical fitness, heat acclimatization status, hydration/nutrition status, and health (including prior history of repetitive occurrences of heat injury, use of medications, alcohol or drugs of abuse). Fit, healthy, heat acclimatized, fully hydrated, and well-rested soldiers will encounter the least heat strain when performing a given military task in hot weather.

b. Soldiers can effectively operate in any naturally occurring hot environment if they are heat acclimatized, consume adequate water and diet (for example, salt), and have sufficient shade and rest. Successful management of heat exposure results in optimal work capabilities and prevention of heat illness/injury.

c. Successful management of heat stress depends on proper education of leaders and troops exposed to heat. Leaders must implement procedures to alert troops of dangerous heat stress levels and must apply interventions to reduce exposure and increase resistance of exposed soldiers. Being alert to signs of soldier distress in the heat is critical so that management procedures can be adjusted accordingly. Heat casualties often occur in groups, so when the first heat casualty occurs others may be imminent. Figure 3-1 provides the heat strain decision-making process.

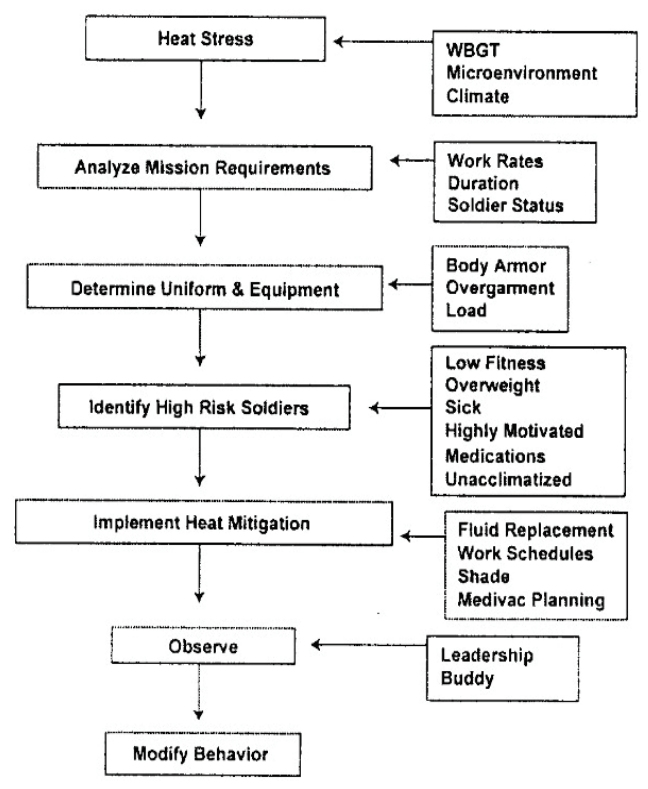

Figure 3-1. Heat strain decision process 
TB MED 507/AFPAM 48-152 (I)

\section{3-2. Heat stress and core temperature}

a. Heat stress can be divided into compensated heat stress (CHS) and uncompensated heat stress (UCHS). CHS and UCHS are primarily determined by biophysical factors (environment, clothing, workrate) and are modestly affected by biological status (heat acclimatization and hydration status). The CHS exists when heat loss occurs at a rate in balance with heat production so that a steady-state core temperature can be achieved at a sustainable level for a requisite activity. The CHS represents the majority of military situations. The UCHS occurs when the individual's evaporative cooling requirements exceed the environment's evaporative cooling capacity. During UCHS, soldiers cannot achieve steadystate core temperature, and core temperature rises until exhaustion occurs at physiological limits. The UCHS examples include performing intense exercise in oppressive heat, wearing NBC protective clothing in hot weather, or performing strenuous work in a boiler room.

b. Figure 3-2 provides an illustration of steady-state core temperature responses (for heat acclimatized, fully hydrated, lightly clothed soldiers) that might be expected at several metabolic rates and environmental (WBGT) conditions. Metabolic rate during marching is dependent upon speed, terrain (slope and surface), and load carried. The metabolic rate is proportional to the amount of body heat that must be dissipated to the environment. Metabolic rates of 250 watt (W), $425 \mathrm{~W}$, and $600 \mathrm{~W}$ represent "easy", "moderate", and "hard" intensity military tasks (see Table 3-1), while 1,000 W represents an activity like competitive running. Wearing heavy clothing has the same effect as exposure to a hotter climate.

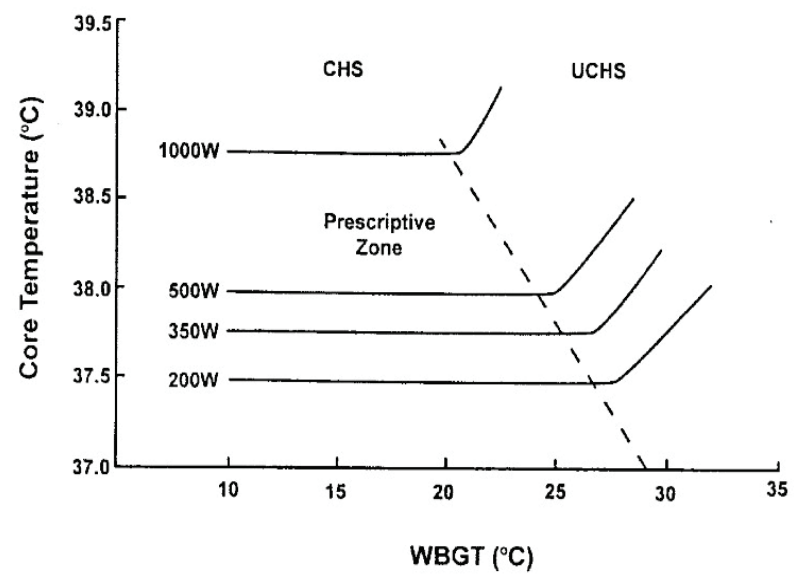

Figure 3-2. Illustration of core temperature (steady-state) responses during physical work (four metabolic rates) during Compensated (CHS) and Uncompensated (UCHS) heat stress.

c. During CHS, a steady-state core temperature is achieved that is proportionate to the metabolic rate. The steady-state core temperature is often independent of the environment; however, as the heat stress becomes more severe (higher WBGT or higher metabolic rate) an elevated steady-state core temperature may be achieved. This zone of elevated steady-state core temperatures and the beginning of UCHS is somewhat influenced by a soldier's ability to defend his or her body temperature (poorly acclimatized persons will transition at lower environmental heat stress). During UCHS, working at higher metabolic rates only increases the rate of body heat storage, thereby reducing the time to achieve a given core temperature. In addition, skin temperatures are high (because of inadequate evaporative cooling) increasing the cardiovascular strain. 
TB MED 507/AFPAM 48-152 (1)

Table 3-1. Fluid replacement and work/rest guidelines for warm weather training conditions (Applies to average size and heat-acclimatized soldier wearing battle dress uniform (BDU), hot weather.)

\begin{tabular}{|c|c|c|c|c|c|c|c|c|}
\hline & & \multicolumn{3}{|c|}{$\begin{array}{c}\text { Easy Work } \\
(250 \mathrm{~W})\end{array}$} & \multicolumn{2}{|c|}{$\begin{array}{c}\text { Moderate Work } \\
(425 \mathrm{~W})\end{array}$} & \multicolumn{2}{|c|}{$\begin{array}{l}\text { Hard Work } \\
(600 \mathrm{~W})\end{array}$} \\
\hline $\begin{array}{c}\text { Heat } \\
\text { Category }\end{array}$ & $\begin{array}{c}\text { WBGT }^{6,7} \\
\text { Index } \\
\left({ }^{\circ} \mathrm{F}\right)\end{array}$ & \multicolumn{2}{|c|}{ Work/Rest ${ }^{1,3}$} & $\begin{array}{l}\text { Water }^{4,5} \\
\text { Intake } \\
(\mathrm{qt} / \mathrm{hr})\end{array}$ & Work/Rest & $\begin{array}{l}\text { Water } \\
\text { Intake } \\
\text { (qt/hr) }\end{array}$ & Work/Rest & $\begin{array}{l}\text { Water } \\
\text { Intake } \\
(\mathrm{qt} / \mathrm{hr})\end{array}$ \\
\hline 1 & $78-81.9$ & \multicolumn{2}{|c|}{$\begin{array}{l}\text { No Limit } \\
(\mathrm{NL})^{2}\end{array}$} & $1 / 2$ & NL & $3 / 4$ & $40 / 20 \mathrm{~min}$ & $3 / 4$ \\
\hline 2 (green) & $82-84.9$ & \multicolumn{2}{|c|}{$\mathrm{NL}$} & $1 / 2$ & $50 / 10 \mathrm{~min}$ & $3 / 4$ & $30 / 30 \mathrm{~min}$ & 1 \\
\hline 3 (yellow) & $85-87.9$ & \multicolumn{2}{|c|}{ NL } & $3 / 4$ & $40 / 20 \mathrm{~min}$ & $3 / 4$ & $30 / 30 \mathrm{~min}$ & 1 \\
\hline 4 (red) & $88-89.9$ & \multicolumn{2}{|c|}{ NL } & $3 / 4$ & $30 / 30 \mathrm{~min}$ & $3 / 4$ & $20 / 40 \mathrm{~min}$ & 1 \\
\hline 5 (black) & $>90$ & \multicolumn{2}{|c|}{$50 / 10 \mathrm{~min}$} & 1 & $20 / 40 \min$ & 1 & $10 / 50 \mathrm{~min}$ & 1 \\
\hline \multicolumn{3}{|c|}{ Easy Work } & \multicolumn{3}{|c|}{ Moderate Work } & \multicolumn{3}{|c|}{ Hard Work } \\
\hline \multicolumn{3}{|c|}{$\begin{array}{l}\text { - Weapon maintenance } \\
\text { - Walking hard surface at } 2.5 \\
\text { mph, <30 pound (lb) load } \\
\text { - Manual of arms } \\
\text { - Marksmanship training } \\
\text { - Drill and ceremony }\end{array}$} & \multicolumn{3}{|c|}{$\begin{array}{l}\text { - Walking loose sand at } 2.5 \\
\text { mph, no load } \\
\text { - Walking hard surface at } 3.5 \\
\text { mph,<40 lb load } \\
\text { - Calisthenics } \\
\text { - Patrolling } \\
\text { - Individual movement } \\
\text { techniques, that is low crawl, } \\
\text { high crawl } \\
\text { - Defensive position } \\
\text { construction }\end{array}$} & \multicolumn{3}{|c|}{$\begin{array}{l}\text { - Walking hard surface at } 3.5 \\
\text { mph, } \geq 40 \mathrm{lb} \text { load } \\
\text { - Walking loose sand at } 2.5 \\
\text { mph with load } \\
\text { - Field Assaults }\end{array}$} \\
\hline
\end{tabular}

1. The work/rest times and fluid replacement volumes will sustain performance and hydration for at least 4 hours of work in the specified heat category. Fluid needs can vary based on individual differences $( \pm 1 / 4 \mathrm{qt} / \mathrm{hr})$ and exposure to full sun or full shade $( \pm 1 / 4 \mathrm{qt} / \mathrm{hr})$.

2. NL equals no limit to work time per hour (up to 4 continuous hours).

3. Rest means minimal physical activity (sitting or standing), accomplished in shade if possible.

4. CAUTION: Hourly fluid intake should not exceed $11 / 2$ quart.

5. Daily fluid intake should not exceed 12 quarts.

6. If wearing body armor, add $5^{\circ} \mathrm{F}$ to WBGT index in humid climates.

7. If wearing NBC clothing (mission-oriented protective posture (MOPP 4)), add $10^{\circ} \mathrm{F}$ to WBGT index for easy work, and $20^{\circ} \mathrm{F}$ to WBGT index for moderate and hard work.

d. Core temperature provides the "best" single physiological measure to estimate physical work capabilities during hot weather operations. Core temperature values will vary depending upon the measurement site. (Do not rely on measurements made at superficial sites such as the mouth, armpits, ear drum, or ear canal.) Esophageal temperature is the most accurate, and it responds rapidly and quantitatively to changes in core temperature. Rectal temperature is typically slightly higher $\left(\sim 0.4^{\circ} \mathrm{F}\right)$ and responds more slowly. Oral temperature is easy to obtain but can be artificially lowered if the subject breathes through the mouth particularly during the rapid breathing of exercise. Pill temperatures are similar to rectal values but may be slightly more variable as the pill moves through the gastrointestinal tract. Tympanic and ear canal temperature measurements are often confounded by head and face skin temperatures, so their use is not recommended. In collapsed hyperthermic athletes, ear temperature readings have been 6 to $10^{\circ} \mathrm{F}$ below rectal. Measuring rectal temperature will be the most practical way to evaluate core body temperature of heat casualties early in the field or at training sites and in the clinical setting at a medical treatment facility (MTF). 


\section{TB MED 507/AFPAM 48-152 (I)}

e. To develop hot weather guidance, core temperature responses for the "average" soldier are predicted via mathematical modeling based upon appropriate environmental and mission factors. The predicted core temperature values are then compared to the percentage of soldiers expected to incur exhaustion from heat strain for a given population (somewhat dependent on physical fitness level and acclimatization state) and heat stress conditions (CHS or UCHS). Military training guidelines for using work-rest cycles are based on achieving core temperatures of $101.3^{\circ} \mathrm{F}\left(38.5^{\circ} \mathrm{C}\right)$ and $100.4^{\circ} \mathrm{F}\left(38^{\circ} \mathrm{C}\right)$, for $\mathrm{CHS}$ and UCHS, respectively. Military training guidelines for continuous physical work times (for example, physical training runs) are based on achieving a core temperature of $104.0^{\circ} \mathrm{F}\left(40.0^{\circ} \mathrm{C}\right)$ in acclimated individuals with appropriate fluid replacement. Core temperatures below these levels can be sustained with "few" persons incurring exhaustion from heat strain. During military operational settings, less conservative guidelines (higher core temperatures) can be employed.

f. Figure 3-3 presents the relationships between core temperature and expected incidence of exhaustion from heat strain. Considerable inter-individual variability exists between and among physically fit, heat acclimatized and field-seasoned soldiers in their ability to tolerate higher core temperatures. Likewise, any given soldier will tolerate higher and lower core temperatures during CHS (right line, representing CHS with cool skin temperature conditions) and UCHS (left line, representing UCHS with warm skin temperature conditions), respectively. During CHS, soldiers can tolerate high core temperatures for extended durations (because core temperature elevation is mostly due to metabolic rate), and exhaustion is often associated with dehydration or physical fatigue (from working at sufficiently high metabolic intensities to induce high core temperatures). During UCHS, soldiers incur heat exhaustion at relatively low core temperatures (because core temperature is elevated by heat stress combined with high skin temperatures) due to cardiovascular strain. Most hot-weather military situations probably fall between these two extremes.

g. The CHS is managed by heat acclimatization, hydration and work rate. UCHS is managed by minimizing heat stress exposure, limiting metabolic rate, and using microclimate (see para 3-5 and glossary) cooling.

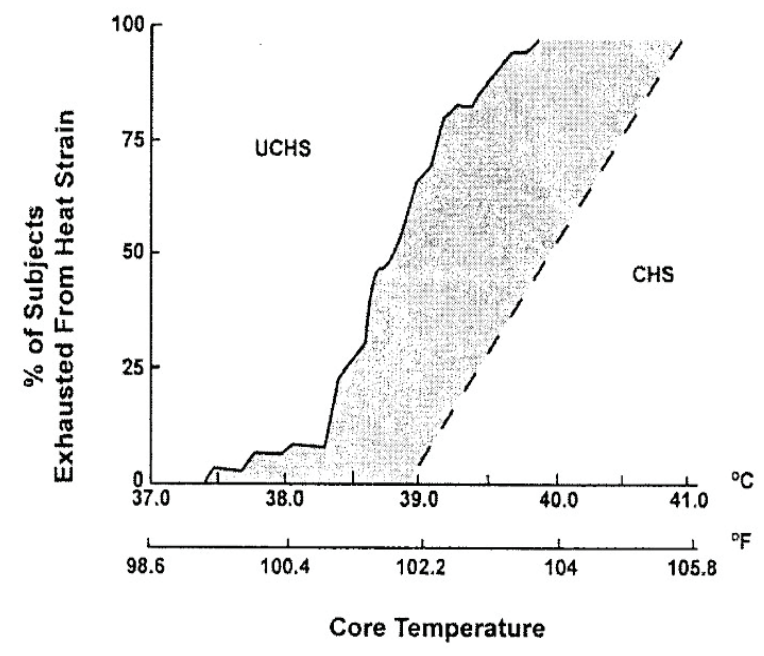

Figure 3-3. Relationship between core temperature and incidence of exhaustion from heat strain during physical work in UCHS and CHS. 
TB MED 507/AFPAM 48-152 (I)

\section{3-3. Heat acclimatization}

a. Physical work and training programs for unacclimatized soldiers should be limited in intensity and time. About two weeks of progressive heat exposure and physical work should be allowed for heat acclimatization.

b. By the second day of acclimatization, significant reductions in physiologic strain can be observed. By the end of the first week and second week, $\sim 50$ percent and $\sim 80$ percent of the physiologic adaptations (for average soldier) are complete, respectively. A day or two of intervening cool weather will not interfere with acclimatization to hot weather. Soldiers who are less fit or unusually susceptible to heat will require several days or weeks more to acclimatize. Very fit soldiers can achieve marked ( 70 percent) heat acclimatization in one week. In addition, several weeks of living and working in the heat (seasoning) may be required to maximize tolerance to high body temperatures. If no further heat exposures occur, the benefits of heat acclimatization will be retained for $\sim 1$ week and then decay with about 75 percent lost by $\sim 3$ weeks.

c. Heat acclimatization is necessary even for very fit soldiers, but they will acclimatize to heat faster than less fit soldiers. The full effects of heat acclimatization are relative to the initial physical fitness level and the total heat stress encountered by the soldier. Soldiers who only perform light physical work will achieve the level of acclimatization needed to perform that task. If they attempt more strenuous work, they will need to gain additional acclimatization and possibly improved physical fitness to perform that task in the heat. Less fit soldiers have reduced work capabilities in the heat. For example, women and middleaged soldiers often have lower work capabilities than men or young adult soldiers, respectively. However, if physical fitness is matched and they are heat acclimatized, they should have similar work capabilities in the heat.

d. Heat acclimatization requires a minimum exposure of two hours per day (can be broken into 1-hour exposures) with some physical exercise requiring cardiovascular endurance, (for example, marching or jogging) rather than strength training (pushups and resistance training). Gradually increase the exercise intensity each day, working up to an appropriate physical training schedule adapted to the environment. Resting in the heat, with activity limited to that required for existence, results in only partial acclimatization; physical exercise in the heat must be performed to accomplish optimal acclimatization for work at that intensity in a given hot environment.

e. Maximize physical fitness and heat acclimatization prior to deployment to hot environments. Maintain physical fitness after deployment with maintenance programs tailored to the environment. If the new environment is much hotter than what the troops are accustomed to, light recreational activities may be appropriate for the first two days. By the third day, unit runs (20 to 40 minutes) at the pace of the slowest participants are feasible.

f. Two groups at extremes need to be monitored: the least fit soldier will have the most difficult time (take longer and suffer greater heat strain) acclimatizing to heat and the most motivated soldiers may overdo their physical activity and be susceptible to heat illness/injury.

g. Table 3-2 provides heat acclimatization strategies that can be considered before and after deployment.

h. If recently deployed troops must perform physical work during the period of acclimatization, take advantage of the cooler hours (morning, evening, or night). Establish a schedule with increasingly longer work periods alternating with rest periods. When possible, two groups of soldiers should be detailed to work in sequence with alternating work/rest periods.

i. Adequate water must be provided and consumption monitored during and after the acclimatization period. Heat acclimatization increases the sweating rate, and therefore increases water requirements. As a result, heat acclimatized soldiers will dehydrate faster if they do not consume fluids. Dehydration negates many of the thermoregulatory advantages conferred by heat acclimatization and high physical fitness. 
TB MED 507/AFPAM 48-152 (l)

Table 3-2. Heat acclimatization strategies

1. Mimic the deployment climate.

2. Ensure adequate heat stress by-

- Invoking sweating.

- Using exercise and rest to modify the heat strain.

- Having 4 to 14 days of heat exposures.

- Maintaining the daily duration of at least 100 minutes.

3. Start early (1 month before deployment).

- Performance benefits may take longer than physiological benefits.

- Be flexible with training.

- Build confidence.

- Pursue optimum physical fitness in the current climate.

4. Methods.

- Pre-deployment: Climate controlled room or hot weather.

- Integrate with training by adding additional acclimatization sessions; inserting acclimatization with training; alternating acclimatization days with training days, and no detraining.

5. On arrival.

- Start slowly and reduce training intensity and duration and limit heat exposure.

- Increase heat and training volume as tolerance permits.

- Acclimatize in heat of day.

- Train in coolest part of day.

- Use work/rest cycles or interval training.

- Be especially observant of salt needs for the first week of acclimatization.

\section{3-4. Work-rest cycles}

a. The recommended threshold WBGT value for initiating hot weather guidelines is $75^{\circ} \mathrm{F}\left(23^{\circ} \mathrm{C}\right)$ depending on the work intensity. As the WBGT value increases, physical work intensity should be reduced (or more frequent and longer rest periods), or under extremely severe conditions (WBGT index $>90^{\circ} \mathrm{F}$ or $32^{\circ} \mathrm{C}$ ), possibly suspended. Work schedules should be customized to the climate, work intensity and military situation.

b. Table 3-1 provides work/rest and fluid replacement guidelines for heat-acclimatized soldiers in a training environment (average soldier wearing BDU, hot weather). The guidelines support at least 4 hours of work. Three time-weighted work intensities are provided representing easy $(\sim 250 \mathrm{~W})$, moderate $(\sim 425$ $\mathrm{W})$, and hard $(\sim 600 \mathrm{~W})$ military tasks; examples are provided. The users should determine the existing weather conditions at the site of training (WBGT index) and then read the recommended work-time. The work-rest cycle is the ratio of minutes of work to minutes of rest within each hour.

c. The information in Table 3-1 is sufficiently robust to estimate guidance for many different scenarios. Soldiers often perform several hours of moderate or hard work interspersed with several hours of easy work. In these situations, the recommended work times for moderate and hard work periods are 
overly conservative. Leaders need to gain experience with estimating guidance for different scenarios and matching that information to their unit's work capabilities. Leaders must recognize that "fudging" and working a unit too hard in the heat may result in increased heat casualties that day or greater susceptibility to heat injuries on the following day. Conversely, unnecessarily limiting work in the heat will result in suboptimal performance.

d. Table 3-3 provides guidelines for the duration of continuous work at metabolic intensities representing easy, moderate, or hard military tasks (see Table 3-1 for examples of these tasks and fluid replacement during warm weather training). Factors increasing the metabolic intensity of a task include carrying heavier backpack loads, marching at faster paces or uphill and loading heavier objects. Remember, activities such as physical fitness runs usually elicit much higher metabolic rates $(\sim 1,000 \mathrm{~W})$ then the "hard work" military activities $(\sim 600 \mathrm{~W})$ represented in this table. It is assumed that soldiers performing these continuous effort tasks shall not have incurred significant exercise-heat stress or dehydration prior to this activity and will have extended (several hours) rest and adequate rehydration afterwards.

e. Rest means minimal physical activity and should be accomplished in the shade with adequate air circulation and without additional clothing or protective equipment. Soldiers should avoid resting on hot ground (such as in the desert) by digging a shallow trench to locate cooler ground.

f. If soldiers are performing physical training as a unit, they should open ranks (double arm interval) to ensure adequate air motion for cooling. Soldiers in the middle of the formation will experience significantly greater heat strain.

g. Protective clothing and body armor can increase heat strain, and several "Rule of Thumb" adjustments can be made. The WBGT index value should be increased by $\sim 10^{\circ} \mathrm{F}\left(6^{\circ} \mathrm{C}\right)$ for easy work and by $\sim 20^{\circ} \mathrm{F}\left(12^{\circ} \mathrm{C}\right)$ for moderate and hard work when wearing NBC protective clothing (MOPP4). Body armor has more modest effects on work/rest guidelines and water requirements; if the environment is humid (observe dripping sweat), then a WBGT index increase by $\sim 5^{\circ} \mathrm{F}\left(3^{\circ} \mathrm{C}\right)$ should be employed.

Table 3-3. Recommendations for continuous work duration and fluid replacement during warm weather training conditions (Applies to average size and heat acclimated soldier wearing $B D U$, hot weather.)

\begin{tabular}{|c|c|c|c|c|c|c|c|}
\hline & & \multicolumn{2}{|c|}{ Easy Work } & \multicolumn{2}{c|}{ Moderate Work } & \multicolumn{2}{c|}{ Hard Work } \\
\hline $\begin{array}{c}\text { Heat } \\
\text { Category }\end{array}$ & $\begin{array}{c}\text { WBGT } \\
\text { Index } \\
\left({ }^{\circ} \mathrm{F}\right)\end{array}$ & $\begin{array}{c}\text { Work } \\
(\mathrm{min})\end{array}$ & $\begin{array}{c}\text { Water } \\
\text { Intake } \\
(\mathrm{qt} / \mathrm{hr})\end{array}$ & $\begin{array}{c}\text { Work } \\
(\mathrm{min})\end{array}$ & $\begin{array}{c}\text { Water } \\
\text { Intake } \\
(\mathrm{qt} / \mathrm{hr})\end{array}$ & $\begin{array}{c}\text { Work } \\
(\mathrm{min})\end{array}$ & $\begin{array}{c}\text { Water } \\
\text { Intake } \\
(\mathrm{qt} / \mathrm{hr})\end{array}$ \\
\hline 1 & $\begin{array}{c}78- \\
81.9\end{array}$ & $\mathrm{NL}^{1}$ & $1 / 2$ & $\mathrm{NL}$ & $\frac{3 / 4}{4}$ & 70 & 1 \\
\hline 2 (green) & $\begin{array}{c}82- \\
84.9\end{array}$ & $\mathrm{NL}$ & $1 / 2$ & 150 & 1 & 65 & $11 / 4$ \\
\hline $\begin{array}{c}3 \\
\text { (yellow) }\end{array}$ & $\begin{array}{c}85- \\
87.9\end{array}$ & $\mathrm{NL}$ & $3 / 4$ & 100 & 1 & 55 & $11 / 4$ \\
\hline 4 (red) & $\begin{array}{c}88- \\
89.9\end{array}$ & $\mathrm{NL}$ & $3 / 4$ & 80 & $11 / 4$ & 50 & $11 / 4$ \\
\hline 5 (black) & $>90$ & 180 & 1 & 70 & $11 \frac{1}{4}$ & 45 & $1 \frac{1}{2}$ \\
\hline
\end{tabular}

Notes:

1. NL can sustain work for at least 4 hours of work in the specified heat category.

2. Fluid needs can vary based on individual differences $( \pm 1 / 4 \mathrm{qt} / \mathrm{hr}$ ) and exposure to full sun or full shade $( \pm 1 / 4 \mathrm{qt} / \mathrm{hr})$. 
TB MED 507/AFPAM 48-152 (I)

h. Figure 3-4 plots the relationship between work-time tolerance and metabolic rate for soldiers during UCHS, wearing NBC protective clothing (MOPP, closed) in hot weather $\left(86^{\circ} \mathrm{F}, 50\right.$ percent relative humidity). This tolerance curve should be used for any suspected UCHS condition. Note that as the timeweighted metabolic rate is reduced the soldier's work-time tolerance is increased. Either lowering the work intensity or providing rest periods can reduce the metabolic rate. Table 3-1 gave examples of military tasks that have time-weighted metabolic rates of approximately $250 \mathrm{~W}, 425 \mathrm{~W}$, and $600 \mathrm{~W}$.

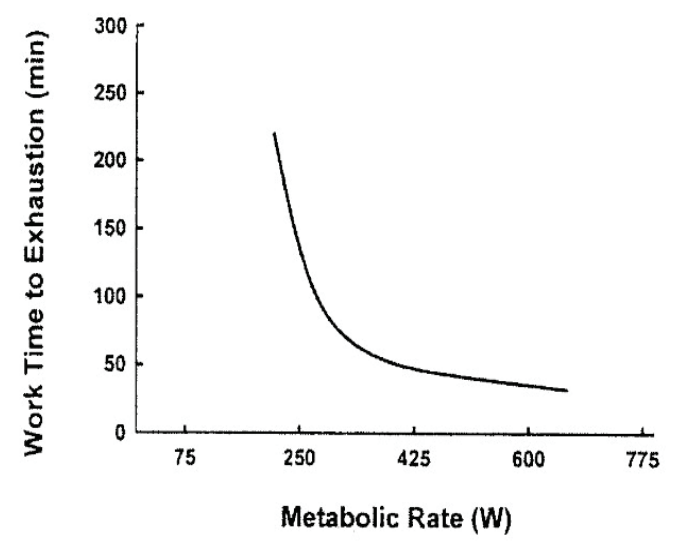

Figure 3-4. Influence of time-weighted metabolic rate (W) on work-time when wearing NBC protective clothing (closed) in hot weather in soldiers with UCHS

\section{3-5. Microclimate cooling}

a. Microclimate cooling systems are effective in alleviating heat stress and extending exercise capabilities in soldiers wearing protective clothing or exposed to UCHS conditions. Microclimate cooling has been successfully used in armored vehicles like the M1A1 tank; however, the technology has not matured sufficiently to support dismounted soldiers working at high metabolic rates.

b. Microclimate cooling systems use circulating cooled air or liquid in tubes over the skin or ice packet vests to remove body heat. In addition, microclimate cooling facilitates heat loss by maintaining the temperature gradient between the body core and the cooled skin. The amount of heat transferred from the body to any microclimate system is dependent on several factors: the amount and location of body area covered by the device, coolant temperature, flow rate, skin temperature, and insulation from the ambient heat.

c. Air-cooled garments are lighter to wear and rely on sweat evaporation to cool the person. While air is not as efficient as water due to the difference in specific heat, air-cooled systems are effective in reducing heat strain and in some environments are felt to be as effective as water-cooled devices. In addition, air-cooled vests provide drier skin conditions thereby improving the thermal comfort as opposed to that provided by liquid-cooled systems. In environments uncontaminated by biological and or chemical agents, ambient air can be employed to circulate under the protective clothing. However, less sweat will be evaporated to provide cooling if ambient humidity is high, and local skin irritation results if the ambient humidity is low and the air temperature is too hot.

d. Microclimate cooling systems that use ice as the cooling medium are not as effective as either liquid- or air-cooled systems, and the logistical problems rendered by ice-cooled systems make them impractical for use as cooling devices in many situations. Once the ice has completely melted, cooling is no longer provided and the torso receives a net heat gain from the hot climate resulting in skin 
TB MED 507/AFPAM 48-152 (I)

temperatures in excess of $35^{\circ} \mathrm{C}$. The cooling efficiency of an ice packet vest can be improved by increasing the number of ice packets attached to the vest (up to the limit of total torso surface area coverage).

\section{3-6. Fluid replacement}

a. Heat stress increases the sweating rate and therefore body water needs. If fluid is not fully replaced, then dehydration will occur. The myth that soldiers can be taught to adjust to decreased water intake has been proven wrong many times.

b. Thirst does not adequately motivate personnel to promptly consume sufficient fluids to replace sweat losses in hot environments. If thirst alone is used to guide fluid replacement, adequate hydration lags behind fluid needs for several hours. Most fluid is replaced at mealtime; the food (solute) helps retain the consumed water in the body, not lost as urine.

c. Soldiers can monitor hydration status by noting the color and volume of their urine and their body weight. Dark, low volume and infrequent urination indicates that fluid consumption should be increased. Likewise, frequent and large volumes of clear urine indicate that fluid replacement should be reduced. The relationship between urine color or specific gravity (an easily obtained measurement) with the magnitude of dehydration is not precise. Soldiers can monitor their body weight before and after exercise (or upon awakening), as most weight loss will be from water. One quart (32 ounces or $\sim 0.95$ liters) of fluid equals about two lbs (or $\sim 0.95$ kilograms) of weight. Note that unclothed weight should be used to avoid the confounding effects of soaked clothing.

d. Assure full hydration of all soldiers before any work period. Provide sufficient water to replace the volume of sweat loss during work. Establish drinking schedules and encourage and monitor drinking. Make water more palatable, if possible, by cooling $\left(50^{\circ}\right.$ to $\left.60^{\circ} \mathrm{F}\right)$ and lightly flavoring with citrus fruit flavors or extracts. Plan operations that include water supply points every three hours or less.

e. Provide adequate time for meals and make fluids readily available. Soldiers usually drink most of their water with meals, and eating food improves water consumption. During mealtime soldiers can drink a variety of fluids (milk, juice, ice tea, sports drink), as each will be equally effective in replacing body water. In addition, meals provide the salt intake necessary to retain body water. Other beverages or fluids served in dining facilities (except those containing alcohol), such as milk, are acceptable for fluid replacement; however, they should not be placed in canteens for use in the field for hygienic reasons.

f. Drinking is limited by how fast fluid is emptied from the stomach (average about $1.2 \mathrm{qt} / \mathrm{hr}$ ) and absorbed by the small intestine (this exceeds the gastric emptying rate). If the stomach is too full, then soldiers will feel bloated. Drinking enough to fill the stomach facilitates rapid gastric emptying. However, dehydration and intense exercise can reduce the gastric emptying rate. Since gastric emptying rates vary between soldiers, each person needs to determine his or her own drinking pattern, based upon comfort. During periods of very high sweat loss, most water replacement will occur during recovery periods. Drinking at high rates will facilitate gastric emptying but will often result in greater urine formation. If water economy is important (limited water supply in survival situation), then sipping water is recommended.

g. The sweating rate is related to activity level, clothing/equipment worn and environmental heat stress conditions. In hot weather, soldiers often have sweating rates of $\sim 0.3$ to $\sim 1.0 \mathrm{gt} / \mathrm{hr}$ while performing most military activities, $\sim 0.5$ to $\sim 1.2 \mathrm{qt} / \mathrm{hr}$ while performing vigorous training activities, and $\sim 1.0$ to $\sim 2.2 \mathrm{qt} / \mathrm{hr}$ while wearing NBC protective clothing while working. These higher sweating rates represent considerable heat strain, and activities eliciting these usually cannot be sustained for extended periods.

h. Tables 3-1 and 3-3 provide water replacement recommendations for work/rest schedules and continuous work situations during training, respectively. The tables specify an upper limit for hourly ( $1.5 \mathrm{qt}$ ) and daily (12 qt) water intake to provide a safeguard against overdrinking and development of water intoxication (hyponatremia) during training. Considerable individual variability exists for water requirements as the tables give values for the "average" soldier. Small soldiers, such as petite women, 


\section{TB MED 507/AFPAM 48-152 (I)}

may have lower sweating rates, while very large persons may have higher sweating rates; therefore, actual fluid replacement may need to be decreased or increased by $\sim 1 / 4 \mathrm{qt} / \mathrm{hr}$ for those soldiers. Likewise, exposure to full shade or full sun can decrease or increase fluid replacement needs by $\sim 1 / 4 \mathrm{qt} /$ hr.

i. The tables are sufficiently robust to be modified for specific scenarios and still maintain appropriate hydration. For example, if soldiers deviate from the recommended work times and extrapolate the appropriate hourly fluid intakes, the legend cautions the user not to drink in excess of $1.5 \mathrm{qt} / \mathrm{hr}$ and no more than $12 \mathrm{qt} /$ day. If soldiers increase their work time per hour but do not modify fluid intake, the original recommendation still prevents excessive dehydration during several hours of training.

j. Knowledge of daily water requirements for hot environments is important for planning purposes. Soldiers will consume from $\sim 3$ to 12 qt/day during military training in hot climates. Inactive soldiers in shaded areas might require $\sim 3$ to 5 qts, those performing moderate activity (most soldiers) might require $\sim 6$ to 8 qts, and very active soldiers (particularly in desert environments) might require $\sim 9$ to 12 qts/day. In training conditions physical activity levels are decreased at higher WBGT levels (therefore water needs are reduced); however, soldiers may not have the option of reducing physical activity during operational conditions.

k. During operational conditions, mission needs may demand sustained high intensity work greater than that encountered during training conditions. In extremely active soldiers (who are also very fit and highly heat acclimatized) water requirements can be $>12$ qt/day. World War II desert operations showed that a few very active soldiers could have daily water requirements of $>16$ qts.

I. Daily water requirements depend upon the environmental heat stress, activity level and duration of exposure. Figure 3-5 estimates daily water requirements at four energy expenditures (activity levels) relative to the daytime average (mean) WBGT levels for heat-acclimated soldiers. Daily mean WBGT is the average daytime temperature, with the assumption that all physical work is performed during this period. The filled area represents the influence of full sun (upper border) and full shade (lower border) on water requirements at each energy expenditure level. Tropical climates generally have less direct sun exposure than desert climates due to cloud cover and vegetation canopy. The lowest energy expenditure $(2,500$ kilocalories per day $(\mathrm{kcal} / \mathrm{d}))$ represents "sedentary" soldiers and is the minimal water requirement.

$\mathrm{m}$. Table 3-4 provides daily energy expenditures for various military activities. Note that the metabolic rate for military units performing field activities usually falls between $\sim 3,500$ and

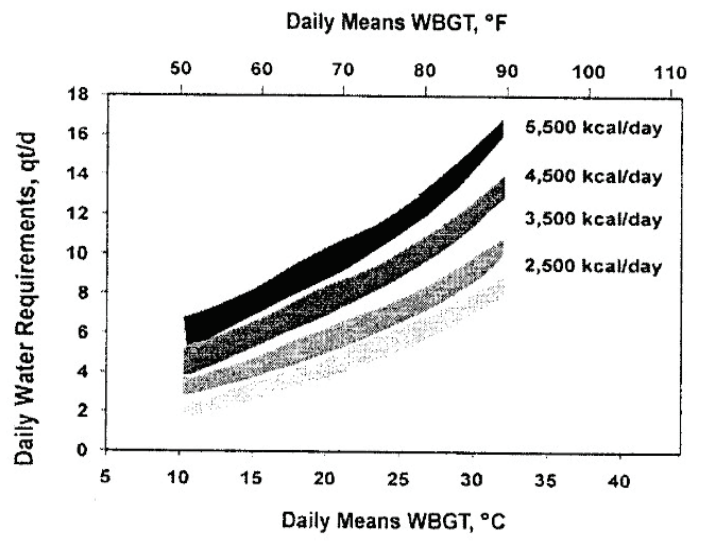

Figure 3-5. Daily water requirements during various daily climatic (day time average WBGT) and metabolic (kcal/d) conditions 
TB MED 507/AFPAM 48-152 (I)

Table 3-4. Daily energy expenditures (measured by double-labeled water) of military activities

\begin{tabular}{|c|c|c|}
\hline Group & Activity & $\mathrm{kcal} / \mathrm{d}$ \\
\hline Army Special Forces & Combat exercise, temperate & 3400 \\
\hline Army Engineers & $\begin{array}{c}\text { Build road and airstrip @ } \\
\text { altitude }\end{array}$ & 3549 \\
\hline $\begin{array}{c}\text { Army Transportation } \\
\text { Company }\end{array}$ & Garrison & 3568 \\
\hline Marine Combat Engineers & Construction & 3668 \\
\hline Israeli Infantry & Combat exercise, summer & 3937 \\
\hline Army & Support hospital & 3960 \\
\hline Army Ranger & Training course & 4010 \\
\hline Army Ranger & Training course & 4090 \\
\hline Marine & Artillery exercise, desert & 4115 \\
\hline Marine & Combat exercise, winter & 4198 \\
\hline Army & Artillery exercise, winter & 4253 \\
\hline Israeli Infantry & Combat exercise, winter & 4281 \\
\hline Army Special Forces & Combat exercise, winter & 4558 \\
\hline Marine & Crucible, women & 4679 \\
\hline Australian Infantry & Jungle training & 4750 \\
\hline Army Special Forces & Assessment school & 5183 \\
\hline Army Ranger & Combat exercise & 5185 \\
\hline Norwegian Ranger & Training course & 6250 \\
\hline Marine & Crucible, men & 6067 \\
\hline Average & & 4405 \\
\hline
\end{tabular}

$\sim 5,000 \mathrm{kcal} / \mathrm{d}$, with some groups exceeding 6,000 kcal/d. Therefore, when using Table 3-4 either the 3,500 or $4,500 \mathrm{kcal} / \mathrm{d}$ energy expenditures can be used to estimate water requirements for most active field units.

$\mathrm{n}$. If the average daytime WBGT were $80^{\circ} \mathrm{F}\left(\sim 27^{\circ} \mathrm{C}\right)$ the daily water requirements could range from $\sim 5(2,500 \mathrm{kcal})$ to $\sim 10(4,500 \mathrm{kcal})$ qt/day for most units. The daily water requirement could achieve $\sim 12 \mathrm{qt} /$ day for the highest energy expenditure $(5,500 \mathrm{kcal} / \mathrm{d})$, thus representing the upper limit for water requirement for very fit and very active units at this WBGT.

o. Extreme operational scenarios can demand daily energy expenditures $>6,000 \mathrm{kcal} / \mathrm{d}$ (Table 3-4) and can expose soldiers to sufficient climatic heat stress that the daily water requirement could achieve, $\sim 16$ qt/day. Such high fluid requirements, however, would only be for "very elite" soldiers with an exceptionally demanding mission in very hot desert-like weather.

p. Water shortages may occur during hot weather military operations, particularly in the desert. Water should be consumed and not wasted by pouring onto the skin. Saving water as long as possible has no physiologic advantage, and soldiers have suffered dehydration exhaustion and death with water still in their canteen. When water is in short supply, water economy can be achieved by working at night, reducing physical activity, and seeking shade. Desert operations demonstrated working at night reduced water requirements from $10 \mathrm{qt}$ to $7 \mathrm{qt} /$ day ( 30 percent savings). Northern African operations in World War II indicated that, if water loss was minimized (during average summer weather), a water ration of $1 \mathrm{qt} /$ day allowed minimal, but seriously impaired, combat efficiency for up to $\sim 4$ to 5 days with survival up to $\sim 10$ days.

q. If soldiers are unexpectedly isolated in the desert, they can walk to safety or wait for help. Table 3-5 provides walking distance obtainable by soldiers carrying limited water before incurring dehydration exhaustion. These estimates assume flat terrain and soldiers resting in shade during daylight 
TB MED 507/AFPAM 48-152 (I)

and walking at night until being dehydrated by 10 percent of body weight. If soldiers rest at all times and wait for help, they can increase their survival time (assuming death when dehydrated by 20 percent of body weight). Survival times (without water) in desert climates with average daily temperatures (dry bulb) of $80^{\circ}, 90^{\circ}, 100^{\circ}$, and $110^{\circ} \mathrm{F}$ are $\sim 7$ days, $\sim 4$ days, 3 days, and 2 days, respectively. For comparison, in a $60^{\circ} \mathrm{F}$ climate soldiers could survive $\sim 16$ days without water.

Table 3-5. Distances that soldiers can march in the desert (at night) with different amounts of water before being limited by dehydration exhaustion

\begin{tabular}{|c|c|c|c|c|}
\hline \multirow{2}{*}{$\begin{array}{l}\text { Daytime } \\
\text { Average } \\
\text { Temperature } \\
\left({ }^{\circ} \mathrm{F}\right)^{*}\end{array}$} & $0 \mathrm{qt}$ & $1 \mathrm{qt}$ & $4 \mathrm{qt}$ & $10 \mathrm{qt}$ \\
\hline 80 & 45 & 50 & 70 & 110 \\
\hline 90 & 20 & 25 & 35 & 50 \\
\hline 100 & 15 & 18 & 20 & 30 \\
\hline 110 & 9 & 10 & 15 & 20 \\
\hline
\end{tabular}

*Daytime average dry bulb temperature was about $15^{\circ} \mathrm{F}$ below maximal temperature.

\section{3-7. Electrolyte (salt) replacement}

a. In addition to water, sodium, chloride and other electrolytes (potassium, calcium, and magnesium) are lost in sweat. Sweat sodium concentration can range from 10 to 70 millimoles per liter (mmol/L) depending on diet, sweating rate, and heat acclimatization status. Heat acclimatization conserves sodium by decreasing sweat salt $(\mathrm{NaCl})$ content by $\sim 50$ percent (for example, sweat sodium decreases from 50 to $25 \mathrm{mmol} / \mathrm{L}$ for the average soldier).

b. Figure 3-6 provides the daily sodium requirements for heat-acclimated soldiers (assuming sweat sodium concentration of $25 \mathrm{mmol} / \mathrm{L}$ ) over a range of daily energy expenditures (activity levels) and daily mean WBGT index levels (2.5 grams $\mathrm{NaCl}$ contains 1 gram sodium). Daily sodium requirements range (for sedentary to very active persons) from $\sim 2$ to 4 grams ( 5 to 10 grams $\mathrm{NaCl}$ ) per day in cool climates and up to $\sim 5$ to 11 grams ( 12 to 28 grams $\mathrm{NaCl}$ ) per day in very hot climates. Most soldiers working and living in hot weather will have daily sodium requirements of 4 to 9 grams per day ( 10 to 23 grams $\mathrm{NaCl}$ ).

c. Daily sodium consumption for garrison dining ranges from 2.3 to 9.5 grams (6 to 24 grams $\mathrm{NaCl} ; 95$ percent confidence limits) and varies because of food preferences. Each meals ready to eat (MRE) contains an average of 3.6 grams of sodium (2.0 grams in food and 1.6 grams in salt packet). If three MRE are consumed, then soldiers will have a maximum of 10.8 grams of sodium ( 27 grams $\mathrm{NaCl})$, but only 6.0 grams of sodium ( 15 grams $\mathrm{NaCl}$ ) if the salt packets are not eaten. Therefore, soldiers should consume their entire MRE ration and salt packets during periods of strenuous physical work in the heat.

d. If soldiers are heat acclimatized and fully consume their meals (MRE, including salt packets), sodium intake will be adequate except for the most extreme hot weather conditions. Increases or decreases in body sodium stores are usually corrected intuitively by adjustments in appetite. Physical activity increases hunger, and the associated increased food consumption usually covers the additional sodium required. If soldiers perceive they need additional sodium, such as the first several days of hot weather, this can be achieved by salting food to taste. Salt tablets are not recommended as their misuse has resulted in gastrointestinal discomfort and incapacitating nausea. 
TB MED 507/AFPAM 48-152 (I)

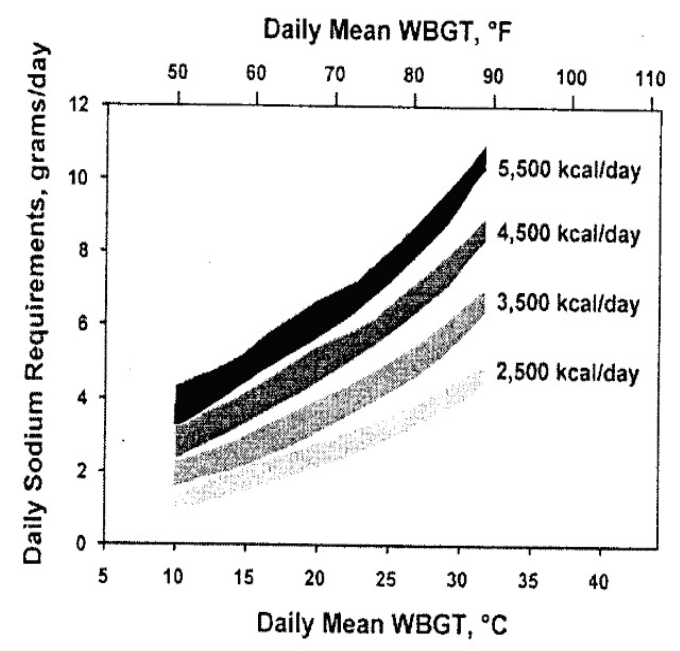

Figure 3-6. Daily sodium requirements during various daily climatic (WBGT) and metabolic ( $k c a l / d)$ conditions

e. If meals are not consumed, salt supplementation should be employed during prolonged ( $>4$ hours) periods of profuse sweating in hot weather. A method to replace salt losses, in approximate proportion to sweat losses, is to salt drinking water at a concentration of 0.1 percent $(17 \mathrm{mmol} / \mathrm{L}$ sodium $)$. Salt can accentuate the taste of chlorine, so the salt concentration may need to be diluted (to taste) in treated water. Mixing the following will produce salted drinking water: (See Appendix D.)

(1) One $\mathrm{lb}$ ( 0.45 kilograms) table salt to 100 gallons of water.

(2) One-fourth teaspoon table salt to each quart of water.

f. Sports drinks are an effective source for electrolyte replacement during prolonged ( $>4$ hours) periods of profuse sweating in hot weather. Sports drinks should meet the following criteria: sodium $\sim 15$ to $\sim 30 \mathrm{mmol} / \mathrm{L}$, potassium $\sim 2$ to $\sim 5 \mathrm{mmol} / \mathrm{L}$, and carbohydrate $\sim 5$ to $\sim 10$ percent. The type of carbohydrate (for example, glucose, sucrose, or polymers) does not matter (although high fructose should be avoided as it may cause gastrointestinal side effects). The carbohydrate in sports drinks makes them an appropriate rehydration beverage for other situations, such as-

(1) Before initiating strenuous exercise if meals are not consumed for $>4$ hours.

(2) During prolonged ( $>6$ hours) exercise if meals are not consumed.

(3) For therapy for heat-related disorders.

g. The primary concerns with sports drinks are their caloric density. If soldiers drink 5 qt ( $\sim 4$ calories per gram carbohydrate and 8 percent solution) of sports drinks that would constitute about $1,600 \mathrm{kcal}$. Therefore, sports drinks should be used during conditions described above and not to totally replace water consumption.

h. Canteens containing carbohydrate (sugar) solutions increase the growth of harmful bacteria, increasing the incidence of gastrointestinal upset. If sugar-containing beverages are carried in the canteen, then additional sanitation efforts are needed. Canteens containing carbohydrate solutions should be rinsed with water daily and treated with hypochlorite solution every two or three days. The frequency of these sanitation actions depends on the quality of water, liquid temperature, and composition of the beverage. Flavoring reduces the effectiveness of chlorine to fight microbial growth, so these beverages should be added to already purified water and consumed within several hours.

i. Commercially flavored electrolyte powders with no calories are available (for example, Oral Rehydration Salts and Gator LYTES ${ }^{\circledast}$ ), and electrolyte/carbohydrate powdered (for example, Powerade ${ }^{\circledast}$ 


\section{TB MED 507/AFPAM 48-152 (l)}

and Gatorade ${ }^{\circledast}$ ) products are available. These products can be dissolved and diluted to taste in canteens (containing purified water). Gator LYTES $^{\mathbb{}}$ and Gatorade ${ }^{\circledR}$ are registered trademarks of PepsiCo, Inc., 700 Anderson Hill Road, Purchase, NY 10577. Powerade ${ }^{\circledast}$ is a registered trademark of The Coca-Cola Company, P.O. Box 1734, Atlanta, GA 30301.

\section{3-8. Special military situations}

a. U.S. Navy heat stress problems aboard ship often involve high heat and humidity (greater than $90^{\circ} \mathrm{F}$ dry bulb temperature or $81^{\circ} \mathrm{F}$ wet bulb temperature) conditions. Physiological Heat Exposure Limit (PHEL) guidelines have been developed for these situations and published in Navy Medical Department Publication (NAVMED P)-5010-3. The PHELs are the maximum allowable conditions of work and WBGT index levels. The PHEL guidelines are to be used for short-term work exposure of up to eight hours. The limits presume that no prior heat injury is present and that no cumulative fatigue exists prior to exposure.

b. Aviation heat stress problems involve maintenance crews and flight crews who are exposed to heat stress. Flight crews encounter heat stress during preflight, engine start, taxiing out, and standing by for takeoff. Total ground time can be considerable even in fighter aircraft. Additionally, the heat load experienced in the cockpit is more severe than on the ramp because of the reduced air velocity, personal equipment worn and increased radiant heat load. The WBGT index in the cockpit may be as much as $20^{\circ} \mathrm{F}\left(11^{\circ} \mathrm{C}\right)$ higher.

c. Flight crews of high-performance aircraft require effective protection from heat and dehydration in order to maintain both physiological resistance to inflight stress and ability to operate a complex weapons system under dynamic conditions. Specifically, aerial combat entails sequences of aerobatic maneuvers with levels of acceleration (G-stress), which challenge human tolerance limits; both heat stress and dehydration will lower the threshold at which the crew may lose consciousness. Although fighter crews experience only limited physical workloads in the cockpit, flight clothing imposes a significant thermal burden for hot weather operations. The multilayered, protective clothing includes cotton underwear, fireretardant coveralls, antigravity suits, parachute harness, boots, gloves, and helmet. A chemical defense layer may be added as underwear or incorporated into the coverall. The process of dressing in this ensemble, walking to the aircraft, and conducting preflight inspection on a hot ramp significantly raises core temperature. Thus, it is an already warm crew that enters the cockpit of a heat-soaked aircraft and goes through the sequences required for engine start.

d. Modern fighter aircraft often has cockpit cooling during ground operations (standby and taxi); however, the thick clothing and impermeable layers of the antigravity suit mean that the occupants receive only limited benefit. Typically, heat removal occurs so slowly that the aircraft is in combat or returning to base before cooling is complete. In wartime, crews are expected to fly two, three, or more missions in quick succession with little chance to achieve full recovery in terms of body temperature and hydration.

e. The Fighter Index Thermal Stress (FITS) provides a measure of heat stress expected by aircrew in jet aircraft with canopies (see Air Force Pamphlet 48-151) and is calculated as follows:

$$
{ }^{\circ} \mathrm{F}=0.83 \mathrm{~T}_{\mathrm{wb}}+0.35 \mathrm{~T}_{\mathrm{db}}+\mathbf{5 . 0 8}
$$

The following FITS procedures are designed to minimize heat stress impact assuming (as described in Table 3-6):

(1) FITS caution zone (dry bulb temperature from $100^{\circ} \mathrm{F}$ to $110^{\circ} \mathrm{F}$ ).

(a) Encourage crews to drink water before cockpit entry, during standby, and in flight.

(b) Be alert to symptoms of heat stress.

(c) Avoid exercise 4 hours before take-off.

(d) Precool cockpits by means of air-conditioning the ground carts.

(e) Assign alternate crewmembers to perform preflight aircraft inspection. 
TB MED 507/AFPAM 48-152 (I)

(f) Keep the sun out of transparencies by using rolling roofs or fabric covers.

(g) Transport crewmembers directly to the aircraft.

(h) Limit the permitted duration of in-cockpit standby.

(2) FITS danger zone (dry bulb temperature $115^{\circ} \mathrm{F}$ to $120^{\circ} \mathrm{F}$ ), plus caution zone recommendations.

(a) Keep the sun out of transparencies by using rolling roofs or fabric covers.

(b) Allow only one change of aircraft before requiring return to ready room in cases of mechanical delay.

(c) Optimize conditions for cooling and rehydration between flights.

(d) Support self-assessment and empower crews to stand down when they judge that further flights would be unsafe.

Table 3-6. FITS reference values

\begin{tabular}{|c|c|c|c|c|c|c|c|c|c|c|}
\hline $\begin{array}{c}\text { Dry Bulb } \\
\text { Temperature }\end{array}$ & Zone & \multicolumn{8}{|c|}{ Dew Point Temperature } \\
\hline$(\mathrm{F})$ & & 30 & 40 & 50 & 60 & 70 & 80 & 90 & 100 & $>110$ \\
\hline 70 & & 70 & 73 & 76 & 81 & 86 & $\mathrm{X}$ & $\mathrm{X}$ & $\mathrm{X}$ & $\mathrm{X}$ \\
\hline 75 & & 74 & 77 & 80 & 84 & 89 & $\mathrm{X}$ & $\mathrm{X}$ & $\mathrm{X}$ & $\mathrm{X}$ \\
\hline 80 & NORMAL & 77 & 80 & 83 & 87 & 92 & 98 & $\mathrm{X}$ & $\mathrm{X}$ & $\mathrm{X}$ \\
\hline 85 & & 81 & 83 & 86 & 90 & 95 & 101 & $\mathrm{X}$ & $\mathrm{X}$ & $\mathrm{X}$ \\
\hline 90 & & 84 & 87 & 90 & 93 & 98 & 104 & 110 & $\mathrm{X}$ & $\mathrm{X}$ \\
\hline 95 & & 88 & 90 & 93 & 96 & 101 & 108 & 112 & $\mathrm{X}$ & $\mathrm{X}$ \\
\hline 100 & & 91 & 93 & 96 & 99 & 104 & 109 & 115 & 122 & $\mathrm{X}$ \\
\hline 105 & CAUTION & 94 & 96 & 99 & 102 & 107 & 112 & 118 & 124 & $\mathrm{X}$ \\
\hline 110 & & 97 & 99 & 102 & 105 & 109 & 114 & 120 & 126 & 133 \\
\hline 115 & & 100 & 102 & 105 & 109 & 112 & 117 & 123 & 129 & 136 \\
\hline 120 & DANGER & 104 & 105 & 108 & 111 & 115 & 120 & 125 & 131 & 138 \\
\hline
\end{tabular}


TB MED 507/AFPAM 48-152 (I)

\section{CHAPTER 4}

\section{HEAT ILLNESS AND INJURY}

\section{4-1. Injury spectrum}

a. Minor heat illnesses include heat cramps and heat exhaustion. Major heat injuries include EHI, exertional rhabdomyolysis, and heat stroke. The diagnostic categories of heat exhaustion, EHI, and heat stroke have overlapping features and should be thought of as different regions on a continuum rather than discrete disorders, each with its own distinct pathogenesis.

b. Figure 4-1 depicts the spectrum of heat casualties in terms of severity and categories of physiological dysfunction (hyperthermia, dehydration, nephropathy, cell lysis, encephalopathy). Whatever category is diagnosed, all are related to elevation of body core temperature and the metabolic and circulatory processes (including changes in fluid and electrolyte balance) that are brought about by heat strain from exercise, environment and the body's thermoregulatory response.

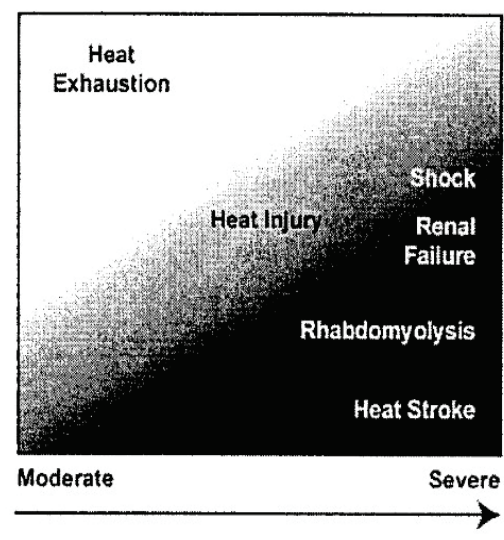

Hyperthermia

Dehydration

Nephropathy

Cell Lysis

Encephalopathy

Figure 4-1. Spectrum of heat casualties, encompassing the continuum of mild (heat exhaustion) to severe (heat stroke) with associated categories of physiologic dysfunction.

\section{4-2. Risk factors}

a. The incidence and severity of heat casualties has decreased dramatically in military recruits over the past several decades (see Figure 4-2). Army hospitalizations from heat casualties averaged $\sim 60$ per 100,000 soldier-years during the mid-1980's and averaged $~ 35$ per 100,000 soldier-years during the late1990 's. Heat casualties are more frequently seen during intense advanced training (for example, Ranger, $\mathrm{EIB}$, and EFMB) and operational settings.

b. During combat operations under hostile conditions, the mission requirements, supply problems, and physical condition of the troops may seriously impede a leader's ability to manage heat stress. If not adequately planned for, the treatment of heat casualties may be delayed compared with what is possible during training. In such settings, medical officers are likely to see greater numbers and more severe types of heat casualties, with a higher frequency of complications as compared to what occurs during wellsupervised training in peacetime. 
TB MED 507/AFPAM 48-152(I)

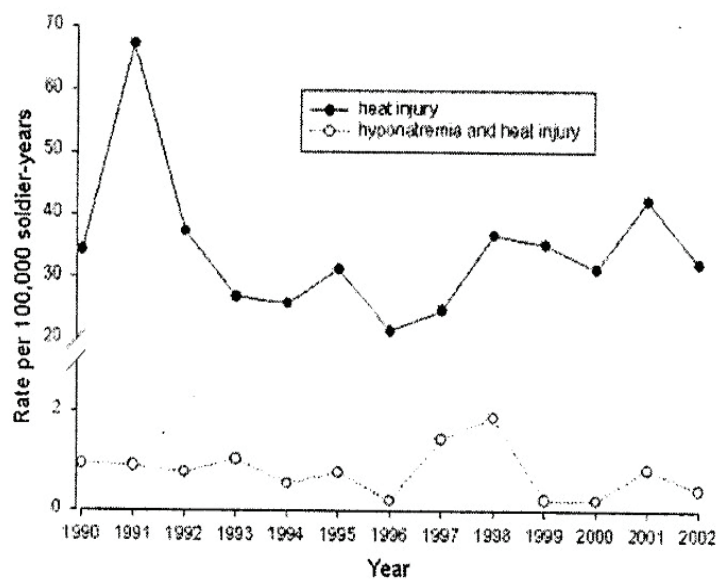

Figure 4-2. Army hospitalizations for heat illnesses and hyposmolality/hyponatremia from 1990 through 2002

(Source: Defense Medical Surveillance System, March 2003)

c. Factors that adversely influence thermoregulation can increase the risk of being a heat casualty. These include-

(1) Dehydration.

(2) Salt depletion.

(3) Lack of heat acclimatization.

(4) Poor physical fitness.

(5) Excessive body weight.

(6) Skin disorders.

(7) Medications (prescription and over-the-counter).

(8) Alcohol use.

(9) Inflammation and fever.

(10) Gastroenteritis. failure).

(11) Chronic disease (for example, diabetes mellitus, cardiovascular disease, and congestive heart

(12) Genetics (for example, mutations for cystic fibrosis and malignant hyperthermia).

d. Considerable information exists relating many risk factors to heat casualties. Military and civilian medical literature provides many examples of dehydration resulting in heat casualties and even stroke. World War II experiences indicated that a month of heat acclimatization decreased the incidence of heat stroke deaths. This suggests that heat acclimatization's (and acquired thermal tolerance) full protective effect against heat stroke might be relatively slow compared to other benefits. Recruits with poor physical fitness ( 1.5 mile run time of 12 minutes or more) and high body mass have an increased risk of heat illness. Recruits with both low aerobic fitness ( $>12$ minute 1.5 mile physical fitness run) and high body mass index ( $>26$ kilograms per meter squared surface area) have $\sim 9$-fold greater risk of heat illness. Sleep deprivation reduces work capabilities and may modestly impair thermoregulation, but its believed association to heat casualties has not been scientifically substantiated.

e. Heat stroke often occurs under conditions the victim had been exposed to many times before, or while others are concurrently being exposed to the same condition without incident. This suggests that these victims were inherently more vulnerable that day and or some unique event triggered the heat injury. 
TB MED 507/AFPAM 48-152 (I)

Evidence suggests some cases might be explained by an association between susceptibility for malignant hyperthermia and exertional heat stroke. Many $(\sim 17$ percent) heat stroke victims are sick on the prior day. Heat stroke cases often occur during the initial hours of exercise-heat stress and do not usually occur during the hottest part of the day. These facts suggest that, on that day, the victims began the exerciseheat stress compromised. Fever and inflammatory responses from muscle injury adversely influence thermoregulation and may help mediate heat illness. Gastrointestinal problems will induce dehydration and increase risk of being a heat casualty.

f. Miliaria rubra (heat rash or prickly heat) impairs sweating by blocking sweat ducts. Rashes of 20 percent of body surface area will markedly elevate core temperature and reduce physical work capabilities for up to 3 weeks after the rash has resolved. Therefore, skin hygiene is important during hot

Table 4-1. Drugs implicated in intolerance to heat stress

\begin{tabular}{|c|c|}
\hline $\begin{array}{r}\text { Drug or drug class } \\
\end{array}$ & Proposed mechanism of action \\
\hline Anticholinergics properties (Atropine) & Impaired sweating \\
\hline Antihistamines & Impaired sweating \\
\hline Gluthemide (Doriden ${ }^{2}$ ) & Impaired sweating \\
\hline $\begin{array}{l}\text { Phenothiazines (a class of antipsychotic drugs, } \\
\text { including thorazine }{ }^{\otimes} \text {, stelazine }{ }^{\otimes} \text {, and trilafon }{ }^{\otimes} \text { ) }\end{array}$ & $\begin{array}{l}\text { Impaired sweating, (possibly) disturbed } \\
\text { hypothalamic temperature regulation }\end{array}$ \\
\hline $\begin{array}{l}\text { Tricyclic antidepressants, for example imipramine, } \\
\text { anitriptyline }\end{array}$ & $\begin{array}{l}\text { Impaired sweating, increased motor activity and } \\
\text { heat production }\end{array}$ \\
\hline Amphetamines, cocaine, "Ecstasy" & $\begin{array}{l}\text { Increased psychomotor activity, activated vascular } \\
\text { endothelium }\end{array}$ \\
\hline $\begin{array}{l}\text { Ergogenic stimulants, for example } \\
\text { ephedrine/ephedra }\end{array}$ & Increased heat production \\
\hline Lithium & Nephrogenic diabetes insipidus and water loss \\
\hline Diuretics & Salt depletion and dehydration \\
\hline Beta-blockers, for example propranolol and atenolol & $\begin{array}{l}\text { Reduced skin blood flow and reduced blood } \\
\text { pressure }\end{array}$ \\
\hline Ethanol & Diuresis, possible effects on intestinal permeability \\
\hline
\end{tabular}

weather deployments. Mild sunburn impairs sweating so soldiers should minimize skin exposure to ultraviolet radiation.

g. Table 4-1 lists drugs associated with impaired thermoregulation, reduced work capabilities and or being a heat casualty. Special mention of some of these drugs is merited because of their military relevance, widespread use, and ease of access.

(1) Anticholinergic drugs, such as atropine (used as an antidote against chemical warfare agents and found in Mark I injector) and scopolamine will suppress sweating.

(2) Pyridostigmine, used as a pre-treatment against nerve agent, is an anticholinesterase drug that increases sweating.

(3) Drugs such as glutethimide (a sleep medicine), tricyclic antidepressants, phenothiazines (tranquilizers and antipsychotic drugs), bromocriptine, and antihistamines (commonly found in allergy, cold and sleep medication) have anticholinergic actions and are associated with heat stroke. Other drugs like cocaine and amphetamines (including "Ecstasy") will increase the risk of heat stroke.

(4) Diuretics cause loss of fluid and electrolytes and have a similar effect as dehydration. Lithium can produce a reversible nephrogenic diabetes insipidus and consequent loss of water.

(5) Many commercial ergogenic aid/weight loss products contain Ephedrine (often under the name "Ma Hwang"), which has been implicated in several heat stroke cases. Ergogenic aids are a particularly insidious risk factor, since many people who take them do not know what they contain and often do not consider them a drug. 


\section{TB MED 507/AFPAM 48-152 (I)}

(6) Drugs prescribed for treating hypertension include diuretics, angiotensin-converting enzyme inhibitors, and beta-adrenergic receptor antagonists, all of which may interfere with the physiological adaptations to exercise-heat stress by (respectively) promoting loss of salt and water, interfering with the retention of salt and water during acclimatization to heat, or impairing cardiovascular homeostatic reflexes. Beta-blockers also blunt skin blood flow responses, but may increase sweat responses to persons performing exercise in the heat. Future deployments to hot regions are likely to include large numbers of personnel being treated with these common antihypertensive agents. The effects of these drugs on heat tolerance of patients taking them for long-term management of hypertension are not well understood.

h. Doriden ${ }^{\otimes}$ is a registered trademark of U.S. Pharmacopeial Convention, Inc., 12601 Twinbrook Parkway, Rockville, MD 20852. Thorazine $e^{\circledast}$ and stelazine $e^{\circledast}$ are registered trademarks of GlaxoSmithKline, 5 Moore Drive, P.O. Box 13398, Research Triangle Park, NC 27709. Trilafon ${ }^{\circledR}$ is a registered trademark of Geneva Pharmaceuticals, Inc., 2655 W. Midway Blvd., P.O. Box 446, Broomfield, CO 80038-0446.

\section{4-3. Minor heat illnesses and heat-related conditions}

Minor heat-related illnesses and conditions include heat edema, miliaria rubra, sunburn, heat tetany, parade syncope (heat syncope) and heat cramps.

a. Heat edema presents swelling and discomfort of the hands and or feet. Victims of heat edema may complain that their shoes feel tight or are ill fitting. The exact physiologic mechanism is unknown but probably includes venodilation and extravascular fluid shifts. The symptoms usually resolve within a few days, as the person becomes heat acclimatized. Treatment for this self-limiting condition is reassurance and leg evaluation.

b. Miliaria rubra (prickly heat or heat rash) occurs when sweat gland pores become blocked by macerated stratum corneum and may develop into secondary staphylococcal infection. Eccrine secretions accumulate in the occluded ducts and infiltrate into the surrounding dermis. These obstructed ducts may rupture, with subsequent development of vesicles. Miliarial skin cannot fully participate in thermoregulatory sweating; therefore, the risk of heat illness is increased in proportion to the amount of skin surface involved.

(1) The patient will present with the complaint of a puritic rash initially. The second or profunda stage occurs when the ducts become plugged with keratin. Their eventual rupture causes formation of vesicles in the deeper layers of the skin.

(2) Miliaria rubra is treated through the cooling and drying of affected skin, avoiding conditions that induce sweating, controlling infection, and relieving pruritis. Treatment is handled with chlorhexidine lotion or cream with or without salicylic acid or with low dose topical corticosteroids (possibly with 0.25 percent menthol added). For diffuse pustular rash, systemic antibiotics may be prescribed. Proper prevention includes proper skin hygiene; wearing clean, loose-fitting clothes; and avoiding talc and creams.

c. Sunburn impairs sweating over the affected skin and predisposes soldiers to heat injury from systemic effects, including fever, that influence central thermoregulation. Sunburn should be prevented by making sun-blocking lotions available to soldiers, insisting that they use them, and ensuring soldiers are protected from sun overexposure with protective clothing and adequate shelter or shade. When sunburn does occur over 5 percent of the body's surface area, affected individuals should be kept from significant heat strain until the burn has healed.

d. Heat tetany is the result of hyperventilation by an individual after being exposed to heat stress. It generally occurs before heat acclimatization. Symptoms include muscle spasm (local and generalized) and perioral numbness and tingling. Victims are alkalotic, and blood work may show hypocabia and high $\mathrm{pO}_{2}$. Treatment is handled by temporarily removing from heat stress.

e. Parade syncope is a temporary circulatory failure due to pooling of blood in the peripheral veins especially those of the lower extremity - and a consequent decrease in diastolic filling of the heart. Symptoms range from lightheadedness to loss of consciousness. Parade syncope often, but not always, 
TB MED 507/AFPAM 48-152 (I)

occurs during prolonged standing and is often associated with hot weather environments. In addition, it may occur if standing still after completing a vigorous activity. Core temperature may not be elevated unless the attack follows exercise and the skin may be wet and cool. Victims of parade syncope will recover rapidly once they sit or lay supine, though complete recovery of stable blood pressure and heart rate may take an hour or two. A complete history has to be obtained to rule out other causes of syncope, including more severe heat illness or medical diagnosis unrelated to heat. Parade syncope occurring after more than 5 days of heat exposure may indicate dehydration or heat exhaustion. Syncope occurring during or after work in the heat may indicate heat exhaustion or EHI.

f. Heat cramps are brief, recurrent, and often are agonizing skeletal muscle cramps of the limbs and trunk. The cramp in an individual muscle is usually preceded by palpable or visible fasciculations and lasts $\sim 2$ to 3 minutes. Cramps tend to be re-recurrent and may be precipitated by vigorous use of affected muscles. The cramp produces a hard lump in the muscle. Heat cramps often occur in salt-depleted persons during a period of recovery (up to many hours) after a period of intense work in the heat. Smooth, cardiac, and diaphragm muscles are not involved. There are no systemic manifestations.

(1) The etiology of heat cramps is not known. It is postulated that intracellular calcium $\left(\mathrm{Ca}^{++}\right)$is increased via a reduction in the sodium concentration gradient across the cell membrane favoring $\mathrm{Ca}^{++}$ accumulation and impaired sodium and $\mathrm{Ca}^{++}$transport due to muscle injury during exercise and or subsequent cooling. The resultant increased intracellular $\mathrm{Ca}^{++}$accumulation then stimulates actin-myosin interactions causing the muscle contractions.

(2) Patients with heat cramps usually have substantial sodium deficits. Replenishment of salt often resolves heat cramps rapidly. Although some physicians recommend oral administration of 0.05 to 0.1 percent salt solutions to treat heat cramps, medical evidence does not indicate that treatment is more effective than the simple passage of time. Salt tablets should not be used as an oral salt source. The immediate goal of treatment is relief of the cramps, not replacement of salt losses, which takes longer and is best accomplished by ingestion of salted foods or fluids over many hours.

(3) No significant complications have been reported from heat cramps except muscle soreness and perhaps local muscle injury. An episode of heat cramps does not imply any predisposition to heat injury. No profile is needed except to assure an adequate period of recovery. Heat cramps are usually seen in unacclimatized persons and an attempt should be made to determine the reason for the episode so that appropriate advice can be given to the soldier and chain-of-command to avoid future episodes. Salt supplementation will reduce the incidence of heat cramps in populations at risk.

\section{4-4. Heat exhaustion}

a. Heat exhaustion is the most common form of heat casualty and is not associated with evidence of organ damage. It occurs when the body cannot sustain the level of cardiac output necessary to meet the combined demands of skin blood flow for thermoregulation and blood flow for the metabolic requirements of exercising skeletal muscle and vital organs. Contributing factors include dehydration-mediated hypovolemia, peripheral blood pooling in dilated and compliant skin, and possibly failure of splanchnic vasoconstriction which together limits venous return.

b. The signs and symptoms of heat exhaustion include generalized weakness, fatigue, ataxia, dizziness, headache, nausea, vomiting, malaise, hypotension, tachycardia, muscle cramps, hyperventilation and transient alteration in mental status. Sweating persists and may even be profuse. The diagnosis of heat exhaustion versus more severe heat illness (that is, EHI or heat stroke) is important due to the difference in treatment and prognosis. Treatment should begin immediately to prevent progression to a severe heat injury.

c. Heat stroke should be the working diagnosis in anyone who has a heat casualty and has alteration in mental status. Individuals who have mild symptoms but don't improve or worsen with initial management or those who have severe symptoms, need to be evacuated to the nearest medical facility for additional assessment to include laboratory evaluation. The diagnosis of heat exhaustion in those with severe 
TB MED 507/AFPAM 48-152 (I)

symptoms is primarily a diagnosis of exclusion. Measuring the hepatic transaminases, aspartate transaminase, (AST/SGOT) and alanine transaminase (ALT/SGPT) can help make a definitive diagnosis of a more severe heat injury victim; such victims tend to have values 100 or more times the upper limit of normal.

d. Management is directed to correcting the two pathogenic components of the illness: excessive cardiovascular demand and water-electrolyte depletion. The load on the heart is reduced by rest and cooling. Heavy clothing should be removed from patients and they should be allowed to rest in a shaded and ventilated space, while active cooling is initiated (see para 5-2). Water-electrolyte depletion is corrected by administering oral or parenteral fluids. Heat exhaustion victims should improve rapidly with shaded rest, cooling, and rehydration; those who don't improve or get worse need to be forwarded to the next higher level of medical care.

e. Heat exhaustion casualties retain the ability to cool spontaneously if removed from heat stressors. However active cooling to a core temperature of $101^{\circ} \mathrm{F}\left(38.3^{\circ} \mathrm{C}\right)$ is strongly recommended, for two reasons. First, the resulting skin vasoconstriction rapidly reduces circulatory demand and improves venous return. Second, if casualties with the more severe condition of EHI are not cooled actively, their core temperatures may continue to rise or may fall too slowly. Since heat exhaustion and more severe heat injuries may be hard to distinguish initially, medical personnel who elect to delay active cooling to see whether a casualty can spontaneously cool will sometimes fail to provide immediate active cooling when it is required. In addition, those with heat exhaustion may progress to a more severe heat injury if not promptly cooled.

f. Rectal temperature should be monitored frequently (at least every $15 \mathrm{~min}$ ) to ensure that core temperature is falling to normothermic levels. Although it is convenient to measure temperature in the mouth or the ear canal, medical personnel should not use these temperatures in the evaluation or management of heat casualties. Hyperventilation may cause oral temperature to be $\sim 3^{\circ} \mathrm{C}\left(5^{\circ} \mathrm{F}\right)$ lower than rectal temperature in heat stroke, and the temperature of the external auditory canal or tympanic membrane has been observed to be as much as $\sim 5^{\circ} \mathrm{C}\left(\sim 9^{\circ} \mathrm{F}\right)$ below rectal temperature in collapsed hyperthermic runners.

Table 4-2. Questions for assessment of mental status

\begin{tabular}{|c|}
\hline $\begin{array}{l}\text { A. Orientation: (Normal, oriented to person, place, and time) } \\
\text { 1. Your name? Who are you? What are you doing here? } \\
\text { 2. What is the year, season, month, date, day of the week? } \\
\text { 3. Where are we? Country? State? City/base? This building? }\end{array}$ \\
\hline B. Your last address and phone number before coming to this site? \\
\hline $\begin{array}{l}\text { C. Amnesia: Describe events from the start of activity to arrival here (especially just before and after any } \\
\text { fainting episode). Include exertional activities and name three persons with you at the time of onset and } \\
\text { describe one person traveling here with you. }\end{array}$ \\
\hline $\begin{array}{l}\text { D. Optional tests: } \\
\text { 1. Calculate serial } 7 \text { 's (subtract } 7 \text { from } 100,93,86,79,72,65 \text {, etc.). } \\
\text { 2. Recall three objects after five minutes. } \\
\text { 3. Recall own social security number. }\end{array}$ \\
\hline
\end{tabular}

g. Any loss of consciousness and any mental status changes need to be documented. Such patients need to be evaluated as potential EHI or heat stroke as in paragraphs 4-5 and 4-6. Mental status can be determined with questions (see Table 4-2) regarding the soldier's name, location, date and personal identifiers (for example, social security number, address, phone number). Amnesia can be determined by having the soldier describe events prior to sickness or fainting. 
TB MED 507/AFPAM 48-152 (I)

h. The patient should be reassessed frequently including repeated core temperatures and mental status checks. Intravenous lines may be placed if the patient is unable to take adequate oral fluid replacements or if medical evacuation to a higher level of care is indicated (as needed). Patients that aren't responding to initial treatment will require laboratory tests to rule out a more severe heat illness. These tests should include complete blood count (hemoglobin, hematocrit, white blood count, and platelet count), chemistry panel (sodium, chloride, potassium, bicarbonate, glucose, blood urea nitrogen, creatinine, and osmolality), hepatic transaminases (AST/SLT), creatine, phophokinase, lactate dehydrogenase (LDH), uric acid, and myoglobin. Urine should be collected for urine analyses and urine myoglobin. More severe cases would include evaluation of calcium, magnesium, phosphorous, protein, albumin, and lactic acid. Cases that are unexpected for the degree of heat stress exposure or seem to respond poorly to appropriate treatment should have blood and urine analysis for cocaine or other substances of abuse or medications. Continuous monitoring of blood pressure, urine output and mental status is needed. Cooling procedures should be stopped once the individual's core temperature has reached $101^{\circ} \mathrm{F}$

$\left(38.3^{\circ} \mathrm{C}\right)$ to prevent over-shoot hypothermia.

i. Heat exhaustion victims experience rapid clinical recovery. Young healthy individuals who have mild symptoms may be treated in the field. Those who fully recover within one hour and up to two liters of rehydration may return to light duty on a profile for the remainder of the day and full duty the next day. However, they must avoid re-exposure to heat stress for at least 24 hours. These patients do not require further medical evaluation or reporting. Patients who do not fully recover within one hour or require more than two liters of rehydration should be evaluated in an emergency department, usually to include laboratory tests, reporting, follow-up, and profiling.

j. A single episode of heat exhaustion does not imply any predisposition to heat injury; however, victims of more serious heat injuries can subsequently have decreased heat tolerance. Repeated heat exhaustion episodes require a thorough medical evaluation.

\section{4-5. Exertional heat injury and exertional rhabdomyolysis}

a. Exertional heat injury represents a continuum intermediate in severity between heat exhaustion and heat stroke. There is no consensus on diagnostic criteria for distinguishing EHI from heat exhaustion or heat stroke; therefore, close monitoring of vital signs and serum chemistries is essential since during the first few hours, clinical symptoms may not reflect profound underlying metabolic abnormalities.

b. EHI patients show evidence of organ (for example, liver or renal) or tissue (for example, muscle) injury or dysfunction but do not display sufficient neurological abnormalities to meet the usual criteria of heat stroke. Other manifestations may include neurological symptoms, high core temperature and metabolic acidosis. Patients demonstrating combativeness, delirium, obtundation, or coma most likely have heat stroke rather than $\mathrm{EHI}$.

c. Organ dysfunction or tissue damage may not be manifest in early EHI, so during the first hours of illness it may not be possible to distinguish EHI from heat exhaustion by symptom complex alone. Therefore, all suspected EHI patients should be thoroughly evaluated for organ damage/dysfunction before release, with re-evaluation necessary on the following day.

(1) Levels of the enzymes creatine kinase (CK), AST, ALT, and LDH should be interpreted in the context of the patient's recent activity, since CK levels as high as 3,000 international units per liter, and more modest elevations in AST, ALT, and LDH are compatible with a normal response to strenuous training.

(2) Rhabdomyolysis may release large amounts of creatine and nucleic acids into the blood, where they are converted to creatinine and uric acid, respectively. In the presence of rhabdomyolysis, therefore, serum levels of creatinine and uric acid may give a misleading impression of renal impairment if they are interpreted apart from blood urea nitrogen levels obtained at the same time.

d. Suspected EHI patients should be immediately and actively cooled to a core temperature of $101^{\circ} \mathrm{F}$ $\left(38.3^{\circ} \mathrm{C}\right)$. Most EHI victims are sweating profusely and will cool spontaneously after removal from the 
TB MED 507/AFPAM 48-152 (I)

stressful circumstances; however, in some their core temperatures may continue to rise. Delaying active cooling, to see whether a casualty can cool spontaneously, is not advised. It is important to prevent progression of the heat injury process. Persistent elevation of body temperature suggests the probability of more severe pathology. Occasionally, cooling leads to inappropriate shivering while the core temperature is still elevated. This might aggravate rhabdomyolysis, but it does not increase body heat storage.

e. Fluid and electrolyte deficits should be corrected. Urine output should be monitored to assure that renal perfusion and urine flow are good. If rhabdomyolysis and myoglobinuria are present, high urine flow and alkalinizing the urine will prevent or minimize renal injury. Patients who do not respond dramatically to cooling, rest and fluid-electrolyte repletion should be observed for at least 24 hours after all findings return to normal with laboratory surveillance for the delayed complications of heat stroke. Return to regular duty should be guided by clinical and laboratory values.

f. Exertional rhabdomyolysis may occur without elevations in body core temperature or encephalopathy but frequently occurs as part of the clinical syndromes of severe heat casualty. Exertional rhabdomyolysis is caused by skeletal muscle damage with release of cellular contents into the blood circulation, including myoglobin, potassium, phosphate, $\mathrm{CK}$ and uric acid. Figure 4-3 provides a schematic for the treatment of acute exertional rhabdomyolysis.

(1) Rhabdomyolysis manifestations can vary from asymptomatic elevations of skeletal muscle enzymes to muscle pain, weakness and tenderness with associated myoglobinuria with or without acute renal failure.

(2) Exertional rhabdomyolysis cannot be defined by a specific CK level, but CK is the most sensitive test for its presence. Exercising military trainees frequently develop CK levels ranging from 500 to 1,000 units per liter without other clinical abnormalities, but seldom above 3,000 units per liter in the absence of EHI. Treatment includes saline infusion and urine alkalinization.

\section{4-6. Heat stroke}

a. Heat stroke is characterized by elevated body temperature $\left(>40^{\circ} \mathrm{C}\right.$ or $104^{\circ} \mathrm{F}$, core temperature could be lower if measured after body cooling has occurred) and central nervous system dysfunction that results in delirium, convulsions, or coma. Heat stroke is a catastrophic medical emergency resulting from a failure of the thermoregulatory mechanisms. It can cause extreme elevation of the body temperature (for example, $108^{\circ} \mathrm{F}\left(42^{\circ} \mathrm{C}\right)$ ), producing multi-organ dysfunction. However, many cases of exertional heat stroke with severe encephalopathy but modest hyperthermia have been reported. Major neurological disturbances typically are characteristic of a non-focal encephalopathy, while some patients may show transient or persistent abnormalities of cerebellar function. The onset of heat stroke may be heralded by up to an hour of prodromata, including headache, dizziness, drowsiness, restlessness, ataxia, confusion and irrational or aggressive behavior. Heat stroke may be complicated by liver damage, electrolyte abnormalities and, especially in the exertional form, by rhabdomyolysis, disseminated intravascular coagulation (DIC) or renal failure.

b. Exertional and classical are two types of heat stroke that occur under different settings and produce different clinical pictures. Exertional heat stroke occurs in physically active persons who are producing substantial metabolic heat loads. It is the most common form among military personnel and athletes, and it can occur in both hot and temperate conditions. Classical heat stroke occurs in vulnerable populations (young children, elderly persons, and those without potable water), frequently with impaired thermoregulation due to illness or medication, exposed passively to heat, and often dehydrated. It often presents as an epidemic during urban heat waves. Table 4-3 compares the characteristics of patients with classical and exertional heat stroke. A major difference is that exertional heat stroke is often complicated by acute rhabdomyolysis, with renal failure as a common consequence.

c. The traditional diagnostic criteria of heat stroke, coma or convulsions, hot dry skin, and core temperature above $106^{\circ} \mathrm{F}\left(41.3^{\circ} \mathrm{C}\right)$ reflect experience primarily with the classical form. Rigid adherence to these criteria will lead to under diagnosis of exertional heat stroke, since coma, convulsions, and 
TB MED 507/AFPAM 48-152 (I)

cessation of sweating may be late events in exertional heat stroke. Moreover, patients may receive medical attention after they have had a chance to cool somewhat and regain consciousness, especially if they still are sweating.

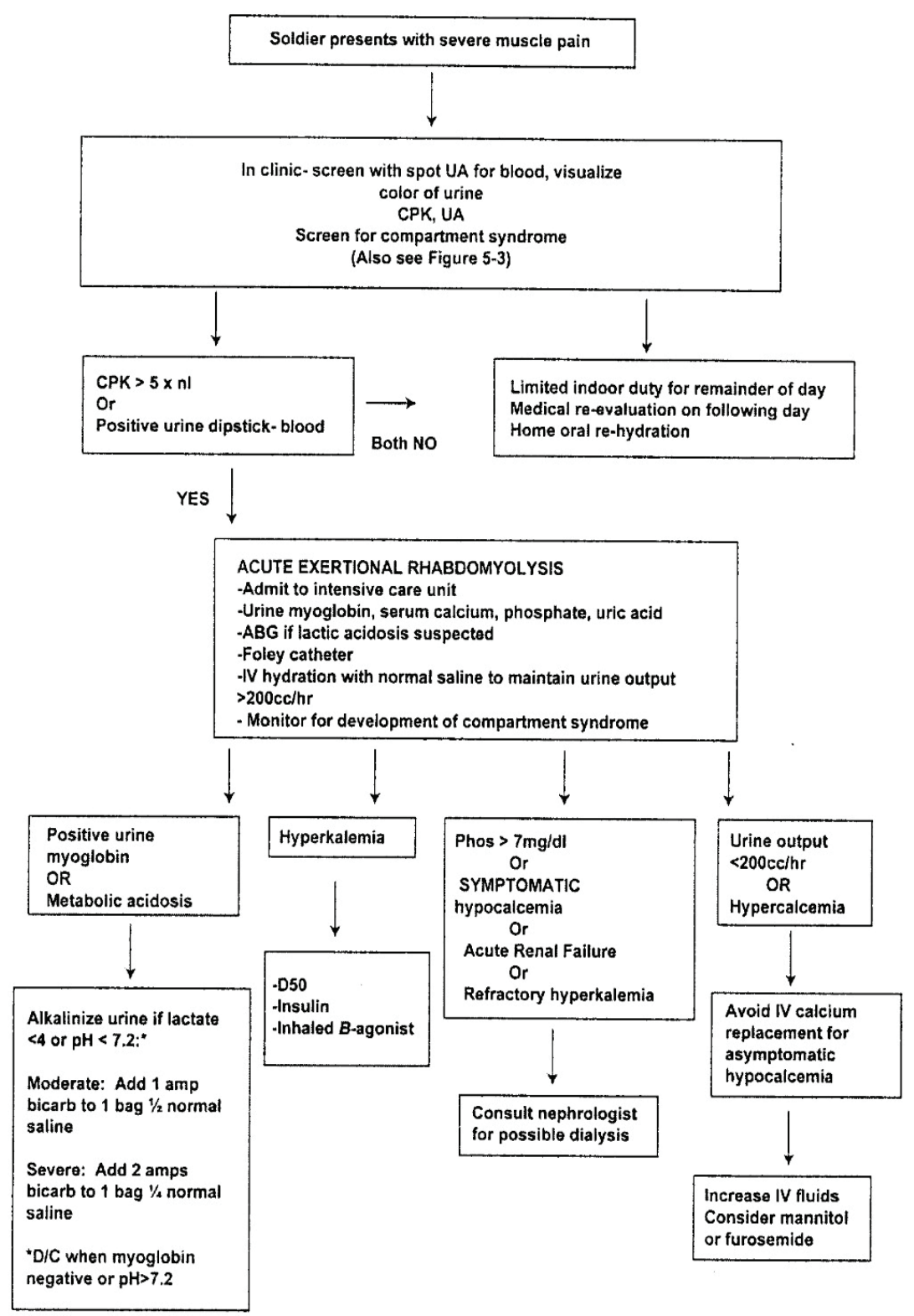

Figure 4-3. Schematic for Treatment of Acute Exertional Rhabdomyolosis 
TB MED 507/AFPAM 48-152 (I)

Table 4-3. Comparison of classical and exertional heat stroke

\begin{tabular}{|l|l|l|}
\hline \multicolumn{1}{|c|}{ Patient Characteristics } & \multicolumn{1}{c|}{ Classical } & \multicolumn{1}{c|}{ Exertional } \\
\hline Age & Young children or elderly & I5-45 years \\
\hline Health & Chronic illness common & Usually healthy \\
\hline $\begin{array}{l}\text { History of febrile illness or } \\
\text { immunization }\end{array}$ & Unusual & Common \\
\hline Prevailing weather & Frequent in prolonged heat waves & Variable \\
\hline Activity & Sedentary & Strenuous exercise \\
\hline Drug use & $\begin{array}{l}\text { Diuretics, antidepressants, } \\
\text { anticholinergics, phenothiazines }\end{array}$ & $\begin{array}{l}\text { Usually none, sometimes } \\
\text { ergogenic stimulants or cocaine }\end{array}$ \\
\hline Sweating & Usually absent & Often present \\
\hline Acid-base disturbances & Respiratory alkalosis & Lactic acidosis \\
\hline Acute renal failure & Fairly rare (<5\%) & Common $(~ 30 \%)$ \\
\hline Rhabdomyolysis & Seldom severe & Common, may be severe \\
\hline Hyperuricemia & Modest & Marked \\
\hline $\begin{array}{l}\text { Creatinine: blood urea nitrogen } \\
\text { ratio }\end{array}$ & $1: 10$ & Elevated \\
\hline CK, aldolase & Mildly elevated & Markedly elevated \\
\hline Hyperkalemia & Usually absent & Often present \\
\hline Hypocalcemia & Uncommon & Common \\
\hline DIC & Mild & May be marked \\
\hline Hypoglycemia & Uncommon & Common \\
\hline
\end{tabular}

d. The principle foci of heat stroke injury are brain, liver, kidneys, muscle and hemostasis. Since the seriousness of injury is mostly, but not entirely, predicted by the magnitude of body temperature elevation and duration, other pathogenic factors probably have a role in the evolution of heat stroke, including tissue ischemia, hypokalemia, exercise-induced lactic acidosis and systemic inflammatory response, perhaps triggered by products of muscle injury and or by endotoxin leaking from the gut.

e. Profound neuropsychiatric impairments present early and universally in victims of advanced exertional heat stroke. Delirium, coma, euphoria, hallucinations, rapid eye movement, seizures, and cerebellar dysfunction (dysarthia and ataxia) may be seen. Muscle rigidity with tonic contractions, tremors, and muscle cramps that alternate with seizures may be presented. The electroencephalogram is usually normal. Cerebrospinal fluid is usually clear, with normal pressure, occasional pleocytosis, or elevated protein levels as much as 150 milligram per deciliter.

f. Severe hepatic injury is generally observed in heat stroke patients. Serum transaminase levels have values 100 or more times the upper limit of normal, and jaundice may be noted within 24 to 36 hours of onset. Hypoglycemia is a frequent complication of exertional heat stroke.

g. Acute renal failure caused by acute tubular necrosis is seen in up to 30 percent of patients who have exertional heat stroke, which is sometimes preceded by rhabdomyolysis. Hypotension, myoglobinuria, DIC, and decreased renal blood flow all contribute to the development of oliguric renal failure. Pyuria, proteinuria, microscopic hematuria, and granular casts may be seen on microscopic examination of the urine.

h. Muscles are often rigid and contracted. High muscle enzyme levels in plasma and myoglobinuria are often present because of rhabdomyolysis. Acute muscular necrosis releases large quantities of potassium, myoglobin, phosphate, uric acid, and creatine (which is slowly converted to creatinine) and sequesters calcium in the exposed contractile proteins. White blood cell count can be as high as 30,000 to 40,000 per microliter.

i. Coagulation abnormalities manifested by heparin sensitivity, abnormalities of prothrombin consumption, thromboplastin generation, clotting time and clot retraction can be observed. Coagulopathy due to DIC may be present from damage to vascular endothelium, hepatocyte damage, rhabdomyolysis, and perhaps thermal platelet activation causing intravascular microthrombi. Fibrinolysis is secondarily activated. Hepatic dysfunction and thermal injury to megakaryocytes slows the repletion of clotting 
TB MED 507/AFPAM 48-152 (l)

factors. Platelet count is usually low and so are levels of factors V and VIII. In addition, systemic exposure to lipopolysaccharides (from gut ischemia) and some cytokines (for example, tumor necrosis factor alpha, interleukin-1) can also represent triggering events. Abnormal hemostasis is manifested clinically by purpura, conjunctival hemorrhages, hemoptysis, hematuria, and neurological findings due to central nervous system hemorrhage.

j. Clinically, patients exhibit either a hypodynamic or hyperdynamic circulatory state, depending on their cardiac reserve, volume status, and the degree of myocardial heat injury. Low systemic vascular resistance, sinus tachycardia (as high as 150 beats per minute), and increased cardiac index (CI) are common findings. Hypotension is a late finding and represents circulatory collapse. Pulse pressure is almost always high. Central venous pressure may be normal or elevated with moderate fluid requirement. Electrocardiogram $(\mathrm{ECG})$ findings may include ST-segment depression, T-wave abnormalities, and conduction disturbances.

k. Diarrhea and vomiting are frequently observed. Compensatory mesenteric vascular constriction may produce local areas of mucosal ulcerations. Hematemesis and melena may also be encountered. Hyperventilation with respiratory alkalosis is seen and may be severe enough to produce tetany. Hemoptysis may be a complication of coagulation abnormalities. Pulmonary edema may be present and is often severe.

I. The clinical outcome of patients with heat stroke is primarily a function of the magnitude and duration of body temperature elevation. The most important therapeutic measure is rapid reduction of body core temperature. Rapid cooling can reduce heat stroke mortality from 50 to 5 percent. Cooling should begin in the field, and victims must be quickly removed to a cool shady place, their clothes removed, and their skin kept moist. Active cooling should be started immediately and continued during evacuation. Cooling and evaluation should proceed simultaneously. While cooling is underway, rectal temperature should be closely monitored. Active cooling should be discontinued when the rectal temperature reaches $101^{\circ} \mathrm{F}\left(38.3^{\circ} \mathrm{C}\right)$ to avoid hypothermia.

$\mathrm{m}$. Any effective means of cooling is acceptable. Immersion in cool or iced water with skin massage is the most rapid method. Ice sheets and ice packs are effective. No pharmacologic agents that will "theoretically" accelerate cooling should be used. If attempts to cool the patient are successful, the body core temperature may rise again once cooling is stopped. Occasionally, cooling leads to inappropriate shivering while the temperature is elevated; however, the active cooling will remove much more heat than being produced.

n. After cooling and hemodynamic stabilization, continuing care is supportive and directed at the complications of heat stroke as they appear. Patients with heat stroke frequently have impaired temperature regulation for several days with alternate periods of hyperthermia and hypothermia. Constant monitoring is essential, and clinically significant deviations in temperature may require either cooling or warming measures. Body temperature changes may be due to reasons other than hypothalamic instability, such as infection.

o. Medications to be avoided include antipyretics and some sedatives.

(1) Antipyretics lower the body temperature set point in the hypothalamus. Heat stroke does not alter the thermoregulatory set point. Disadvantages of antipyretics include risk of severe liver injury with acetaminophen; reduced potassium excretion with nonsteroidal anti-inflammatory drugs; depressed platelet function and risk of subsequent DIC with aspirin; and risk of gastric irritation or bleeding.

(2) Chlorpromazine should not be used because of a relatively high incidence of hypotension in patients with serious heat illness. Lorazepam is probably the safest drug for sedation and control of seizures, in part because of its low risk for hepatotoxicity and its rapid metabolism.

p. Heat stroke patients require early evacuation to medical facilities with intensive care capabilities. These patients will require prolonged care. Heat stroke patients should receive profiles restricting heat exposure until clinical recovery is complete and their heat tolerance has been evaluated. Only 10 percent of persons have been reported to be heat intolerant after recovery from heat stroke. 


\section{TB MED 507/AFPAM 48-152 (I)}

q. Heat stroke and rhabdomyolysis patients should be referred to a medical evaluation board. If the soldier has had full clinical recovery, the medical evaluation board should give a 3-month P-3 (T) profile, which restricts the soldier from heat exposure and from performing vigorous physical exercise for periods longer than 15 minutes. Maximal efforts, such as the Army Physical Fitness Test run and airborne operations are not permitted. If, after three months, the soldier has not manifested any heat intolerance, the profile will be modified to $\mathrm{P}-2$ (P) and normal work permitted. Maximal exertion and significant heat exposure (such as wearing MOPP4) are still restricted. If the soldier manifests no heat intolerance through the next summer, normal activities can be resumed and the soldier may be returned to full unrestricted duty without a physical evaluation board. Lack of full recovery or any evidence of significant heat intolerance during the period of the profile, requires referral to a physical evaluation board. (See AR 40-501, para 3-45b). This medical evaluation board process must be explained to the soldier's chain-ofcommand, since it will fall below the 90 -day standard from when medical staff identifies a soldier as requiring a medical evaluation board to when the packet is sent to the physical evaluation board.

\section{4-7. Fluid and electrolyte imbalances}

a. Dehydration as evidenced by hypovolemia and hyperosmolality often contributes to the high core temperature that typically occurs with heat casualty. In addition, dehydration will reduce physical and mental work capabilities in hot weather.

b. Water depletion dehydration develops from sweat rates in excess of water replacement rates. While the loss of water occurs from both intracellular and extracellular (ECF) fluids, the ECF contraction is often rapid and symptoms evolve quickly.

c. Salt depletion dehydration usually develops over several days, so ECF contraction is gradual and symptoms develop slowly. Because salt depletion does not produce hypertonicity, thirst is not as prominent until the ECF has contracted enough to cause volumetric stimulation of thirst. Nausea and vomiting are common but of uncertain mechanism. However, intense constriction of the intestinal vascular bed, to maintain circulatory function, may contribute to these symptoms. Muscle cramps commonly accompany sodium depletion. Potassium depletion commonly accompanies salt depletion due to diminished intake and mineralocorticoid driven kaliuresis, but frank hypokalemia is uncommon.

d. Hyponatremia refers to blood sodium below 130 milliequivalents per liter $(\mathrm{mEq} / \mathrm{L})$. In published case reports of symptomatic exertional hyponatremia, serum sodium concentrations at presentation averaged $121 \mathrm{mEq} / \mathrm{L}$ and ranged from 109 to $131 \mathrm{mEq} / \mathrm{L}$. Hyponatremia is associated with prolonged ( $>6$ hours) physical work and arises primarily from fluid overload, under-replacement of sodium losses, or usually a combination of both. The reduction of ECF solute leads to movement of water into the intracellular fluid space. If intracellular swelling is of sufficient magnitude, symptoms of central nervous system dysfunction, lung congestion and muscle weakness can occur. Symptomatic hyponatremia is rare.

e. Hyponatremia and dehydration mediated heat exhaustion share many symptoms, and laboratory tests are necessary to distinguish the two disorders. Therefore, the initial treatment of patients, who in fact have mild hyponatremia, is likely to have been the administration of oral fluids (maximum of 1 hour with 1 quart per $30 \mathrm{~min}$ ), on the presumption that they were suffering from water-depletion heat exhaustion. Patients with water-depletion heat exhaustion respond fairly quickly to fluid replacement, while hyponatremia is aggravated by administering hypotonic fluids and may progress to life-threatening cerebral edema. If a patient who is presumed to have heat exhaustion does not improve quickly in response to the administration of hypotonic fluids, such treatment should not be continued without further medical evaluation. Repeated emesis is more often seen with hyponatremia. If two cases of emesis occur with a general deterioration, the soldier should be evacuated for further medical evaluation. 
TB MED 507/AFPAM 48-152 (I)

\section{CHAPTER 5}

\section{MANAGEMENT OF HEAT CASUALTIES}

\section{5-1. Clinical management}

a. In controlled settings, emergency medical care for heat casualties shall be arranged in advance. In addition, the first responder(s) will assist the chain-of-command in implementing the risk management guidelines for prevention of heat casualties per Appendix D. (First responders can be $91 \mathrm{~W}$ medics, civilian emergency medical technician personnel, or Combat Life Savers). Management of heat casualties should always be urgent to avoid the potential for rapid deterioration into heat injury. Casualties' immediate access to medical support in the field may include, at a minimum, measurement of core temperature, brief assessment of vital signs and mental status, and immediate, effective cooling. First responders should also be prepared to provide basic life support and first aid for injuries. If transportation to a medical department will require more than 10 minutes, provisions should be made to administer advanced cardiac life support (to include automated defibrillation) and intravenous fluids prior to arrival at the emergency department.

b. The field medical team needs to provide an accurate clinical description of the immediate events, symptoms, signs, vital signs, and mental status of the patient, along with training activities, environmental conditions, clothing, and treatment given prior to arrival at the medical facility. To avoid substantial delay in treatment in settings where heat casualties are common, strenuous physical training should not be conducted without on-site medical capabilities. For example, a recruit-training center should have at least one medic or medical corpsman (with equipment, ice, and a transport vehicle) on site while strenuous training is conducted in hot weather.

c. Soldiers should be familiar with the signs and symptoms of heat illness and injury so that they can seek medical support. Figure 5-1 provides the warning signs and symptoms of possible heat casualties.

d. Figure 5-2 presents a schematic for the field treatment of heat casualties by $91 \mathrm{~W}$ medics.

e. The severity of heat injury is often not apparent on initial presentation in the field. Soldiers involved in strenuous hot weather activity and who present with associated symptoms (for example, unsteady gait, sweaty, flushed skin, dizzy, headache, tachycardia, paresthesias, weakness, nausea, cramps) should be immediately evaluated for their mental status and core (rectal) temperature and vital signs. Poor or worsening mental status (ataxia, confusion) represents a true medical emergency, and these soldiers need rapid intervention and evacuation to an MTF.

f. All soldiers suspected of having heat injury must have early initiation of cooling and rehydration in the field. Delay in cooling probably represents the single most important factor leading to death or residual, serious disability in those who survive. The patient should lie down and as much clothing should be removed as is practical. Body cooling should be initiated by the most practical means as quickly as possible. Thirsty and alert patients can be given oral fluids (initially 1 hour of 1 quart per 30 minutes). Heat exhaustion patients generally demonstrate rapid improvement (within the first hour) with cooling and rehydration; however, those failing to respond to treatment should be forwarded to an MTF.

g. Figure 5-3 provides a schematic for the treatment of heat casualties at the MTF.

\section{5-2. Body cooling}

a. Body cooling is the treatment foundation and must be initiated as soon as possible, using the most practical means available. First the patient needs to lie down. An obtunded or comatose patient should be placed on one side, with the airway closely monitored to avoid aspiration of vomitus. 
TB MED 507/AFPAM 48-152(I)

\section{Warning signs and symptoms of possible heat illness and injury}

\section{More Common Signs/Symptoms ${ }^{\star}$}

- Dizziness

- Headache

- Nausea

- Unsteady walk

- Weakness

- Muscle cramps

- Fatigue

- Chills

Serious Signs/Symptoms

- Hot body, high temperature

- Confusion/disorientation (mental status assessment)

- Vomiting

- Involuntary bowel movement

- Convulsions

- Weak or rapid pulse

- Agitation

- Unresponsiveness, coma

\section{Immediate Actions}

- Remove from training

- Allow casualty to rest in shade and fan and spray with water

- Loosen clothing

- Take sips of water

- While doing the above, call for medic evaluation of the soldier. (Medic will monitor temperature and check for mental confusion.)

- If no medic is available, call for ambulance or medical evacuation.

Immediately Call Medical Evacuation or Ambulance For Emergent Transport While Doing the Following:

- Laying person down in shade with feet elevated until medical evacuation or ambulance arrives.

- Undressing as much as possible.

- Pouring cool water over the person and fanning

- Cool by best means available (water immersion or ice sheets/packs).

- Giving $\underline{\operatorname{sip} s}$ of water if conscious.

- Monitoring airway and breathing.

*With any of the signs or symptoms, immediately call for medical evaluation by a medic.

Figure 5-1. Warning signs and symptoms of heat illness and injury 


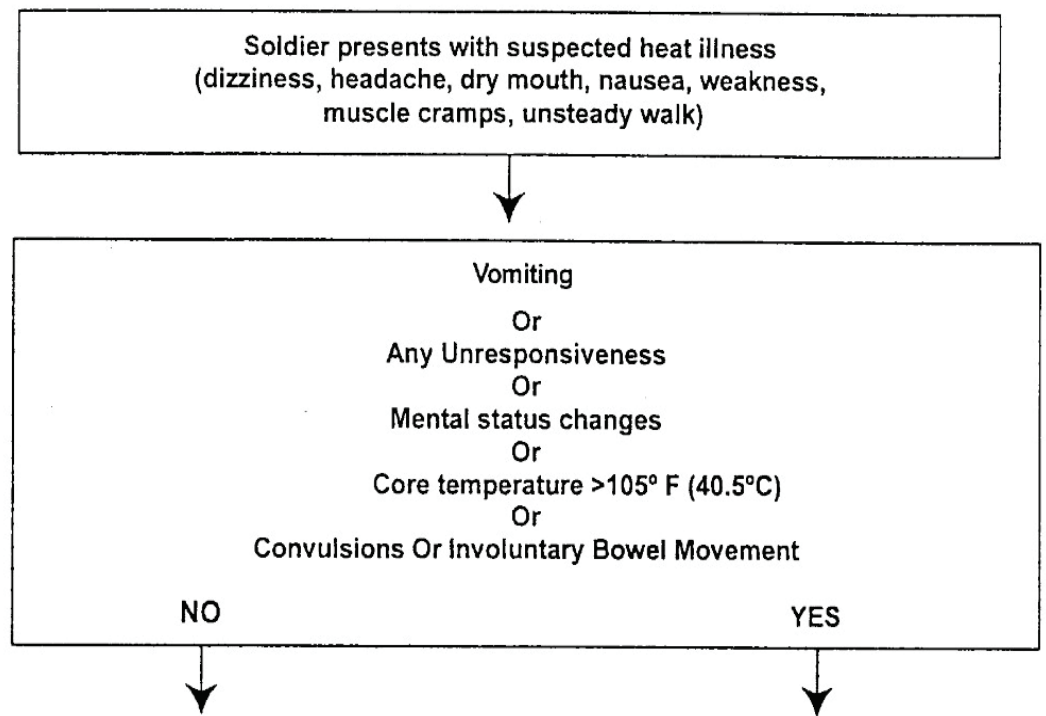

- Loosen clothing

- Place patient in shade

- Provide fluids by mouth - Not to exceed $1 \mathrm{qt} /$ hour

- Give snack

- Helpcool
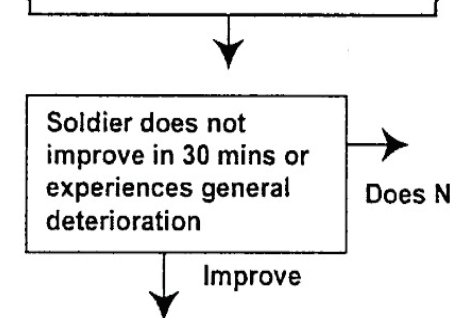

- Limited indoor duty for remainder of day

- Medical evaluation within 24 hours (sooner if soldier not at baseline)

- No further heat stress until medical evaluation has been completed

\section{EVACUATE}

- Place soldier in shade

- Loosen and remove clothing

- Fan patient

- Actively cool by sponging with water and/or wetting clothing

- Intravenous hydration only if emergency evacuation is delayed (limit to 500 cc Normal Saline)

- Confirm core temperature when evacuation arrives

- Report temps and SGBT on Injury Report

Figure 5-2. Schematic for field treatment of heat casualties by $91 \mathrm{~W}$ medics 
TB MED 507/AFPAM 48-152 (I)

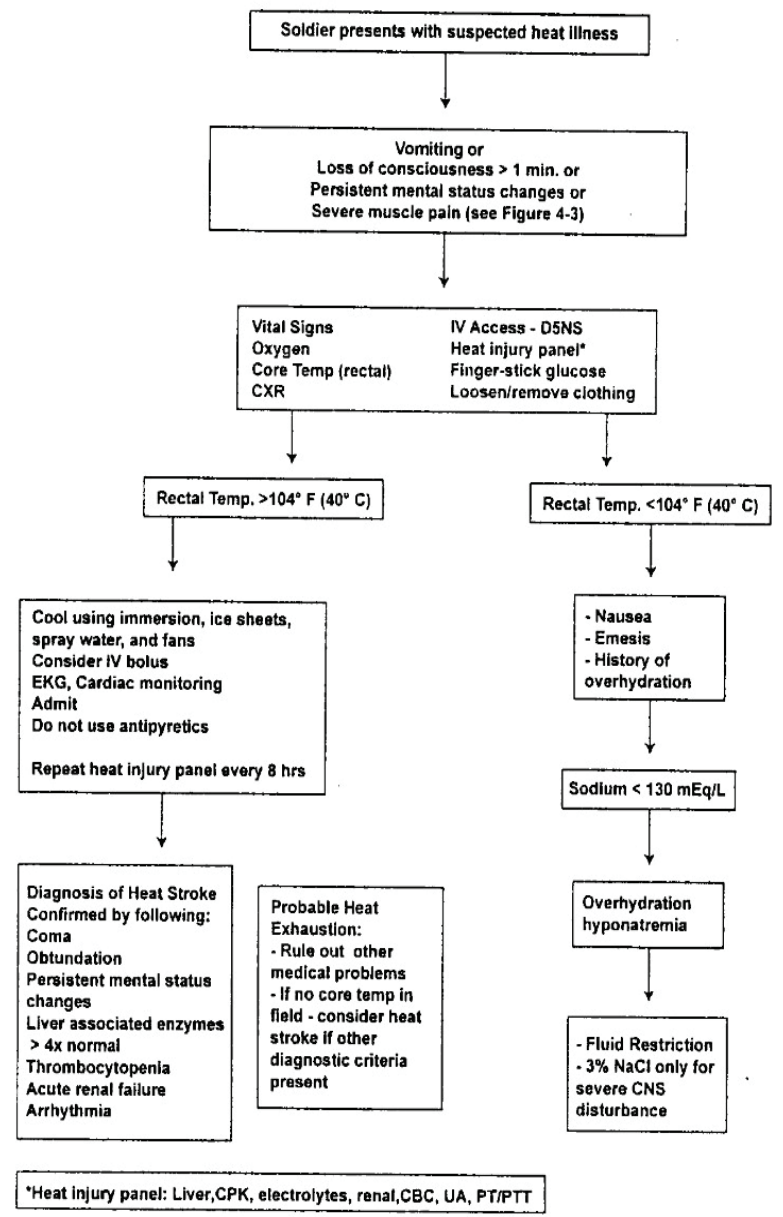

Figure 5-3. Schematic for MTF treatment of heat casualties

b. Initial cooling methods include removing outer layers of clothing, soaking the skin with water, using wet sheets, ice packs or spray bottles, massaging the skin, and resoaking. Cold-water applications may be alternated with massage to encourage local blood flow and heat dissipation.

c. Both cool and ice water immersion are the most effective methods in lowering body temperature. Ice water produces a slightly faster cooling; however, ice water is an uncomfortable environment in which to work and, in the field, is very difficult to obtain. Conscious patients will occasionally fight ice water immersion, thus complicating management. Cool water is less demanding logistically and easier for the medical attendants. Patients can be partially immersed using a stretcher over a tub of water. If the patient's buttocks and back are immersed, the anterior arms and trunk will be accessible for clinical purposes.

d. In desert environments, field expedient immersion baths that keep water cool can be constructed by digging plastic-lined shaded pits (the water is cooled by contact with cool subsurface sand and surface evaporation) or by rigging shallow canvas tubs with elevated frames in ventilated shade (the water is cooled by evaporation from the wet canvas surface). In canvas tubs, the water can cool to nearly the atmospheric dew point temperature, often as low as $50^{\circ} \mathrm{F}\left(10^{\circ} \mathrm{C}\right)$ in deserts. Heat stroke patients 
TB MED 507/AFPAM 48-152 (I)

frequently have diarrhea and vomiting; because of this the water immersion baths should be disinfected between cases.

e. Wetting the body surface and accelerating evaporation by fanning can achieve cooling. The water can be applied by spraying or by application of thin conforming cloth wraps (sheets or cotton underwear). Evaporative cooling will not be as effective in humid environments. NOTE: Several authors have speculated that evaporative cooling is more effective than immersion cooling with cool or cold water; however, clinical measurements on heat stroke patients unequivocally affirm the greater effectiveness of cooling with cool or cold water.

f. Ice packs or a cooling blanket (iced sheets)-especially when placed over major arteries-can provide cooling while the patient lies on a bed board. In this situation, cardiopulmonary resuscitation and advanced cardiac life support can safely be implemented. The room should be air conditioned to maintain a low humidity and air temperature. Rapid cooling of hyperthermic patients should continue until the rectal temperature remains below $101^{\circ} \mathrm{F}\left(38.3^{\circ} \mathrm{C}\right.$ ), after which cooling can proceed without cold water (such as a tepid shower) until the rectal temperature remains below $100^{\circ} \mathrm{F}\left(37.8^{\circ} \mathrm{C}\right)$.

g. The following invasive cooling techniques are not recommended: ice water lavage or enemas and peritoneal lavage with cool fluids. These techniques do not provide faster cooling and have the additional disadvantages of potential complications and substantial inappropriate fluid loads.

\section{5-3. Rehydration}

a. Oral fluids work well for most dehydrated patients whose mental status is good and who can take fluids without risk of vomiting. For moderately dehydrated athletes, oral rehydration is equally as effective as intravenous infusion (replacing similar volume and salt load) in restoring exercise performance capabilities in the heat. Water is usually given for rehydration; however, for markedly dehydrated soldiers, sports drinks can be of value. Heat cramps respond to oral salt solutions ( 0.5 percent salt or 1 teaspoon per quart of water).

b. Intravenous fluids replenish the ECF quickly, and $\mathrm{NaCl}$ can be given parenterally in concentrations substantially higher than can be tolerated orally. Patients with evidence of clinically significant plasma volume depletion (hypotension, tachycardia at rest, or orthostatic signs) should initially receive normal saline in 200 to 250 cubic centimeter boluses, an amount sufficient to restore normal circulatory function. No more than 2 liters of parenteral fluid should be administered without laboratory results, and the composition of subsequently administered parenteral fluid should be guided by measurements of serum electrolytes.

c. Potassium depletion is best treated orally, but patients with severe heat injury may not be able to take oral medications because of obtundation or nausea and vomiting. Intravenous potassium replacement should be administered in half-normal or normal saline; dextrose (which tends to move potassium into cells) should be avoided. Rates of infusion are usually limited to $20 \mathrm{mmol} / \mathrm{hr}$ unless paralysis or malignant ventricular arrhythmias are present, in which case higher rates are recommended. Close electrocardiographic (ECG) and neurological monitoring is required.

d. The earliest ECG sign of hyperkalemia is peaked T waves. Hyperkalemia should always be suspected when young exercising individuals collapse with arrhythmias. When hyperkalemia is found by chemical analysis, the medical officer should exclude pseudohyperkalemia, primarily due to needle hemolysis (with an elevated LDH level), fist clenching during blood drawing, marked leukocytosis or megakaryocytosis, or erroneous assay. An ECG should be performed while awaiting results of the repeat assay. The acute treatment of severe hyperkalemia is a medical emergency; the management of which has been well described. Treatment of either hypokalemia or hyperkalemia requires careful monitoring of responses because of shifts between intracellular and extracellular compartments and changes in the rate of renal loss. 
TB MED 507/AFPAM 48-152 (I)

e. Rapid lowering of plasma osmolality, even from an initially elevated level, can cause cerebral edema. Therefore, significant hypernatremia should be corrected slowly at a reduction of no more than $2 \mathrm{~L} / \mathrm{hr}$ to avoid cerebral edema.

\section{5-4. Adjunctive therapy}

a. Supportive care, as in any emergency medical situation, requires health care providers follow the $\mathrm{ABC}$ algorithm for stabilization, while treating a patient who has heat illness. In a comatose patient, a cuffed endotracheal tube should be placed to protect the airway. Patients may have severe hypoxemia secondary to aspiration, pneumonitis, pulmonary infarction, pulmonary hemorrhage, or pulmonary edema and therefore may require supplemental oxygen. If hypoxemia persists, positive pressure ventilation may be indicated.

b. The patient's vital signs need to be monitored continuously. A rectal probe should be placed for continuous core temperature recording. A large-bore intravenous catheter should be inserted. Normal saline can be used to replace fluids. It is prudent to be very cautious while rehydrating these patients, as they often have or readily develop pulmonary edema and renal failure.

c. Hemodynamic monitoring with pulmonary artery catheter may be indicated in patients who have compromised cardiac function, hemodynamic instability, or uncertain hemodynamic status. Most patients show a hyperdynamic circulation with high cardiac index (CI), low systemic vascular resistance, and elevated central venous pressure secondary to right-sided heart failure. These patients need mild to moderate fluid replacement, since cooling alone causes vasoconstriction and thus increases blood pressure. Some patients have hypodynamic response with low $\mathrm{CI}$, elevated central venous pressure, and hypotension. Alpha-adrenergic drugs (norepinephrine) are contraindicated, until cooling is achieved, because they produce vasoconstriction, resulting in decreased heat loss. Moreover, hypotensive patients who do not respond to fluid replacement should receive inotropic support. Dopamine and dobutamine are reasonable choices and have the potential added advantage of improving renal perfusion. Pulmonary artery wedge pressure monitoring should be used in patients with persistent hemodynamic instability.

$\mathrm{d}$. Other aspects of monitoring should include urine output measurement. To increase renal blood flow and to prevent acute renal failure from myoglobinuria, use of mannitol may be indicated. Furosimide may also be used to increase urine output. Progressive renal failure warrants early dialysis.

e. Patients often develop marked agitation. In the past, the use of chlorpromazine was advocated in such situations. Arguments against the use of chlorpromazine include the associated increased risk of toxicity in patients who have liver failure and the decreased threshold for seizures. Benzodiazepines are sedatives of choice in this situation.

f. In the presence of coagulopathy, initial therapy with fresh frozen plasma and platelets may be indicated. Monitoring of platelet count, prothrombin time (PT), partial thromboplastin time, fibrin split products, and fibrinogen is indicated.

g. Use of steroids in heat stroke has not been shown to be beneficial, and use of antibiotics should be limited to specific indications, as in other clinical situations.

\section{5-5. Surveillance}

a. Surveillance includes heightened provider awareness of cases meeting the heat injury criteria and vigilance in reportable disease reporting through the preventive medicine activity to the U.S. Army Medical Surveillance Activity. The U.S. Army Safety Center should be notified per AR 385-40, para 2-6(d) of a class A through $\mathrm{C}$ occupational illness/injury. Only through data-based-policy decision-making can prevention of heat injury and its serious complications be minimized.

b. Reported heat illness/injury cases should meet the case definition found in the Tri-Service Reportable Events list published by U.S. Army Medical Surveillance Activity. This list and the laboratory criteria can be obtained from http://amsa.army.mil. Heat stroke [U.S. Army Medical Surveillance Activity 
TB MED 507/AFPAM 48-152 (I)

code 992.0] and Heat Stroke [U.S. Army Medical Surveillance Activity code 992.3] are defined as follows:

(1) Clinical Description: Heat Exhaustion: Occurs during exercise in hot conditions, resulting in or inability to continue work. Heat Stroke: Characterized by clinically significant tissue damage-especially hepatic injury, renal damage, DIC, rhabdomyolysis and encephalopathy. Altered mental status, caused by heat injury to the brain is common. Based upon these definitions, exertional heat injury would be reported as a heat stroke.

(2) Clinical Case Definition: Heat Exhaustion: A variable combination of dizziness, fatigue, headache, thirst and GI distress with normal or slightly altered mental status and elevated core body temperature. Reportable cases are those that require medical intervention and result in more that 4 hours of lost duty time. Heat Stroke: Significantly altered mental status at presentation and or elevated muscle (CPK) and hepatic (ALT, AST) enzymes at 24 hours.

c. Recordkeeping should include the circumstances under which the illness occurred and the time course of clinical symptoms and signs. An effective heat stress/injury surveillance program should document--

(1) Active monitoring of outcomes and all exercise-related deaths.

(2) Training activities.

(3) Personal risk factors in the training population.

(4) Weather conditions.

(5) Amount and timing of exercise.

(6) Adherence to rest/work cycles and fluid consumption.

(7) Clothing and gear involved.

(8) Medications (prescriptions and over-the-counter) taken before the event.

(9) Nutritional supplement use associated with the heat injury event. 
TB MED 507/AFPAM 48-152 (I)

\section{APPENDIX A}

\section{REFERENCES}

\section{A-1. Related Publications}

AFPAM 48-151

Thermal Injury

AR 40-5

Preventive Medicine

AR 40-25/BUMEDINST 10110.6/AFI 44-141

Nutritional Allowances: Standards and Education

AR 40-400

Patient Administration

AR 40-501

Standards of Medical Fitness

AR $385-40$

Accident Reporting and Records

Field Manual 4-02.17

Preventive Medicine Services

Field Manual 4-25.12

Unit Field Sanitation Team

Field Manual 8-55

Planning for Health Service Support

Field Manual 21-10/MCRP 4-11.10

Field Hygiene and Sanitation

NAVMED-P-5010-3

Manual of Naval Preventive Medicine

U.S. Army Medical Surveillance Activity, 1998. Tri-Service Reportable Events: Guidelines and Case Definitions, Version 1.0. Available from http://amsa.army.mil/TriServiceRE/Jul98TriServREGuide.pdf.

U.S. Army Research Institute of Environmental Medicine Technical Note 91-3

Heat Illness: A Handbook for Medical Officers

U.S. Department of Health and Human Services Publication No. 86-113

Occupational Exposure to Hot Environments 


\section{TB MED 507/AFPAM 48-152 (I)}

Unnumbered Publications

Pandolf, K.B., J.A. Gonzalez and M.N. Sawka. An Updated Review: Microclimate Cooling/Cooling of Protective Clothing in the Heat. Perspectives on Microclimate Cooling/Conditioning of Protective Clothing in the Heat - Volume 1 K.B. Pandolf ed., Subgroup U: The Technical Cooperative Program, pp. 1-80, 1995.

Petersdorf, R.G. Hypothermia and hyperthermia. Harrison's Principles of Internal Medicine, edited by Isselbacher, K.J., Braunwald, E., Wilson, J.D., Martin, J.B., Fauci, A.S., and Kasper, D.L., 13th ed., New York, NY: McGraw-Hill, Health Professions Division, 1994: 2473 - 2479.

Singer, GG. Fluid and electrolyte management. The Washington Manual of Medical Therapeutics. Carey, C.F., Lee, H.H., and Woeltje, K.F. eds. 29th ed. Philadelphia, PA: Lippincott-Raven, 1998: Chapter 3.

\section{A-2. Prescribed Forms}

No entries for this section.

\section{A-3. Referenced Forms}

No entries for this section.

\section{A-4. Selected Bibliography}

Blatteis CM, editor. 1998. Physiology and Pathophysiology of Temperature Regulation. World Scientific: River Edge, NJ.

Bouchama, A. and J.P. Knochel. Heat stroke. New England Journal of Medicine. 346:1978-1988, 2002.

Department of the Army, 19 April 1994. Subject: Implementation of New Medical Surveillance System. Memorandum, SGPS-PSP. Available from http://amsa.army.mil/documents/otsg_memo.pdf.

Department of the Army, 17 June 1998. Subject: Tri-Service Reportable Events List. Memorandum, MCHO-CL-W. Available from http://amsa.army.mil/documents/medcom_memo.pdf.

Dill DB, Adolph EF, Wilber CG, editors. 1964. Handbook of Physiology, Section 4, Adaptation to the Environment. Williams and Wilkins: Baltimore, American Physiological Society.

Fregley MJ, Blattis CM, editors. 1996. Handbook of Physiology, Section 4, Environmental Physiology. Vol. 1, Oxford, University Press: New York, American Physiological Society.

Gisolfi CV, Lamb DR, editors. 1990. Fluid Homeostasis During Exercise, Volume 3, Perspectives in Exercise Science and Sports Medicine. Benchmark Press, Carmel Press: IN.

Gisolfi CV, Lamb DR, Nadel ER, editors. 1993. Exercise, Heat, and Thermoregulation, Volume 6, Perspectives in Exercise Science and Sports Medicine. Cooper Publishing Group: Traverse City, MI. 
TB MED 507/AFPAM 48-152 (l)

Marriott, BM, editor. 1993. Nutritional Needs in Hot Environments. Committee on Military Nutrition Research, National Academy Press: Washington, DC.

Marriott, BM, editor. 1994. Fluid Replacement and Heat Stress. Committee on Military Nutrition Research, National Academy Press: Washington, DC.

Montain, SJ, Sawka MN, Wenger, CB, 2001. Hyponatremia Associated with Exercise: Risk and Pathogenesis. Exercise and Sports Science Reviews 29:113-117.

Pandolf, KB, Sawka, MN, Gonzalez, RR, editors. 1988. Human Performance Physiology and Environmental Medicine at Environmental Extremes. Cooper Publishing Group: Traverse City, MI.

Pandolf, KB, Burr, RE, Wenger, CB, Pozos, RS, editors. 2002. Medical Aspects of Harsh Environments. Vol. 1 in Zajtchuk, R, Bellamy, RF, editors. Textbook of Military Medicine. Washington, DC.

Proulx, C.I., M.B. Ducharme, and G.P. Kenny. Effect of water temperature on cooling efficiency during hyperthermia in humans. The Journal of Applied Physiology. 94: 1317-1323, 2003.

Rosen, P, Barkin, RM, Hockberger, RS, Ling, LJ, Markovchick, VJ, Marx, JA, Newton, E, Smith, M, Walls, RM, editors. 7th edition, 2002. Emergence Medicine: Concepts and Clinical Practice. Mosby: St. Louis, MO.

Sawka, M.N., R.P. Francesconi, A.J. Young, and K.B. Pandolf. Influence of hydration level and body fluids on exercise performance in the heat. The Journal of the American Medical Association. 252:11651169, 1984. 
TB MED 507/AFPAM 48-152 (I)

\section{APPENDIX B}

\section{WET BULB GLOBE TEMPERATURE INDEX}

\section{B-1. Method}

a. The WBGT is an empirical index of environmental heat stress:

(1) Outdoor WBGT equals 0.7 natural wet bulb plus 0.2 black globe plus 0.1 dry bulb.

(2) Indoor WBGT equals 0.7 natural wet bulb plus 0.3 black globe.

b. The WBGT index is computed from readings of-

(1) A stationary wet bulb thermometer exposed to the sun and prevailing wind. See Figure B-1.

(2) A black globe thermometer similarly exposed.

(3) A dry bulb thermometer shielded from direct rays of the sun.

c. All readings for the WBGT index are taken at the location representative of the conditions to which soldiers are exposed. The wet bulb and globe thermometers are suspended in the sun at a height of four feet above the ground. A period of 20 minutes should elapse before readings are taken.

\section{B-2. Equipment}

a. The natural wet bulb temperature is obtained from a stationary thermometer bulb covered by a wetted wick (heavy white shoestring) and exposed to the natural prevailing air movement. A standard laboratory glass thermometer can be used with a range of $23^{\circ} \mathrm{F}$ to $122^{\circ} \mathrm{F}\left(-5^{\circ} \mathrm{C}\right.$ to $\left.+50^{\circ} \mathrm{C}\right)$ and accuracy of $0.9^{\circ} \mathrm{F}\left(0.5^{\circ} \mathrm{C}\right)$. The wick dips into a flask of clean, preferably distilled, water. The mouth of the flask should be $\sim 3 / 4$ of an inch below the tip of the thermometer bulb. The water level in the flask should be high enough to ensure thorough wetting of the wick. It is not acceptable to depend upon capillary action to completely wet the wick. The wick should be wetted by direct application of water from a syringe $\sim 1 / 2$ hour before each reading. The wick should be clean and new wicks should be washed before using; in addition, flask water should be changed daily.

b. Black globe-thermometer apparatus consists of a six-inch ( 15 centimeter) hollow copper sphere painted flat (matte) black on the outside, containing a thermometer with its bulb at the center of the sphere. The thermometer should have a range of $23^{\circ} \mathrm{F}$ to $212^{\circ} \mathrm{F}\left(-5^{\circ} \mathrm{C}\right.$ to $\left.+100^{\circ} \mathrm{C}\right)$ with an accuracy of $0.9^{\circ} \mathrm{F}\left(0.5^{\circ} \mathrm{C}\right)$. The thermometer stem protrudes to the outside through a stopper tightly fitted into a brass tube soldered to the sphere. The sphere has two small holes near the top used for suspending the sphere with wire or strong cords. The globe must be kept dull black at all times, free of dust or rain streaks, by dusting, washing, or repairing if necessary. The globe thermometer should be exposed at least 25 minutes before it is read.

c. Shaded dry bulb thermometer is used to measure ambient air. A standard laboratory glass thermometer can be used with a range of $23^{\circ} \mathrm{F}$ to $122^{\circ} \mathrm{F}\left(-5^{\circ} \mathrm{C}\right.$ to $\left.+50^{\circ} \mathrm{C}\right)$ and accuracy of $0.9^{\circ} \mathrm{F}$ $\left(0.5^{\circ} \mathrm{C}\right)$. Degrees $\mathrm{F}$ and $\mathrm{C}$ can be converted by:

$$
\begin{gathered}
{ }^{\circ} \mathrm{C}=\left({ }^{\circ} \mathrm{F}-32\right) \times 0.555 \\
{ }^{\circ} \mathrm{F}=\left({ }^{\circ} \mathrm{C} \times 1.8\right)+32
\end{gathered}
$$

d. The following is a list of WBGT equipment and national stock numbers:

(1) WBGT, without tripod, 6665-00-159-2218.

(2) WBGT, with tripod, 6665-01-381-3023.

(3) WBGT black globe thermometer, replacement part, 6685-01-110-4429.

(4) WBGT wet bulb thermometer, replacement part, 6685-01-110-4430.

(5) WBGT dry bulb thermometer, replacement part, 6685-01-110-6563.

(6) Hand-held automated heat stress monitor, 2H-6685-01-055-5298, developed by the U.S. Navy. 
TB MED 507/AFPAM 48-152 (I)

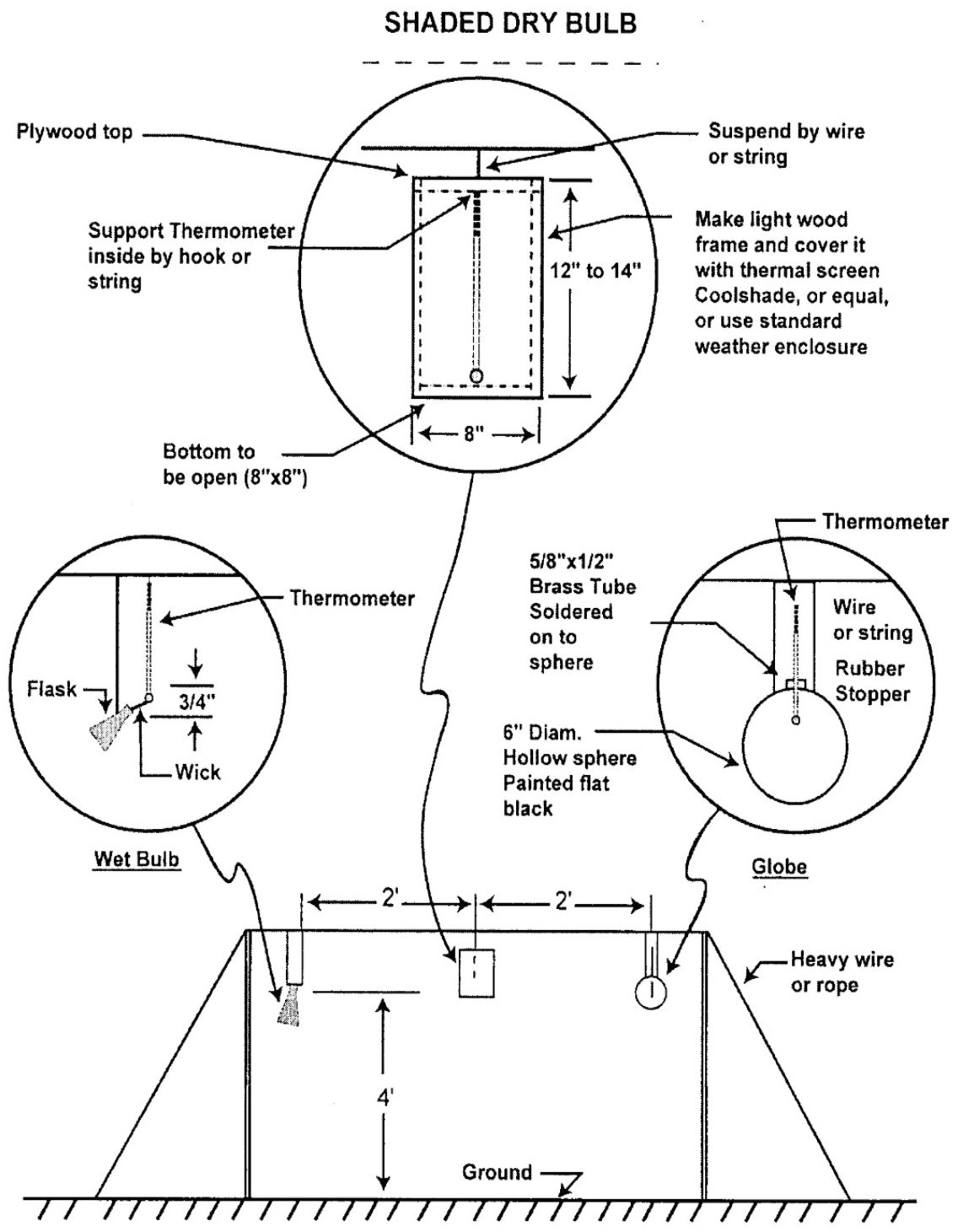

Figure B-1. Dry and wet bulb thermometers.

(7) Wet bulb-globe temperature wick, replacement part, 5180-0001.

(8) Water reservoir, 6013-0145.

(9) Black globe analog, round piece that fits over black thermometer, 6013-0142.

e. Commercial automated WBGT heat stress monitors can be obtained from-

(1) Environmental Heat Stress Monitor, Southwest Research Institute, 6220 Culebra Road, San Antonio, TX 78228, http://www.swri.edu/

(2) AFC International Inc., P.O. Box 894, DeMotte, IN 46310, http://www.afcintl.com/.

(3) Vista Environmental, 4 Quality Street, Williamsport, PA 17701, http://www.gruenberg.com/ vista.htm. 
TB MED 507/AFPAM 48-152 (I)

(4) Kyoto Electronics Manufacturing Co., LTD, 8 - 3 Niban-cho Chiyoda-ku, Tokyo 102-0084, Japan, http://www.kagaku.com/kem/english.html\#product.

(5) ESI Environmental Sensors, Inc., 100-4243 Glanford Ave., Victoria, British Columbia, Canada V8Z 4B9, http://www.esica.com/index.html

(6) INNOVA AirTech Instruments A/S, Energivej 30, 2750 Ballerup, Denmark, http:// www.innova.dk/.

(7) CIH Equipment Co., Inc., 107-G Dunbar Avenue, Oldsmar, FL 34677, http://www.cihequip.com/

(8) Sigma-Aldrich Corp., St. Louis, MO, http://www.sigmaaldrich.com.

\section{B-3. Use of WBGT to control physical activity}

a. When the WBGT index reaches $78^{\circ} \mathrm{F}\left(26^{\circ} \mathrm{C}\right)$, hard physical work may precipitate heat illness or injury; therefore, hard physical work should be limited and fluid replacement emphasized.

b. When the WBGT index reaches $82^{\circ} \mathrm{F}\left(28^{\circ} \mathrm{C}\right)$, moderate and hard physical work should be limited and fluid replacement emphasized.

c. When the WBGT index value reaches $85^{\circ} \mathrm{F}\left(29^{\circ} \mathrm{C}\right)$, increased rest periods for moderate and hard work should be employed and fluid replacement emphasized. Outdoor classes in the sun should be avoided.

d. When the WBGT index value reaches $90^{\circ} \mathrm{F}\left(32^{\circ} \mathrm{C}\right)$, easy, moderate and hard work should be limited and fluid replacement emphasized. Physical training and hard work should be suspended for all personnel (excluding essential operational commitments not for training purposes, where the risk of heat illness/injury may be warranted).

e. Wearing of NBC clothing (MOPP) in effect adds $10^{\circ} \mathrm{F}\left(6^{\circ} \mathrm{C}\right)$ for easy work but $20^{\circ} \mathrm{F}\left(12^{\circ} \mathrm{C}\right)$ for moderate and hard work. Wearing body armor adds $5^{\circ} \mathrm{F}\left(3^{\circ} \mathrm{C}\right)$ to WBGT index in humid climates.

Guidance should be adjusted appropriately.

f. Specific guidance for work periods, work-rest ratios and fluid replacement are provided in tables within this document. 
TB MED 507/AFPAM 48-152 (I)

\section{APPENDIX C}

\section{HOT WEATHER DEPLOYMENT TIPS}

\section{C-1. Prevention categories}

Measures to prevent heat casualties fall into several categories: acclimatization/physical fitness, hydration/ nutrition, work-rest cycles/reduced heat exposure, and clothing/equipment/supplies. Observe soldiers carefully for signs of distress in the heat and adjust work-rest schedules, work rates and water consumption according to conditions. Heat strain and dehydration can accumulate over several days before causing heat illness; therefore, during recovery periods, emphasize rest, shade, rehydration and eating.

\section{C-2. Weak link rule}

When the first heat casualty occurs, assess the status of the whole unit.

\section{C-3. Acclimatization/physical fitness}

a. Maximize physical fitness and heat acclimatization prior to deployment. Maintain physical fitness after deployment with maintenance programs tailored to the environment. Physically fit soldiers acclimatize to heat faster than less fit soldiers.

b. Significant heat acclimatization requires at least three to five days. Full heat acclimatization takes seven to fourteen days. heat.

c. Heat acclimatization requires at least two hours per day of carefully supervised exercise in the

d. Gradually increase the exercise intensity each day, working up to an appropriate physical training schedule adapted to the environment. During the first two days of heat exposure, light recreational activities (for example, softball, volleyball) are appropriate. By the third day of heat exposure, 2-mile unit runs at the pace of the slowest participants are feasible. Remember, the least fit soldiers will suffer the greatest heat strain.

e. Heat acclimatization does NOT reduce, and may actually increase, water requirements. Acclimatization increases sweating, which enhances evaporative cooling. Increased sweating requires additional water consumption.

\section{C-4. Hydration/nutrition}

a. Emphasize the importance of drinking fluids. Military operations will interfere with maintaining hydration.

b. Establish mandatory drinking schedules by using Tables 3-1 and 3-3. Water required to replace sweating may exceed the body's ability to absorb fluid, which is about $1.5 \mathrm{qt} / \mathrm{hr}$. Soldiers should not be expected to drink more than this amount per hour; the rest must be consumed later.

c. Assure adequate hydration of all soldiers before any exercise or work. Carry water in your belly; don't "save" it in your canteen.

d. Plan operations to include water resupply points no less than every three hours. One-hour intervals are better. Carry as much water as possible when separated from approved sources of drinking water. Ensure that soldiers always have at least one full canteen in reserve; know when and where water resupply will be available. Soldiers can live longer without food than without water.

e. Complete consumption of rations including salt packets will provide an adequate salt intake. Soldiers may have a few days of increased salt requirements upon initial deployment, because sweat contains more sodium before heat acclimatization. Additional salt supplementation is not appropriate 


\section{TB MED 507/AFPAM 48-152 (I)}

unless directed by medical personnel. Because female soldiers are smaller than men, they may not need to consume all the salt packets in their rations.

f. Monitor hydration status by noting the color and volume of a soldier's urine. Teach soldiers that dark yellow urine and infrequent urination indicate that fluid consumption should be increased. If soldiers are frequently urinating large volumes of clear urine, they may be over hydrated.

g. Remove barriers to drinking. Make flavored, cool water accessible and provide enough time to drink and eat. Soldiers drink most of their water with meals, and improving water availability increases food consumption.

h. Carbohydrate and electrolyte beverages (sports drinks) are not required and, if used, should not be the only source of liquid for extended periods. For healthy soldiers, these beverages generally provide no advantage over water; however, they can enhance fluid consumption because of their flavor and reduce risk of hyponatremia because of sodium. If meals have not been consumed for several hours before, sports beverages can provide an advantage (over water) when performing strenuous work in the heat.

i. Cool water by shading and insulating water buffaloes or by using small mobile chillers. Drink water instead of splashing it on skin. Water splashed on the skin is wasted water; it might briefly improve comfort but does little to sustain performance and avoid heat illness.

\section{C-5. Work-rest cycles/reduced heat exposure}

a. Review management of work-rest cycles. Establish mandatory work-rest schedules.

b. Prevent a dangerous increase in body temperature by minimizing heat production through reduction of work pace and increased rest periods. Body temperatures can rise rapidly due to the combination of excessive heat, clothing and equipment worn and sustained activity.

c. Plan to perform heavy work (including physical training) in early morning or cool evening hours whenever possible. Avoid the heat of the day. If performing physical training in formation, open ranks to enable ventilation of soldiers inside the ranks.

d. Provide shade to reduce solar load. When possible, make shade with canvas, ponchos, or parachutes. Ensure that shaded areas have good air circulation.

e. Resting on hot ground increases heat stress; the more body surface in contact with the ground, the greater the heat strain. The ground heated by the sun is hot, in deserts often 30 to 45 degrees hotter than air, and may reach $150^{\circ} \mathrm{F}$ when air temperature is $120^{\circ} \mathrm{F}$. Cooler ground is just inches down; a shaded, shallow trench will provide a cool resting spot.

\section{C-6. Clothing/equipment/supplies}

a. Wear appropriate uniforms to protect against sun, wind and other hazards. Use hats, head cloths, goggles and sunscreen as necessary.

b. Wearing the BDU will reduce heat strain by protecting soldiers from solar load. Restrain the desire to loosen and take off clothing to improve ventilation because of the hazards from sun, wind and insect exposure.

c. Keep clothing clean, since clean clothes protect better and help prevent skin rashes. Whenever possible, wash clothing and air-dry or sun dry.

d. Change socks at least twice a day. Prolonged wear of wet socks can lead to foot injury (for example, blisters) or foot fungus ("athletes foot"). Sweat accumulation in the boot can be reduced by wearing a sock that is absorptive and thick enough to "wick" moisture away from the foot and toward the top of the boot where evaporation can occur (for example, use a sock equivalent to the tan, ski-mountain sock, National Stock Number 8440-00-153-6717). Wearing a thin polypropylene sock next to the skin under your sock can also help prevent blisters.

e. Wearing the Battle Dress Overgarment decreases evaporative cooling and increases sweating and heat strain. Wearing underwear and the complete desert BDU, with the sleeves rolled down, under the 
TB MED 507/AFPAM 48-152 (I)

Battle Dress Overgarment, provides additional protection against chemical agents. However, this clothing combination will also substantially increase the risk of heat casualty.

\section{C-7. First aid for heat illness}

a. Signs of overheating include the inability to work, flushed face, confusion, disorientation and fainting. It is always better to take care of a problem early. When in doubt, treat as a heat illness.

b. Immediately get heat-stricken soldiers into the shade and remove any heavy clothing. If they are alert and not vomiting, have them slowly drink water. They may need 2 quarts over the next hours. The water should be cool to improve acceptance.

c. Seek medical evaluation for heat casualties even though rest, shade, ventilation, and water might control the mild signs and symptoms. Give the highest priority for medical evacuation to soldiers who are incoherent or unconscious; they may have heat stroke or other serious illnesses.

d. Wet the skin or T-shirt (with uncontaminated water), and fan the casualty. If available, the immersion in cool water is the best way of reducing body temperature. A field expedient immersion device can be built from tent canvas mounted in a frame off the ground. If an above ground frame cannot be constructed, a shallow pit lined with canvas can be used.

e. Drink liquids that contain some added salt or electrolytes for heat cramps. If the victim can drink, give slowly, no more than $1.0 \mathrm{qt} / 30 \mathrm{~min}$ (with maximum of 2 qts over the hour), either salted water ( 0.5 percent salt or 1 teaspoon per quart of water; or 1 MRE packet of table salt per quart), or oral rehydration solution or commercial glucose/electrolyte beverages (sports drinks). 
TB MED 507/AFPAM 48-152 (I)

\section{APPENDIX D \\ COMMANDER'S, SENIOR NCO'S AND INSTRUCTOR'S GUIDE TO RISK MANAGEMENT OF HEAT CASUALTIES}

\section{D-1. Introduction}

A comprehensive hot weather injury prevention and management program should follow the principles of Risk Management by identifying hazards, assessing the hazards in terms of severity and probability, and implementing appropriate controls to abate the hazards. Spot-checking and supervision by first-line leaders should be employed to ensure control measures are being implemented. Units train using Risk Management principles; therefore, it is imperative that commanders and leaders are educated on the prevention of hot weather injuries using this terminology. Heat casualty prevention is a Command responsibility. This appendix provides information that will assist in presenting hot weather injury prevention in this format. A more detailed guide on risk management of heat casualties can be obtained from http://usachppm.apgea.army.mil/doem//pgm34/HIPP.aspx

\section{D-2. Identifying hazards}

Hot weather may present a hazard if any one of the following is present-

a. High heat category, especially on several sequential days. The WBGT should be measured when ambient temperature is over $75^{\circ} \mathrm{F}$.

b. An exertional level of training, especially on several sequential days.

c. Lack of acclimatization (at least 10 to 14 days for trainees to become acclimated) and other individual risk factors, such as-

(1) Exposure to two to three days of any of the following -

(a) Increased heat exposure.

(b) Increased exertional levels.

(c) Lack of quality sleep.

(2) Poor fitness (unable to run two miles in less than 16 minutes).

(3) Overweight.

(4) Minor illnesses such as cold symptoms.

(5) Taking prescribed or over-the-counter medications/supplements/dietary aids.

(6) Use of alcohol within the last 24 hours.

(7) Prior history of heat illness (any heat stroke or more than two episodes of heat exhaustion).

(8) Skin disorders such as heat rash and sunburn.

(9) Age (greater than 40 years).

d. High temperature at night/rest overnight.

\section{D-3. Assessing hazards}

The potential for heat casualties can be assessed by--

a. Using the WBGT to assess the heat category when ambient temperature is over $75^{\circ} \mathrm{F}$.

b. Knowing your soldiers individual risk factors. Early identification of who will be at increased risk will be beneficial to the overall unit's performance.

c. Checking hydration status at the end of each training day using the Riley (water) card or Ogden cords or asking about urine color. If hydration is inadequate, give extra fluid at night and in the morning.

d. Using a risk matrix daily to assess the overall risk for developing a heat casualty. 


\section{TB MED 507/AFPAM 48-152 (I)}

\section{D-4. Developing controls}

Heat casualties can be controlled through-

a. Education, to include-

(1) Establishing standing operating procedures.

(2) Posting heat casualty prevention information where it is easily accessible.

b. Planning training events, to include-

(1) Minimizing consecutive days of heavy physical training when heat stressors exist.

(2) Providing medical and evacuation support.

(3) Providing adequate hydration.

(4) Choosing the appropriate time of day - morning is cooler, location, clothing apparel, and location in training cycle for the training event.

c. Identification of the following-

(1) Previous heat exhaustion or heat stroke soldiers. The uniforms should be marked with tape or cord.

(2) Overweight soldiers and those who are unfit.

(3) Soldiers on medications. Mark the uniforms with tape or cord.

(4) Soldiers who have consumed alcohol within the last 24 hours. Consider removing these soldiers from training.

(5) Soldiers who are ill. Consider having these soldiers report to sick call.

(6) Heat category hourly. The WBGT must be positioned at the training site.

d. A hydration monitoring system such as the Riley (water) card or the Ogden Cord.

e. Knowledge of standardized guidelines for warm weather training conditions such as the fluid replacement and work-rest guides.

\section{D-5. Implementing controls}

Heat casualty controls can be implemented through the following-

a. A decision to accept risk at the appropriate level through a local SOP.

b. Hydration standards.

c. Food intake.

d. Random checks.

e. Clothing recommendations.

\section{D-6. Supervising and evaluating}

The final step to the risk management process is the supervision and evaluation of the controls taken to prevent heat casualties. Examples are as follows:

a. Enforcing SOPs.

b. Delegating responsibilities to ensure control-measures have been implemented.

c. Monitoring progress of control measures.

d. Conducting spot checks of cadre and recruits. 
TB MED 507/AFPAM 48-152 (I)

\section{APPENDIX E}

\section{PREPARATION OF 0.1 PERCENT SALT WATER DRINKING SOLUTION}

To prepare a saturated salt solution, dissolve nine level mess kit spoons of table salt in two-thirds of a canteen cup of water. This solution can be diluted into a larger container of water that does not enable easy mixing. Use the following ratios when diluting:

a. One-eighth of a canteen cap (one-qt. size) to a one-qt. canteen.

b. One-fourth canteen cap (two-qt. size) to a two-qt. canteen.

c. One mess kit spoon of salt to one gallon of water.

d. Five mess kit spoons to a five-gallon can.

e. One-half canteen cup to a Lyster Bag.

f. Four canteen cups to a two hundred and fifty-gallon water trailer. 
TB MED 507/AFPAM 48-152 (I)

\title{
GLOSSARY
}

\author{
Section I \\ Abbreviations \\ BDU \\ battle dress uniform \\ BWL \\ body weight loss \\ C \\ centigrade \\ CHS \\ compensated heat stress \\ CK \\ creatine kinase \\ DIC \\ disseminated intravascular coagulation \\ ECF \\ extracellular fluid \\ EHI \\ exertional heat injury \\ F \\ fahrenheit \\ HSP \\ heat shock proteins \\ $\mathrm{kcal} / \mathrm{d}$ \\ kilocalories per day \\ lb \\ pound \\ LDH \\ lactate dehydrogenase \\ $\mathrm{mEq} / \mathrm{L}$ \\ milliequivalents per liter
}




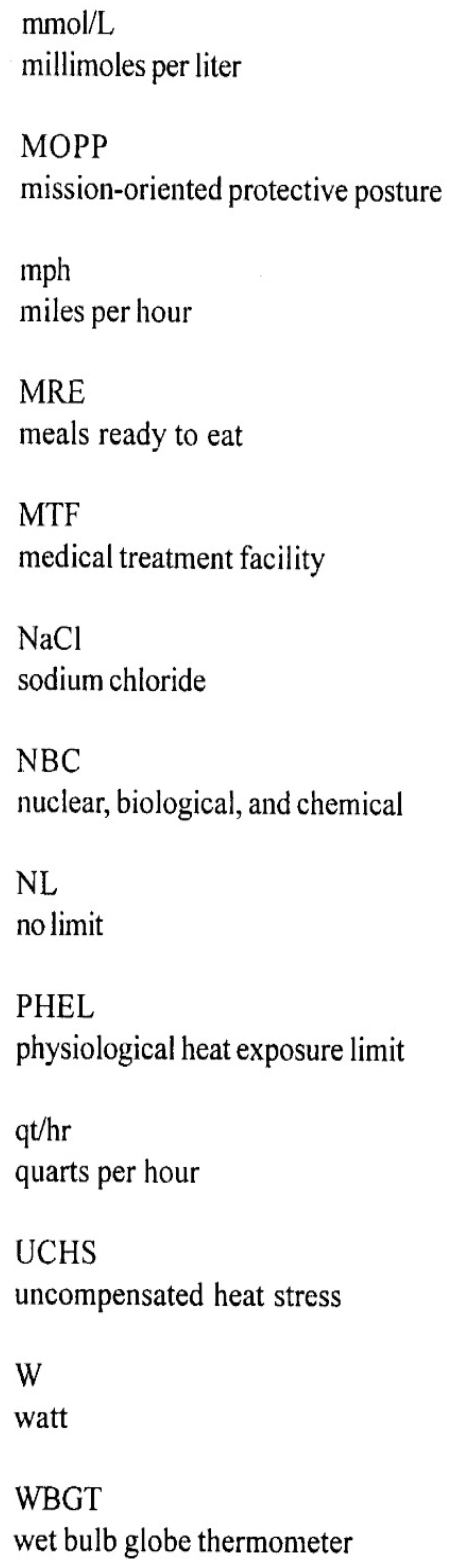


TB MED 507/AFPAM 48-152 (I)

\section{Section II}

Terms

Acquired thermal tolerance

Cellular adaptations that allow tissues, organs, or organisms to become more resistant to heat injury.

Dehydration

Reduction of total body water, with some resultant reduction in plasma volume.

Dry bulb temperature

Air temperature that is a measure of the kinetic energy of the molecules in the air and is measured inside a Stevenson screen using a PT 100 Resistance Temperature Dependent Thermometer.

Dry bulb thermometer

Thermometer on a psychrometer used to determine current air temperature. This measurement and the reading from a wet bulb thermometer are then used for the determination of relative humidity or dew point from a psychrometric table.

Exertional heat cramps

Painful, migratory skeletal muscle spasms.

Exertional heat illness

A spectrum of disorders deriving from the combined stresses of exertion and heat stress, including heat cramps, heat exhaustion, exertional heat injury and heat stroke. These illnesses can be accompanied by fluid electrolyte disturbances and exertional rhabdomyolysis.

Exertional heat injury

Progressive multisystem disorder, with hyperthermia accompanied by organ damage or severe dysfunction (usually metabolic acidosis, acute renal failure, muscle necrosis, or liver necrosis.

Exertional heat stroke

Heat stress related body core temperature $>104^{\circ} \mathrm{F}$ with central nervous system injury caused by physical exertion and heat stress.

Exertional rhabdomyolysis

Skeletal muscle damage with release of cellular contents into the circulation, including myoglobin, potassium, phosphate, CK, lactic acid, and uric acid.

Heat acclimatization

Body's improved response to heat stress after a few days of heat exposure and regular strenuous exercise.

Heat dissipation

When the body's thermal energy is carried to the skin by the blood, where it is then transferred through conduction, convection, radiation, and evaporation.

Heat edema

Swelling and discomfort of the hands and feet 
TB MED 507/AFPAM 48-152 (I)

Heat rash

A pruritic red popular rash, located in areas of restrictive clothing and heavy sweating.

Hyperpnea

Abnormally deep or rapid breathing.

Hyperthermia

Elevated body temperature.

Hyponatremia

Low blood sodium. Often the consequence of prolonged excessive hydration combined with inadequate sodium replacement, for sweat losses. Serious cases have resulted from misdiagnosis as dehydration and overly aggressive rehydration.

Microclimate cooling

Systems that cool or dissipate heat from the body's surface without cooling the entire working environment.

Parade syncope

Fainting during prolonged standing due to inadequate venous blood return to the heart and brain.

Strenuous exercise

Physical activity that exceeds 70 percent of a person's physical fitness level.

Wet bulb temperature

Temperature air would have if its energy were used to evaporate an amount of water equal to the amount of water vapour it contains. It is measured inside a Stevenson screen using a PT 100 Resistance

Temperature Dependent Thermometer surrounded by a moist wick.

Wet bulb globe thermometer

A system that simultaneously accounts for conduction, convection, evaporation, and radiation. Provides a single temperature reading to estimate the cooling capacity of the surrounding environment. Consists of a dry and wet bulb and a black globe. 
TB MED 507/AFPAM 48-152 (I)

By Order of the Secretary of the Army:

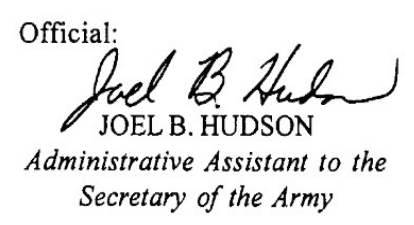

ERIC K. SHINSEKI

General, United States Army Chief of Staff

\section{GEORGE P. TAYLOR, JR., Lt General, MC, CFS} Surgeon General of the Air Force

Distribution:

To be distributed in accordance with the Initial Distribution Number (IDN), 3417716, requirements for TB MED 507. 


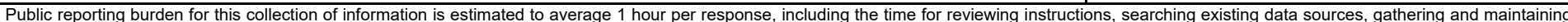

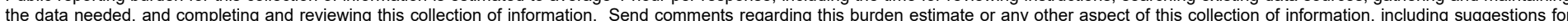

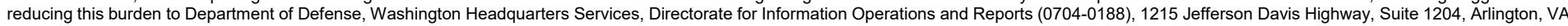

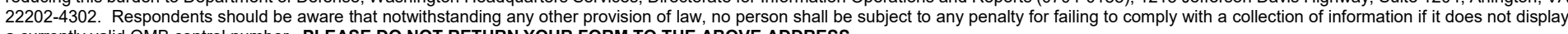
a currently valid OMB control number. PLEASE DO NOT RETURN YOUR FORM TO THE ABOVE ADDRESS.

\begin{tabular}{l|l|l} 
1. REPORT DATE (DD-MM-YYYY) & 2. REPORT TYPE & 3. DATES COVERED (FrOm - To)
\end{tabular} July 2019 4. TITLE AND SUBTITLE Final

Range Days Lost to Heat Risk Model User's Guide 5a. CONTRACT NUMBER

5b. GRANT NUMBER

5c. PROGRAM ELEMENT NUMBER

\section{AUTHOR(S)}

Byron M. Garton

5d. PROJECT NUMBER

402188

5e. TASK NUMBER

5f. WORK UNIT NUMBER

8. PERFORMING ORGANIZATION REPORT NUMBER

ERDC/ITL SR-19-10

Information Technology Laboratory

U.S. Army Engineer Research and Development Center

3909 Halls Ferry Road

Vicksburg, MS 39180

9. SPONSORING / MONITORING AGENCY NAME(S) AND ADDRESS(ES)

U.S. Army Corps of Engineers

Washington, DC 20314-1000

12. DISTRIBUTION / AVAILABILITY STATEMENT

Approved for public release; distribution is unlimited

\section{SUPPLEMENTARY NOTES}

\section{ABSTRACT}

Maintaining and increasing the capacity to perform training exercises on Department of Defense (DoD) lands is essential to future force readiness and effectiveness. The risk of heat related illness on ranges as a potential result of climate change is one factor affecting the availability of training areas. Assessing the impact of future climate change is an essential part of ensuring future availability of live fire ranges.

This document describes the process of executing the Range Days Lost to Heat Risk Model, as it exists at the time of this writing, within the common computational environment established under the software integration effort of the Integrated Climate Assessment for Army Enterprise Planning work package.

15. SUBJECT TERMS

Military bases

Bombing and gunnery ranges

Rifle-ranges
Heat waves (Meteorology)

Heat--Physiological effect

Climatic changes--Risk assessment

\section{SECURITY CLASSIFICATION OF:}

\begin{tabular}{|c|r|}
\hline $\begin{array}{l}\text { a. REPORT } \\
\text { Unclassified }\end{array}$ & b. ABSTRACT \\
Unclassified
\end{tabular}

c. THIS PAGE

Unclassified
17. LIMITATION OF ABSTRACT

\section{NUMBER OF PAGES}

88 19a. NAME OF RESPONSIBLE PERSON

19b. TELEPHONE NUMBER (include area code) 